\title{
23 Years of Development of the Solar Power Generation Sector in Spain: A Comprehensive Review of the Period 1998-2020 from a Regulatory Perspective
}

\author{
Sergio Coronas* $*$, Jordi de la Hoz, Àlex Alonso (D) and Helena Martín (D) \\ Electrical Engineering Department, Escola d'Enginyeria de Barcelona Est, Polytechnic University of Catalonia, \\ 08019 Barcelona, Spain; jordi.de.la.hoz@upc.edu (J.d.1.H.); alexandre.alonso.travesset@upc.edu (À.A.); \\ m.helena.martin@upc.edu (H.M.) \\ * Correspondence: sergio.coronas@upc.edu
}

check for updates

Citation: Coronas, S.; de la Hoz, J.; Alonso, À.; Martín, H. 23 Years of Development of the Solar Power Generation Sector in Spain: A Comprehensive Review of the Period 1998-2020 from a Regulatory Perspective. Energies 2022, 15, 1593. https://doi.org/10.3390/ en15041593

Academic Editor: Juri Belikov

Received: 15 January 2022

Accepted: 18 February 2022

Published: 21 February 2022

Publisher's Note: MDPI stays neutral with regard to jurisdictional claims in published maps and institutional affiliations.

Copyright: (C) 2022 by the authors. Licensee MDPI, Basel, Switzerland. This article is an open access article distributed under the terms and conditions of the Creative Commons Attribution (CC BY) license (https:// creativecommons.org/licenses/by/ $4.0 /)$.

\begin{abstract}
Spain has become one of the leading countries in the world in promoting electricity generation from renewable energy sources (RES), due to their positive socioeconomic and environmental impacts, through highly favorable regulatory frameworks and public incentives set by Spanish governments mainly during the first decade of 2000s, i.e., Royal Decree (RD) 2818/1998, RD 436/2004 and RD 661/2007. Conversely, the highly favorable regime applicable to RES, and specifically to solar power plants during the 1998-2008 promotion period turned into an extremely unfavorable scenario during the 2008-2020 cost-containment stage, characterized by the dismantling of the previous promotion schemes so as to reduce the skyrocketing electricity system tariff deficit, in which regulations such as RD 1578/2008, Royal Decree Law (RDL) 6/2009, RDL 14/2010, RDL 1/2012, Law 15/2012, RDL 9/2013, Law 24/2013 and RD 413/2014 stood out. Nonetheless, the Spanish renewable sector, and especially the solar power sector, has shown great dynamism in its energy policy in the period 1998-2020. This academic contribution provides a comprehensive review of the energy policy evolution for the whole solar power sector in Spain, specifically both solar photovoltaic (PV) and concentrating solar power (CSP) plants, over the last 23 years. Thus, considering both the boom in the solar power sector as well as the solar sector's bust, a survey of the different legislation in force during the 1998-2020 period, as well as of the existing academic literature dealing with this issue, is conducted to first contextualize and describe, and then carefully assess, the last 23 years of solar energy policy in Spain. In brief, the decisive role of the Spanish government in developing the RES sector, and especially the solar power sector, in recent years has been noted. In this vein, a good planning of the energy development model, the regulatory stability, the simplicity and agility of the corresponding administrative process, the appropriate design of support mechanisms, as well as security and predictability of support levels in the mid and long term, play an important role in providing certainty to all the stakeholders. During the 1998-2008 promotion stage, even with a stable, quite favorable and easily predictable RES support mechanism in place, the Spanish solar system behaved as an open-loop system without any control structure detecting and reacting to problematic situations. The fact that the Spanish government was compelled to implement ex-post measures during the period 2008-2020, seriously jeopardizing the viability of the power plants in operation, as well as compromising the legal-economic stability of the renewable energy sector, clearly indicated a malfunctioning of the energy policy control mechanism. In essence, it is hoped that the lessons extracted from this 23-year comprehensive review of the Spanish solar power sector pathway could be quite useful for other countries either in the initial development stage or fully immersed in the promotion of solar power sector or any other renewable technology.
\end{abstract}

Keywords: Spain; review; regulatory framework; energy policy; promotion; cost-containment; public support; renewable energy; solar PV; CSP 


\section{Introduction}

\subsection{Setting the Context}

Power generation has been, and remains, a fundamental sector to bear in mind in any energy policy across the world aimed at reducing greenhouse gas (GHG) emissions in the fight against global warming [1-4]. In fact, the energy sector is the biggest emitter of global GHG emissions, responsible for almost $75 \%$ by 2020 , while the electricity sector accounted for $36 \%$ of all energy-related carbon dioxide $\left(\mathrm{CO}_{2}\right)$ emissions [5]. In this regard, the development of electricity production through renewable energy sources (RES), and therefore the substitution and reduction of usage of fossil fuels (coal, oil and natural gas), is the mainstay of the decarbonization of the worldwide electricity sector towards a lowcarbon and more sustainable economy. Furthermore, RES ensure the enhancement in national security of energy supply and energy self-sufficiency from imported fossil fuels, commonly characterized by complex geopolitical environments [2,3,6-8]. The share of fossil fuels in the global energy mix has remained at around 80\% throughout recent decades [5].

The development of non-GHG-emitting and non-depletable RES has followed a significant and accelerating trend in the global energy sector as a policy-driven phenomenon over the last few decades. Accordingly, most of the advancement in the expansion of renewable technologies has been acquired due to strong country-specific public promotion policies and regulatory frameworks, coupled with ambitious RES goals, substantiated by their positive socioeconomic and environmental impacts $[3,4,7,9-16]$. Indeed, RES policies are presently the rule rather than the exception. Specifically, nearly all countries worldwide had in place RES support policies by the end of 2020 [4,16].

The conversion of the power generation sector has been one of the cornerstones of the European Union (EU) energy policy in recent decades, giving rise to an intense legislative activity in the different European countries. First focusing on the liberalization of the electricity sector, one of the most highly regulated economic activities, and later curtailing the environmental impact of electricity production by promoting RES [8,17].

Spain has not been an exception in the EU market, but an especially relevant case, as it has been one of the world's leading countries in promoting RES through highly favorable public subsidies and legal-economic frameworks. Thus, resulting in a significant expansion of renewable technologies for electricity generation in the last two decades, particularly wind and solar energy $[3,8,18]$. Spain is in a particularly advantageous position with the most plentiful solar resource in the entire EU $[15,19,20]$. In this respect, Spain ranked seventh-highest for the share of electricity production from solar in 2019 among the International Energy Agency (IEA) countries [21].

From the 1990s, the national energy policy priority for the different Spanish governments was to support RES given its potential benefits related to environmental protection aligned with the EU policies, heightened awareness within society of the fight against global warming, job creation, diversification of the energy mix and decrease in energy reliance on fossil-fuel imports [8,22-24]. In particular, the Spanish energy system has always been characterized by its high dependence on imports for fossil fuels, i.e., Spain's national production only has covered about one quarter of total energy supply over the last two decades $[2,19,21,25]$.

Several international institutions pointed to the Spanish RES development system as a successful story. Nevertheless, there have also been some shadows in the Spanish experience with the public support to RES, and especially to solar technologies, related to the substantial increase of its promotion costs [26-30]. Spain has experienced numerous legislative changes in the regulation of RES since the 1990s, receiving worldwide attention in recent years. Specifically, the last 23 years of the solar power generation sector can be divided into two periods with opposite goals, i.e., the 1998-2008 promotion period, characterized by quite favorable support mechanisms for the development of solar power plants, and the 2008-2020 containment period, marked by the dismantling of the previous promotion schemes so as to lessen the disproportionate solar power support costs to the electricity system, giving rise to highly unfavorable conditions for these renewable assets. 
As for the 1998-2008 promotion period, Spain implemented a special regime (SR) promotion mechanism for RES, prompting high deployment levels of electricity generation from renewable technologies in that period. Specifically, the Spanish government introduced a feed-in promotion scheme, i.e., feed-in tariff (FIT) and feed-in premium (FIP), which were the most widespread RES promotion mechanism in the EU, and the most significant regarding the amount of support awarded at that time [1,3,8,22,24,29,31,32]. By way of example, almost all the new solar photovoltaic (PV) capacity in the EU was installed by means of FIT schemes during that period [33].

It is important to highlight that after a favorable promotion policy and public subsidies for solar technology especially in the second half of the 1998-2008 period, Spain suffered an unprecedented PV boom between 2007 and 2008 under Royal Decree (RD) 661/2007 framework, putting the country's solar PV sector as a global role model of technological advancement and installation rates. By that time, more than $70 \%$ of all European grid-connected solar PV facilities were in Spain, which is the biggest solar PV market $[9,20,23,24,34-37]$. Regarding the dispatchable concentrating solar power (CSP), which is regarded by the Spanish government as a strategic technology [8], the foundations for the subsequent 2011-2012 CSP bubble were laid during the latter part of the 1998-2008 period, due to the generous incentives for this technology. Since then, Spain has become the world leader in installed CSP capacity followed by the United States, although the progress in those two countries stalled in 2013 and 2015, respectively [10,38-40]. In the wake of the proactive RES policies deployed by the Spanish governments during the 1998-2008 promotion period, the electricity produced in Spain through fossil fuels fell considerably from $74 \%$ in 2000 to $52 \%$ in 2012 [41].

Administratively set feed-in pricing policies, specifically FIT and FIP, have remained as the most widely adopted form of renewable power support worldwide until 2017, when competitive auctions became the main RES promotion mechanism [4]. Furthermore, FIT has been regarded as the most successful mechanism for fostering the RES development in the EU, as demonstrated by the experiences in Germany, Spain and Denmark, among others [3,7,26,42]. Likewise, many other European countries have also implemented feed-in policies to support RES, such as Austria, the Czech Republic, France, the Netherlands, Italy, Portugal and Switzerland [42,43]. Notwithstanding the effectiveness of the incentive-based feed-in instrument, it has had a major drawback concerning its associated cost-burden, generally transferred to electricity consumers through their bills, in countries with significant raises in RES deployment and especially for high-cost renewable technologies. In fact, solar booms have only taken place in countries using FIT mechanisms. Consequently, the cutback of RES promotion costs by reversing the previously set supports and dismantling the renewable energy policies has become a policy priority and a major concern in many countries all over the world, such as Spain, France, Italy and Czech Republic [3,10,11,16,17,27,28,34,44,45].

As for the 2008-2020 containment period, the Spanish RES feed-in policy began to be dismantled by means of retroactive cost-containment measures until it was totally repealed by the electricity reform enacted in 2013, specifically the Spanish electricity sector (SES) Law $24 / 2013$, in an attempt to tackle the overrun cost derived from the excessive RES support incentives (mostly related to solar PV promotion), and therefore the growing tariff deficit of the electricity system $[3,15,18,29,30,36,45,46]$. During that period, the Spanish solar PV sector suffered a significant bust, becoming the first European country to experience a clear boom-and-bust cycle in the solar PV sector. Therefore, Spain moved from a prominent position in the global market concerning the cumulative installed solar PV power, to an insignificant status with the PV sector virtually paralyzed until the 2017 RES auctions under RD 413/2014 framework [23,35,36,47]. Similarly, with no new capacity additions since 2013, Spain's share of global CSP capacity in operation dropped from a peak of almost $80 \%$ in 2012 to just under $40 \%$ by the end of 2020 [4]. The new market-based RD 413/2014 legislative framework for RES relied on an auction support mechanism, which 
has recently been considered a cost-effective worthy option to induce further investments in RES without excessive costs for electricity consumers [17,32].

Spain has seen notable decarbonization of the electricity sector, as the share of electricity production from fossil fuels diminished from $56 \%$ in 2009 to $41 \%$ in 2019 , while electricity production from RES increased from $24 \%$ in 2009 to $38 \%$ in 2019, ranking thirteenth highest in terms of the share of RES that year among the IEA countries [21].

\subsection{State of the Art}

There is wide agreement in the academic literature regarding the need for public policies to encourage RES advancement [13]. Presently, despite the increasing cost competitiveness of RES, their continued expansion remains dependent on policy support [16] Accordingly, numerous articles have focused on the study of RES promotion policies, both from a general and country-specific point of view. In this vein, Spain has become one of the countries in the world that has attracted more attention for becoming one of the most successful countries concerning the public development of energy generation from RES during the 1998-2008 period [48]. Moreover, the continuous and considerable regulatory changes suffered by the Spanish RES sector over the last 23 years, and specifically by the solar power sector that experienced a relevant boom-and-bust cycle, may also have acted as a pole of attraction for the academia.

The legal-economic policy regulating the Spanish RES sector over the last 23 years, and specifically the solar power system, can be divided into two major phases, namely a first promotion stage from 1998 to 2008 and a second containment stage from 2008 to 2020, as explained in the body of this review.

As regards the Spanish country-specific study of the 1998-2008 RES promotion period, Arocena et al. [49] analyzed the regulatory reform in the Spanish electricity industry carried out by the first Law 54/1997 of the power sector. The factors giving rise to quite different diffusion rates of two key RES technologies in Spain, i.e., wind and solar PV, during the period 1994-2003 were assessed in [50], showing that economic and institutional factors played decisive roles in fostering or inhibiting diffusion during that period. In turn, an integrated assessment of one of the most successful policy schemes in Europe, i.e., the Spanish FIT system under RD 2818/1998 during the 1999-2003 period, was provided by [22]. Del Río [48] overviewed the RES promotion legislation in Spain during the period 1998-2007 and assessed the major differences and enhancements of the three main FIT promotion schemes existing in that period, i.e., RD 2818/1998, RD 436/2004 and RD 661/2007. Similarly, de la Hoz et al. [9] provided an authoritative review of the evolution of grid-connected PV power plants in Spain during the period 1998-2008, by analyzing the different legal, economic and technical frameworks affecting solar PV technology from a control theory point of view. Meanwhile the deployment process of a PV facility under RD 436/2004 and RD 661/2007 and its connection to the Spanish electricity network was assessed from an administrative and legal-economic perspective in [19]. Ciarreta et al. [6] overviewed the evolution of the European and the Spanish legislation until 2009 regarding the RES promotion in a context of electricity market liberalization, and studied the impact of the FIT promotion scheme for fostering RES on the oligopolistic Spanish power market under RD 661/2007, while also discussing economic implications of alternative support systems. Schallenberg-Rodriguez and Haas [31] assessed and compared the two alternative support options for RES, namely fixed FIT and premiums, which coexisted at the same time in Spain during the 1998-2009 analysis period, and evaluated their achievement bearing in mind the cap and floor mechanism introduced by RD 661/2007. Likewise, Salas and Olias [25] showed the Spanish solar PV technology status by 2007 taking into account the different support frameworks, as well as the outlook for the coming years. Meanwhile the socioeconomic impacts of increasing the installed CSP capacity in Spain under the provisions of the renewable energy plan (REP) 2005-2010 were estimated in [51].

Other works analyzed the transition from the highly favorable RES promotion legislation existing in Spain over the second half of the 1998-2008 period to the adverse RES 
cost-containment legal framework, with drastic and sometimes retroactive regulatory cuts, thereafter. Specifically, Ortega et al. [42] provided a comparative assessment between the socioeconomic and environmental gains of RES deployment in Spain during the period 2002-2011, in terms of reduction of $\mathrm{CO}_{2}$ emissions and fossil-fuel imports, and the RES public support costs granted through the FIT system. The public acceptance issue of RES was addressed in [52] by analyzing the Spanish solar PV case during the period of both greater expansion and contraction of that sector, i.e., from 2004 to 2010. In turn, del Río and Mir-Artigues [26] provided a summary of the patterns of the Spanish solar PV FIT scheme and its design features during the period 1998-2011, therefore considering the PV boom-and-bust cycle, and identified some implications for the successful and cost-effective expansion of solar PV in Spain. Likewise, a comprehensive review of the 2007-2010 solar PV boom-and-bust in Spain was provided in [23], by assessing in detail the 1998-2012 Spanish solar energy policy. Meanwhile Martín et al. [10] carried out a thorough analysis of the Spanish CSP evolution in the period 1998-2013, by means of a detailed overview of all the regulatory and economic legislations governing the development of the CSP technology. Furthermore, it used basic control theory standards to ease the identification of the major drivers behind the bubble-like behavior shown by the CSP technology. Additionally, Talavera et al. [35] undertook an economic profitability and cost assessment of grid-connected PV systems in Spain since 1998 to 2014 based on the internal rate of return (IRR), the net present value (NPV) and the levelized cost of electricity (LCOE), to identify the impact of the changing and confusing legislations applicable to the solar PV technology in that period on the PV investments. Similarly, Lomas et al. [36] analyzed an operating solar PV facility commissioned in Spain in 2007 from an economic and energy standpoint to analyze the impact of the evolution of the Spanish RES policy during the 2007-2015 period on its investment profitability as well as on its energy generation. In turn, the divergent performance in Germany and Spain of PV grid-connected systems regarding their legislation, profitability and diffusion was analyzed in [47], by reviewing the development of FIT supports and by assessing the cost effectiveness of different kinds of facilities through the IRR for the period 2004-2014. Meanwhile the economic and financial performance of Spanish solar PV energy generation firms over the period 2006-2015 was analyzed in [12], based on a longitudinal sample of around 5469 enterprises from the sector. Likewise, Blanco-Díez et al. [24] first reviewed the evolution of the Spanish RES regulatory framework, to subsequently analyze the economic effects of the retroactive legislative changes on the Spanish PV energy sector between 2004 and 2014, namely RD 436/2004, RD 661/2007 and RD 413/2014. Fernández-González et al. [37] analyzed how institutional changes in the Spanish solar PV sector during the period 2004-2018 affected its structure, by computing its degree of concentration and stability based on data from 5353 firms from the solar PV sector. Meanwhile San Miguel and Corona [39] reviewed the different regulatory frameworks affecting CSP technology in Spain between 1998 and 2015, to later evaluate the economic viability of CSP under those legislations based on the discounted cash flows, the IRR, the NPV and the LCOE.

As for the Spanish country-specific analysis of the 2008-2020 RES containment period, the financial return to the Spanish power system of the latest installed solar PV facilities under RD 1578/2008 saturation mechanism was analyzed by Azofra et al. [53], relied on the incentives perceived and the savings produced for the power market. It also presented alternative scenarios for the implementation of solar PV power in the Spanish network through a temporary redistribution of the power plants that prompted the Spanish 2007-2008 PV boom. De la Hoz et al. [27] described the 2008-2010 regulatory framework for grid-connected PV power plants resulting after the Spanish 2007-2008 PV boom as well as the development of the solar PV sector for that period, and assessed the control performance in terms of basic control theory standards. Likewise, de la Hoz et al. [28] provided a methodology for calculating the overrun cost to the Spanish power system as a result of the large overshoot of the solar PV power goals under RD 661/2007, to later assess the savings achievable by the retroactive cost-containment energy policy issued in the period 2010-2012 
as well as the profitability reduction that those retroactive measures could cause on the PV facilities based on the NPV and the IRR. Meanwhile Mir-Artigues et al. [11] assessed the effects of the 2008-2013 cost-containment measures, implemented by the Spanish government after the 2007-2008 PV boom, on the net cash flows and cost effectiveness of PV facilities. Fernández-González et al. [41] assessed the consequences of eliminating the FIT mechanism for solar PV plants in 2012, due to the excessive budgetary burden involved in maintaining that FIT scheme and after many years of institutional volatility, based on a longitudinal sample of 5354 companies from the solar PV sector. In tun, del Río et al. [29] described in detail the main elements of the new Spanish renewable electricity support scheme under RD 413/2014 enacted in 2014 and provided a brief analysis of its main shortcomings. De la Hoz et al. [46] first analyzed RD 413/2014 legal-economic framework for RES electricity generators in Spain by means of a detailed overview and formulation of RD 413/2014 economic model, to subsequently put the spotlight on its effects on the economic performance of the pre-existing grid-connected PV facilities relied on the treasury, the IRR and the NPV. The impact of RD 413/2014 retroactive electricity support scheme on the cost effectiveness of the Spanish solar PV facilities was assessed in [18]. Similarly, de la Hoz et al. [30] assessed RD 413/2014 economic and regulatory framework for RES in Spain as well as its significant impact on the financial performance of the CSP plants based on the treasury, the NPV and the IRR, by means of a detailed overview and formulation of RD 413/2014 remuneration scheme. Likewise, Coronas et al. [54] analyzed the economic feasibility of the Spanish CSP plants under RD 413/2014 framework, based on the IRR, the NPV, the payback period and the LCOE, from a probabilistic perspective using the discounted cash flow-Monte Carlo method. Meanwhile del Río [32] contextualized and assessed the design elements used in the first (January 2016) and second (May 2017) RES auctions under RD 413/2014 in Spain, putting them in the context of international experiences, and analyzed the outcomes obtained in both auctions. Finally, the policy dismantling process of RES policies in two of the pioneer EU countries in supporting RES, i.e., Spain and Czech Republic, was assessed by [16].

\subsection{Justification and Main Contributions of the Review}

Spain has developed and implemented a great range of actions on promoting RES. Still, it has also been distinguished for becoming one of the most active countries applying cost-containment mechanisms on RES. Perhaps, it could explain why the Spanish legal and economic frameworks, specifically those applied to solar technology power plants, have been widely discussed in the scientific literature.

Nevertheless, to the best of the authors' knowledge, a detailed and complete review of the last 23 years of energy policy regulating the whole solar sector in Spain, namely both PV and CSP technologies, has not been conducted in the academic literature thus far.

In this regard, this academic contribution makes a thorough review of the development of solar energy policy in Spain during the period 1998-2020. This study covers from the enactment of the first SES Law 54/1997 [55], which ushered the process of progressive liberalization of the power sector, until 2020 with the validity of the new SES Law 24/2013 [56] and RD 413/2014 legal-economic framework for RES [57]; but prior to the recent approval of the new economic regime for RES enacted by RD 960/2020 in November 2020 [58]. Moreover, this review integrates and assesses all the relevant information from previously published research works, allowing the readers to enjoy a global vision concerning the most significant insights on the solar energy policy in Spain during the period 1998-2020.

This 23-year comprehensive review of the Spanish solar power sector pathway may be of great interest to any reader in general or specialist immersed in this thematic area who wants to know in considerable detail the trajectory of the solar sector development in Spain from 1998 to 2020 from a regulatory approach. Similarly, this work can be extremely useful for other countries either in the initial development stage or fully immersed in the promotion of solar power sector or any other renewable technology. 
After this introduction, the rest of the review is organized as follows. In Section 2, the Spanish solar energy policy is contextualized during the period 1998-2020 based on the different REPs established in the country, as well as the corresponding European directives in which they are supported. Section 2 indicates the goals set in Spain for the development of PV and CSP technologies throughout the analysis period, as well as the actual results obtained, but without going into detail about the reasons for these results in the Spanish solar power sector. Then, Section 3 provides a detailed review of the different legislations that have taken place in Spain in the 1998-2020 period for the regulation of energy production by RES facilities, and specifically, by solar power plants. The analysis period has been divided into four subperiods according to the purposes of the legislation in force, i.e., the 1998-2004 subperiod, the 2004-2008 subperiod, the 2008-2013 subperiod and the 2013-2020 subperiod, to clearly identify and describe the different phases of the evolution of solar energy policy in Spain. Hereafter, Section 4 carries out a critical analysis of the different legislation that has regulated the Spanish RES sector, and specifically the solar power sector, during the period 1998-2020 based on the results and conclusions obtained from the existing literature analyzing this topic. In this case, the assessment has been divided into two clearly differentiated subperiods, i.e., the 1998-2008 promotion stage and the 2008-2020 containment stage. Lastly, conclusions are drawn in Section 5.

\section{The Spanish Solar Energy Policy-Contextualization, Main Goals and Results}

The development of renewable energies in Spain began to obtain positive results in the 1990s, as a consequence of a strategic energy policy to promote and support the generation of electricity through RES, whose starting point is in the 1980s with the enactment of Law 82/1980, on energy conservation [59], which mainly promoted the hydroelectric production.

The renewable energy power plants were integrated into the SR group, apart from conventional generation facilities, to boost their development by means of economic incentives, which constituted a financial support allowed and encouraged by the EU, given the importance attached to this type of electricity production. The SR concept was regulated in Spain since 1980 and consolidated by RD 2366/1994 [60], on the electricity generation by hydraulic, cogeneration and other RES facilities, and Law 40/1994 [61], on the organization of the national power system.

In December 1999, in response to the commitment emanating from the SES Law 54/1997 [55] enacted two years earlier, the REP for the 10-year period 2000-2010 [62] was approved in Spain. Its final objective was to promote and support electricity production from RES to achieve the major goals of the Spanish energy policy, i.e., the diversification of primary energy sources to ensure the security of supply, the efficient use of available energy resources and the respect to the environment.

In general terms, the REP 2000-2010 set the goal of reaching 12\% of the primary energy consumption from RES in Spain by 2010, taking into account that this percentage was of $6.3 \%$ in 1998. The same overall target set in the White Paper for a Community Strategy and Action Plan for renewable energies by the European Commission in November 1997 [63].

As regards the solar power sector, the REP 2000-2010 set the goal of adding $135 \mathrm{MW}$ of new solar PV capacity (115 MW connected to the grid and $20 \mathrm{MW}$ isolated) and the first 200 MW of CSP capacity by 2010 [62].

In September 2001, two years after the enactment of the REP 2000-2010, it was approved the Directive 2001/77/CE with the aim of promoting the electricity generated from RES in the EU [64]. The Directive 2001/77/CE required Member States to instituted national indicative goals for the consumption of electricity generated from RES in terms of percentage of electricity consumption. It established an objective of reaching a $22 \%$ share of RES in the final electricity consumed in the EU as a whole by 2010. For Spain, this value was set at $29.4 \%$. Likewise, it also considered the indicative goal set by the White Paper of reaching $12 \%$ of the total primary energy consumption with RES in 2010 [64]. 
In May 2003, it was issued the Directive 2003/30/CE on the promotion of the use of biofuels or other renewable fuels in transport [65]. It established the goal of reaching a $5.75 \%$ market share of biofuels in the transport sector in 2010.

At the halfway point of the REP 2000-2010, the global growth in renewable energies was significantly lower than expected. Specifically, at the end of 2004 only $28.4 \%$ of the global increase foreseen for the presence of RES in the Spanish energy system had been fulfilled. In this regard, only three RES were evolving satisfactorily: wind energy, biofuels and biogas. In contrast, other renewable technologies such as solar were developing well below the pace necessary to achieve the targets established [66].

Moreover, the strong growth in the Spanish energy intensity in the period 2000-2004 was an additional compelling reason to update the REP 2000-2010 to meet the RES targets set for 2010 [66].

Accordingly, the REP 2000-2010 was reviewed in August 2005 by the 5-year REP 2005-2010 [66], with the aim of reinforcing the major goals of the Spanish energy policy, increasing the security and quality of the electricity supply and improving the respect for the environment. With this review, the goal was to uphold the agreement to cover at least $12 \%$ of total energy consumption with RES in 2010 , as well as reaching $29.4 \%$ of electricity production with renewables (Directive 2001/77/CE) and using 5.75\% of biofuels in transport (Directive 2003/30/CE) for that year [66].

The REP 2005-2010 set new targets to be met for the different renewable sectors by 2010. Regarding the solar sector, the goal for the accumulated installed power of both PV and CSP increased, from $144 \mathrm{MW}$ to $400 \mathrm{MW}$ (93\% of grid-connected PV systems and 7\% of isolated facilities) and from $200 \mathrm{MW}$ to $500 \mathrm{MW}$, respectively [66].

In April 2009, the Directive 2009/28/CE on the promotion of the use of energy from RES entered into force [67]. It amended and repealed the Directive 2001/77/CE and the Directive 2003/30/CE. The Directive 2009/28/CE established binding national objectives, which for Spain coincided with those of the EU as a whole (20\% of gross final energy consumption from RES by 2020 and 10\% in the transport sector). The Directive 2009/28/CE was part of the so-called European Energy and Climate Change Package, which included as objectives for 2020 the known "20-20-20" targets, i.e., a 20\% share of renewable energies in the EU's final energy consumption, a 20\% improvement in energy efficiency and a $20 \%$ reduction in GHG emissions compared to 1990 levels [67].

Once the period of validity of the REP 2005-2010 was exhausted and according to the mandates of RD 661/2007, which regulated the power generation activity under the SR, and Law 2/2011 on Sustainable Economy, the new REP for the period 2011-2020 was approved in November 2011 [68]. The REP 2011-2020 proposed a 20.8\% share of renewable energies in the gross final energy consumption of Spain in 2020, reaching a $11.3 \%$ share of RES in the transport consumption in that same year, thus exceeding the mandatory minimum goals established for Spain in the Directive 2009/28/CE. The 20.8\% share of RES in the gross final energy consumption represented the $39 \%$ of the total electricity consumption [68].

The REP 2011-2020 set new non-binding targets to be met for the different renewable sectors by 2020. As for the solar power sector, it established as goals for the accumulated capacity and the energy generated by 2020,7250 MW and 12,350 GWh, respectively, for the solar PV technology, and $4800 \mathrm{MW}$ and 14,378 GWh, respectively, for the CSP sector [68].

Figures 1 and 2 show the progression of the Spanish solar power sector in the period 1998-2020 for PV and CSP technology, respectively, in terms of installed capacity and produced energy. In both figures the targets set by the different REPs, namely REP 2000-2010, REP 2005-2010 and REP 2011-2020, are compared with the actual results obtained. Additionally, the period of validity of each REP has been marked in both figures. 


\section{Solar PV sector in Spain in the period 1998-2020 Main goals and results obtained}

\section{(a) Installed PV capacity}

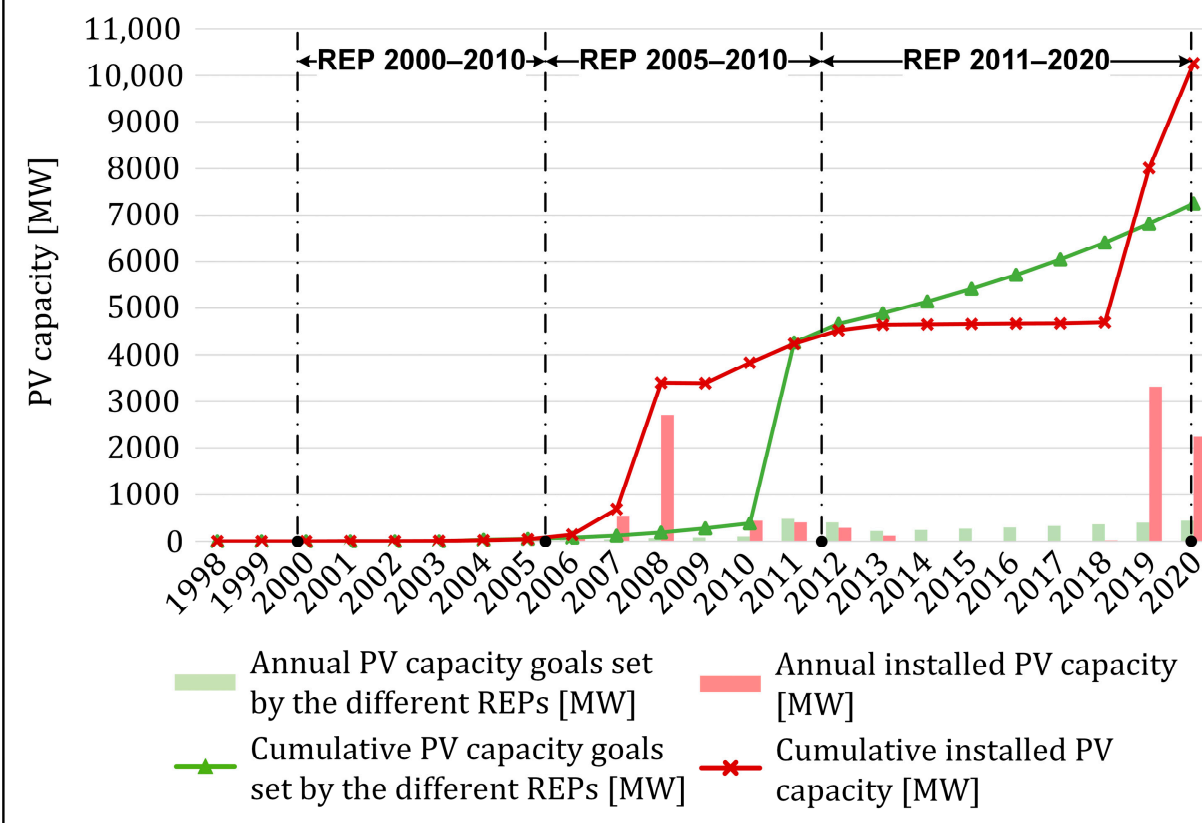

\section{(b) PV energy generated}

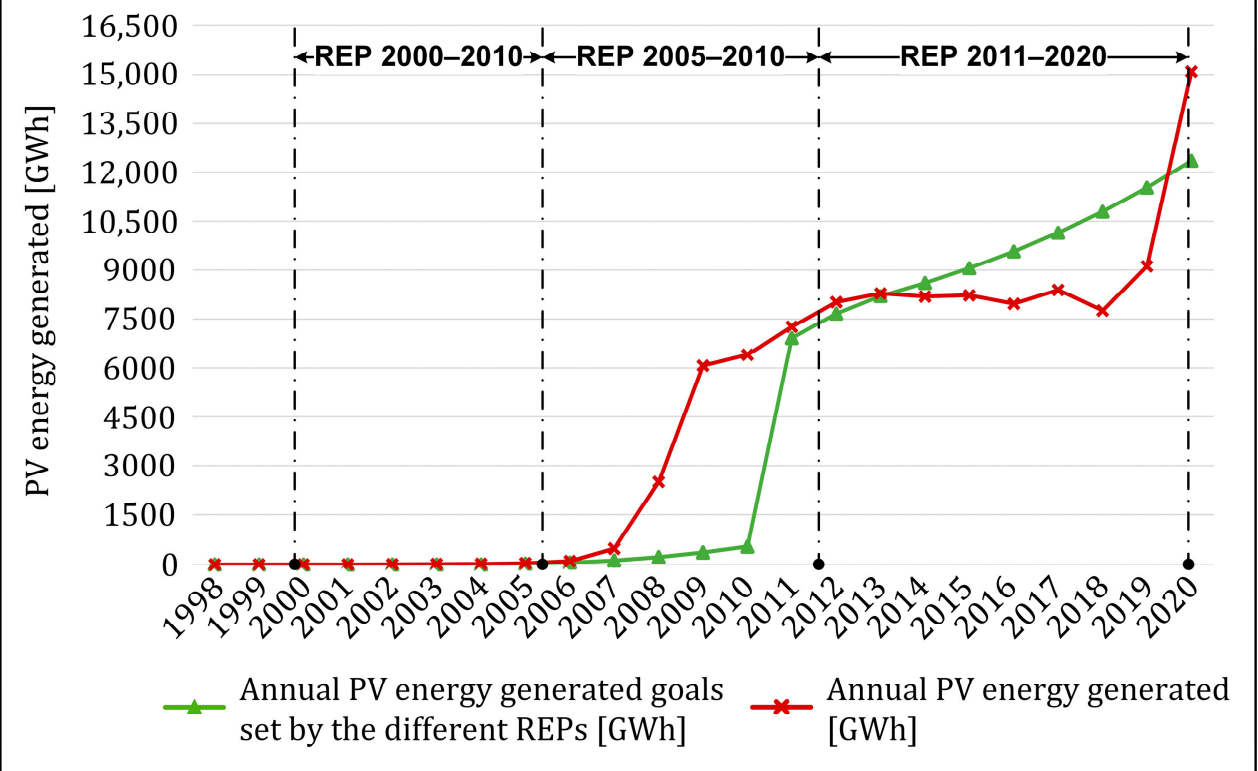

Figure 1. Evolution of the solar PV sector in Spain in the period 1998-2020 in terms of: (a) installed PV capacity; (b) PV energy generated. Source: self-elaboration based on [62,66,68,69]. 


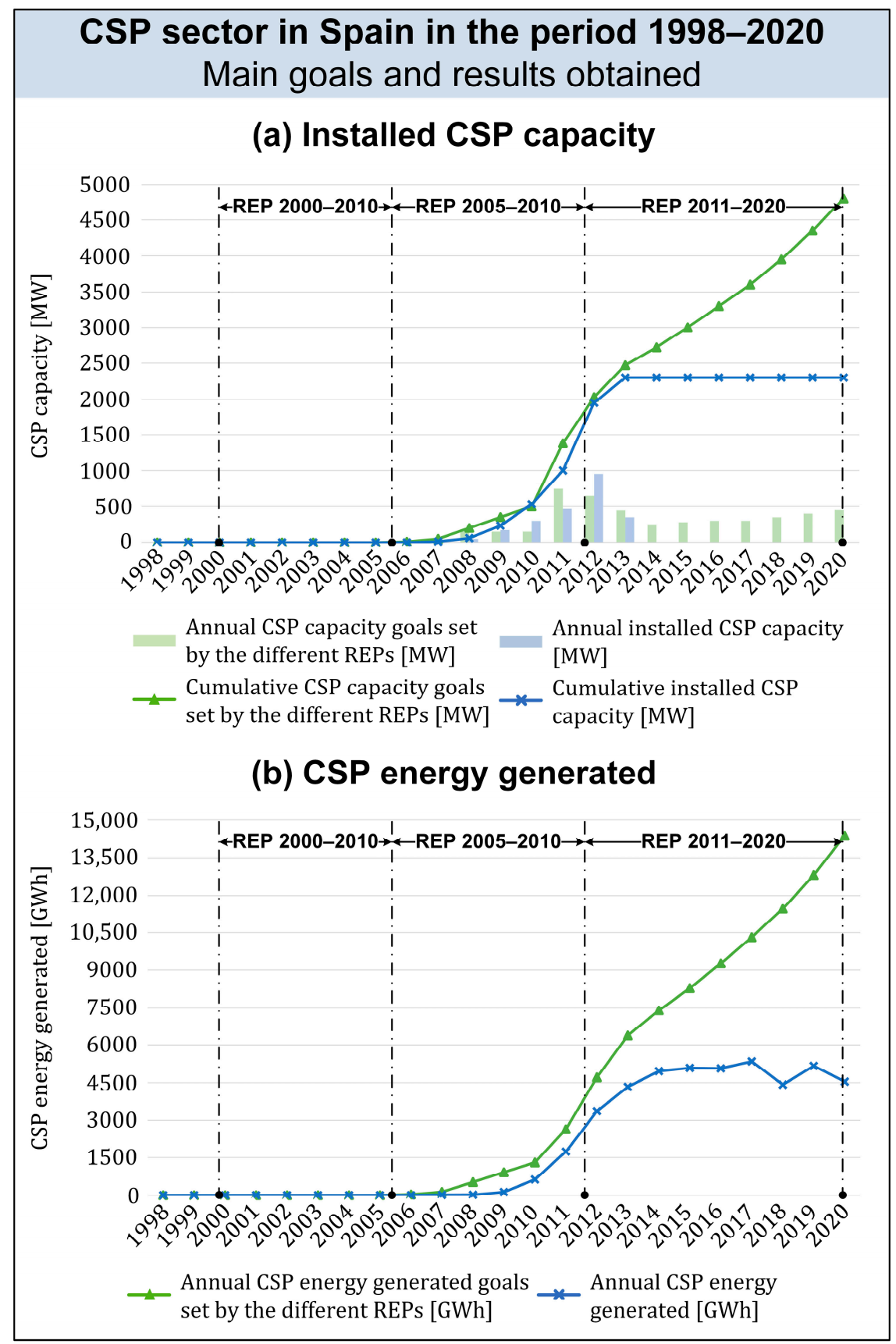

Figure 2. Evolution of the CSP sector in Spain in the period 1998-2020 in terms of: (a) installed CSP capacity; (b) CSP energy generated. Source: self-elaboration based on $[62,66,68,69]$.

In Figure 1a, the cumulative PV capacity goals set by the different REPs are represented with a green solid line with triangle symbols, while the actual cumulative installed PV capacity is plotted by a red solid line with cross symbols. In turn, the annual PV capacity targets set by the different REPs are represented with green-colored vertical bars, while the actual annual installed PV capacity is plotted with red-colored vertical bars. In Figure 1b, the annual PV energy generated goals set by the different REPs are shown using a green solid line with triangle symbols, while the actual annual PV energy generated is represented by a red solid line with cross symbols.

The same pattern is followed in Figure 2 where the Spanish CSP sector is analyzed. In this case, the green color is kept to show the targets set by the different REPs for the CSP technology, but the color used to depict the actual results of this technology is changed to blue. 
On the one hand, before describing and analyzing the period in detail taking into account the different regulatory frameworks in force, the following first lessons can be learned from Figure 1 regarding the evolution of the Spanish solar PV sector in the period 1998-2020:

- In the period 1998-2004, i.e., the period of validity of the REP 2000-2010, the foundations of the Spanish energy regulation regarding the promotion of RES began to be laid, but the solar PV sector did not evolve as planned. In this period, the cumulative installed PV capacity and the energy generated went from 1.5 MW and 1.1 GWh, respectively, in 1998, to $22.8 \mathrm{MW}$ and 16.9 GWh, respectively, in 2004, far from the REP 2000-2010 forecasts. Even so, at the end of 2004 there were a total of 3266 PV facilities in Spain, compared to the 12 existing in 1998;

- The period 2005-2010, i.e., the period of validity of the REP 2005-2010, stood out for the existence of a very favorable legal-economic framework for PV facilities in Spain, in line with the PV energy promotion policy of the period 1998-2004. The moderate growth of the years 2005-2006 gave way to what is known as the "Spanish solar PV boom" in the years 2007-2008. In this 5-year period, the cumulative installed PV capacity and the energy generated increased to 3829.7 MW and 6073 GWh, respectively, by 2010, well above the REP 2005-2010 forecasts. At the end of 2010 there were a total of 54,949 PV plants in Spain, reaching a 2.3\% share of solar PV energy in the energy demand;

- In the period 2011-2020, i.e., the period of validity of the REP 2011-2020, a series of regulatory containment frameworks were approved. From 2010 to 2013 the solar PV sector continued to increase its cumulative installed PV capacity but with a progressive downward trend until the stagnation of this technology in the years 2014-2018. At the end of the period, i.e., years 2019-2020, there was a new boom higher than that of 2007-2008 as a result of the call for new auctions for the solar PV technology. In this period, the cumulative installed PV capacity and the energy generated increased to 10,254.8 MW and 15,092.9 GWh, respectively, in 2020, well above the REP 2011-2020 forecasts. At the end of 2020 there were a total of 61,543 PV facilities in Spain, reaching a $6.1 \%$ share of solar PV energy in the energy demand.

On the other hand, as regards the evolution of the Spanish CSP sector in the period 1998-2020, the following first lessons can be learned from Figure 2:

- At the end of the period 1998-2004, i.e., the period of validity of the REP 2000-2010, there were no CSP plant in operation or in the construction stage in Spain;

- In the period 2005-2010, i.e., the period of validity of the REP 2005-2010, the first CSP facilities were put into operation as a result of the existence of a more favorable legislation for CSP in Spain. Since the commissioning of the first CSP plant in 2007, the sector began a continuous growth until the end of the period. In this 5-year period, the cumulative installed CSP capacity and the energy generated went from $11 \mathrm{MW}$ and 7.6 GWh, respectively, in 2007, to 531.9 MW and 620.9 GWh, respectively, in 2010, quite close to the REP 2005-2010 forecasts. At the end of 2010 there were a total of 13 CSP facilities in Spain, compared to the 1 existing in 2007, reaching a $0.2 \%$ share of solar CSP energy in the energy demand;

- At the beginning of the period 2011-2020, i.e., the period of validity of the REP 20112020, and more specifically in the years 2011-2012, there was the boom of the Spanish CSP sector. Since then, 2013 was the last year in which commercial CSP capacity was installed in Spain due to the series of regulatory containment frameworks that were approved. In this period, the cumulative installed CSP capacity and the energy generated increased to 2299.4 MW and 4542.6 GWh, respectively, in 2020, well below the REP 2011-2020 forecasts. At the end of 2020 there were a total of 50 CSP plants in Spain, reaching a $1.8 \%$ share of solar CSP energy in the energy demand. 


\section{Overview of the 1998-2020 Legal-Economic Frameworks for the Solar Power Plants in Spain}

The Spanish solar power sector has suffered continuous and considerable changes in its regulation in the period 1998-2020 since the enactment of the SES Law 54/1997, denoting a great dynamism and in turn generating high uncertainty in the electricity sector.

In Figure 3 the different legislations regulating the solar sector in Spain during the period 1998-2020 have been plotted chronologically. The European directives are displayed in purple-colored boxes, the Spanish rules in blue-colored boxes and the REPs in green-colored ones. In turn, the different legislative changes have been grouped into four regulatory subperiods according to their purposes, to correctly overview and understand the Spanish solar energy policy development in the 1998-2020 period.

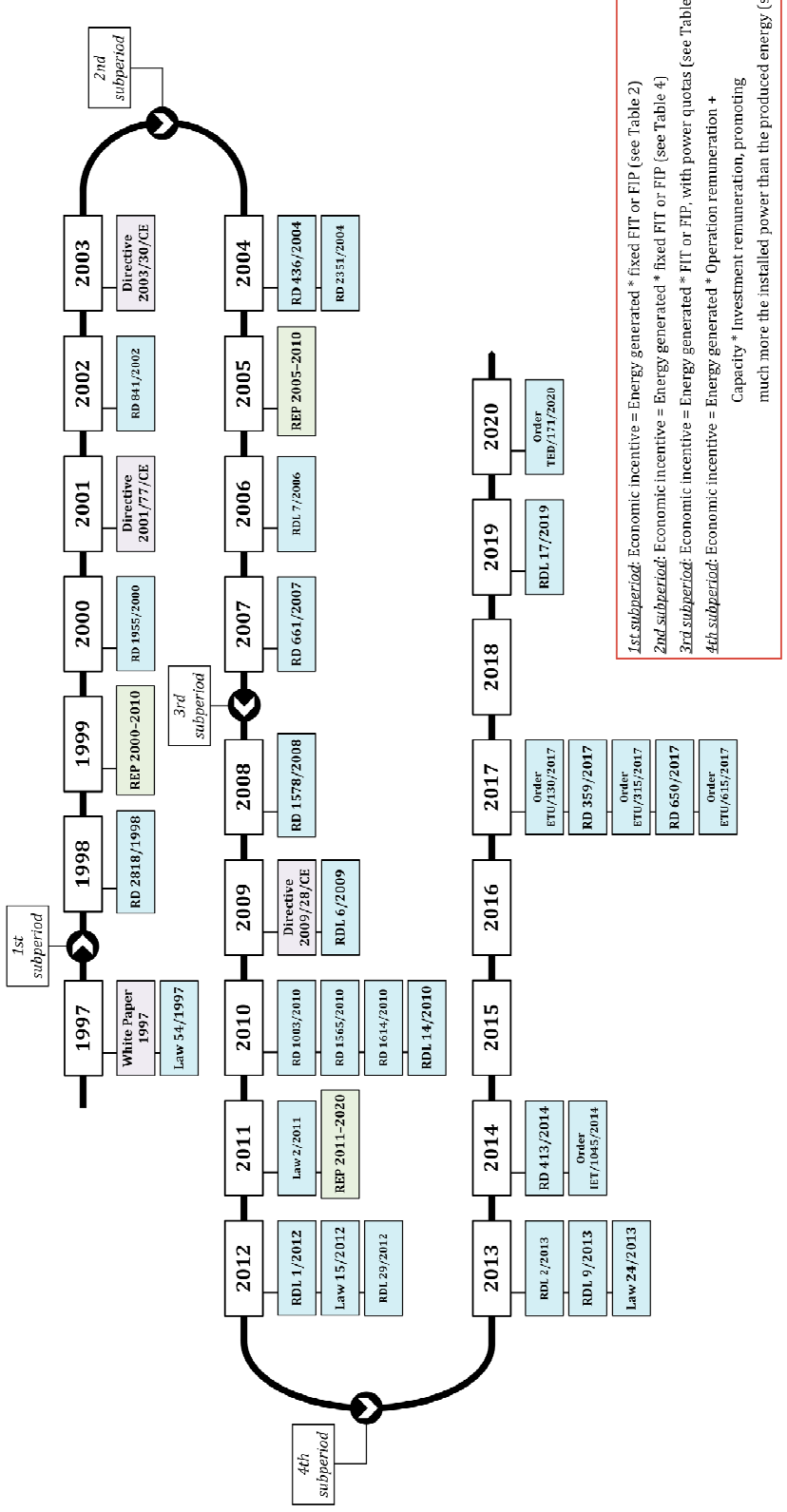

Figure 3. Timeline with the different legislations governing the Spanish solar power sector from 1998 to 2020. Source: self-elaboration. 


\subsection{The 1998-2004 Subperiod: Laying the Foundations of the Spanish Solar Power Sector}

As background to the 1998-2004 subperiod, it is worth highlighting the enactment of the SES Law 54/1997 [55] in November 1997, which set a new operating model for producers of electricity based on free competition in Spain, while seeking to enhance energy efficiency and decrease the energy consumption as well as the GHG emissions. It also incorporated the targets set by the White Paper [63] for 2010, later included in the REP 2000-2010.

The SES Law 54/1997 distinguished two different groups of energy producers, namely those that were part of the SR, which enjoyed of a certain legal and economic singularity, compared to those that were part of the ordinary regime, i.e., conventional technology plants. Specifically, the generation activity under the SR included the production facilities with a capacity not exceeding $50 \mathrm{MW}$ using as primary energy renewable energy, waste or cogeneration. In turn, all those generation power plants that had been authorized, as well as its characteristics and, especially, its power capacity, should be enrolled in the administrative registry of electricity production plants created by the SES Law 54/1997 [55].

Finally, the SES Law 54/1997 required the enactment of a decree adapting the functioning of the SR to the new regulation, namely RD 2818/1998, which was approved in December 1998 [70]. Then, with the enactment of RD 2818/1998, subsequently amended first by RD 1955/2000 [71] of December 2000, and later by RD 841/2002 [72] of August 2002 , started what could be considered to be the first regulatory subperiod in which the rules and guidelines set by SES Law 54/1997 began to be developed. During the 1998-2004 subperiod, the foundations of the Spanish electricity production sector from RES, and more specifically of the Spanish solar power sector, were laid by means of the corresponding legislation. That first subperiod was extended until the first part of 2004 when the adoption of a new legal framework, namely RD 436/2004 [73], updated the legal-economic regime of the electricity generation activity under the SR.

Tables 1 and 2 provide a detailed overview of the main features of the different regulatory frameworks and economic regimes, respectively, in force for solar power plants in Spain in the period 1998-2004, namely RD 2818/1998 and its revisions by RD 1955/2000 and RD 841/2002.

Table 1. Major characteristics of the different regulatory frameworks in force for the Spanish solar power systems in the period 1998-2004. Source: self-elaboration based on [70-72].

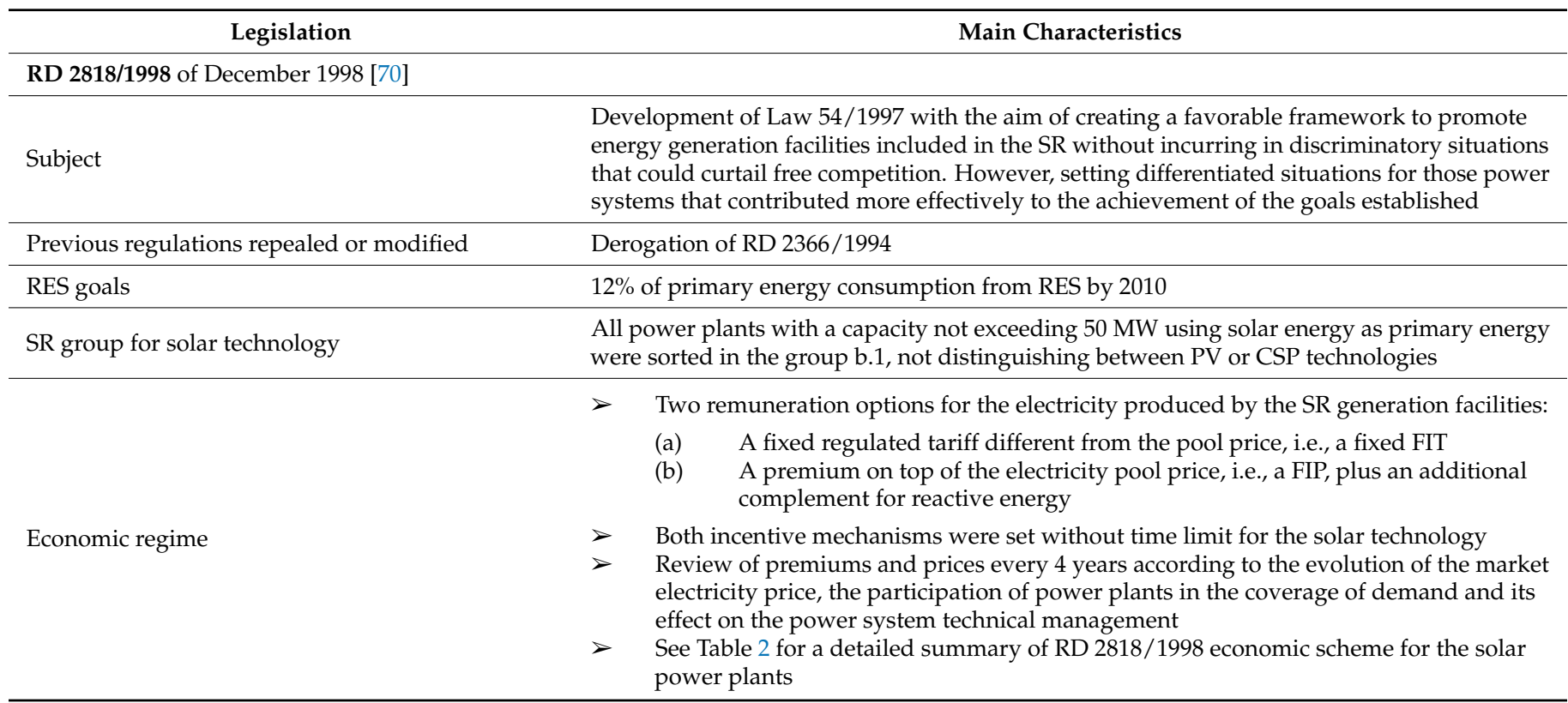


Table 1. Cont.

\begin{tabular}{|c|c|}
\hline Legislation & Main Characteristics \\
\hline Administrative features & - \\
\hline Other issues & $\begin{array}{l}\text { The solar facilities included in group b. } 1 \text { of the SR could incorporate all the energy produced } \\
\text { into the grid, as long as the } 12 \% \text { share of RES in the total energy demand was not reached }\end{array}$ \\
\hline \multicolumn{2}{|l|}{ RD 1955/2000 of December 2000 [71] } \\
\hline Subject & $\begin{array}{l}\text { Inclusion of power plants only using solar thermal energy as primary energy in group b. } 3 \text { of } \\
\text { the SR together with those using tidal, wave, geothermal and hot and dry rocks energies }\end{array}$ \\
\hline Previous regulations repealed or modified & Amendment of RD 2818/1998 \\
\hline RES goals & - \\
\hline SR group for solar technology & $\begin{array}{l}\text { b.1 for solar PV technology plants and b.3 for CSP technology facilities (with an installed } \\
\text { capacity not exceeding } 50 \mathrm{MW} \text { ) }\end{array}$ \\
\hline Economic regime & $\begin{array}{l}\text { See Table } 2 \text { for a detailed summary of the changes introduced by RD 1955/2000 in RD } \\
2818 / 1998 \text { economic scheme for the solar power plants }\end{array}$ \\
\hline Administrative features & - \\
\hline \multicolumn{2}{|l|}{ RD 841/2002 of August 2002 [72] } \\
\hline Subject & New classification for the SR solar facilities set by RD $2818 / 1998$ \\
\hline Previous regulations repealed or modified & $\begin{array}{l}\text { Amendment of RD } 2818 / 1998 \text { and suppression of the modifications introduced by RD } \\
1955 / 2000 \text { concerning the CSP plants }\end{array}$ \\
\hline RES goals & - \\
\hline SR group for solar technology & b.1.1 for solar PV facilities and b.1.2 for CSP plants (with an installed power not exceeding $50 \mathrm{MW}$ ) \\
\hline Economic regime & $\begin{array}{l}\text { See Table } 2 \text { for a detailed summary of the changes introduced by RD 841/2002 in RD } \\
2818 / 1998 \text { economic scheme for the solar power plants }\end{array}$ \\
\hline Administrative features & - \\
\hline Other issues & $\begin{array}{l}\text { Unlike both RD } 2818 / 1998 \text { and RD } 1955 / 2000, \mathrm{RD} 841 / 2002 \text { stated that fuel could be used to } \\
\text { keep the temperature of the heat storage system of CSP facilities in subgroup b.1.2 during } \\
\text { interruption periods of power production }\end{array}$ \\
\hline
\end{tabular}

Table 2. Major characteristics of the different economic regimes in force for solar power systems in Spain in the period 1998-2004. Source: self-elaboration based on [70-72].

\begin{tabular}{|c|c|c|c|c|c|c|c|}
\hline \multirow{3}{*}{ Legislation } & \multirow{3}{*}{ Technology } & \multirow{3}{*}{$\begin{array}{c}\text { SR } \\
\text { Group }\end{array}$} & \multirow{3}{*}{$\begin{array}{l}\text { Rated } \\
\text { Power }\end{array}$} & \multicolumn{2}{|c|}{ Remuneration Options } & \multirow{3}{*}{ Time Limit } & \multirow{3}{*}{ Review and Update } \\
\hline & & & & FIT & FIP $^{1}$ & & \\
\hline & & & & $\begin{array}{c}\text { Regulated } \\
\text { Tariff [cEUR/kWh] }\end{array}$ & $\underset{\text { [cEUR/kWh] }}{\text { Premium }}$ & & \\
\hline \multirow{4}{*}{ RD 2818/1998 } & \multirow{2}{*}{ Solar PV } & \multirow{2}{*}{ b.1 } & $P \leq 5 \mathrm{~kW}$ & 39.6668 & 36.0607 & \multirow{2}{*}{ No } & For both FIT and FIP options: \\
\hline & & & $P>5 \mathrm{~kW}$ & 21.6364 & 18.0304 & & $\begin{array}{ll}-\quad & \text { No annual update } \\
-\quad & \text { Review every } 4 \text { years }\end{array}$ \\
\hline & \multirow{2}{*}{ Solar CSP } & \multirow{2}{*}{ b.1 } & $P \leq 5 \mathrm{~kW}$ & 39.6668 & 36.0607 & \multirow{2}{*}{ No } & For both FIT and FIP options: \\
\hline & & & $P>5 \mathrm{~kW}$ & 21.6364 & 18.0304 & & $\begin{array}{ll}-\quad & \text { No annual update } \\
-\quad & \text { Review every } 4 \text { years }\end{array}$ \\
\hline \multirow{4}{*}{ RD 1955/2000 } & \multirow{2}{*}{ Solar PV } & \multirow{2}{*}{ b.1 } & $P \leq 5 \mathrm{~kW}$ & 39.6668 & 36.0607 & \multirow{2}{*}{ No } & \multirow{2}{*}{$\begin{array}{l}\text { For both FIT and FIP options: } \\
\text { - } \quad \text { No annual update } \\
\text { - } \quad \text { Review every } 4 \text { years }\end{array}$} \\
\hline & & & $P>5 \mathrm{~kW}$ & 21.6364 & 18.0304 & & \\
\hline & & & & & & & For both FIT and FIP options: \\
\hline & Solar CSP & b. 3 & Any & 6.7313 & 3.2755 & No & $\begin{array}{l}\text { Annual update according to } \\
\text { average selling electricity price } \\
\text { - } \quad \text { Review every } 4 \text { years }\end{array}$ \\
\hline \multirow{4}{*}{ RD 841/2002 } & \multirow{2}{*}{ Solar PV } & \multirow{2}{*}{ b.1.1 } & $P \leq 5 \mathrm{~kW}$ & 39.6668 & 36.0607 & \multirow{2}{*}{ No } & \multirow{2}{*}{$\begin{array}{l}\text { For both FIT and FIP options: } \\
\text { - } \quad \text { No annual update } \\
\text { - } \quad \text { Review every } 4 \text { years }\end{array}$} \\
\hline & & & $P>5 \mathrm{~kW}$ & 21.6364 & 18.0304 & & \\
\hline & & & & & & & For both FIT and FIP options: \\
\hline & Solar CSP & b.1.2 & Any & - & 12.0202 & No & $\begin{array}{l}\text { - No annual update } \\
\text { - Review every } 4 \text { years }\end{array}$ \\
\hline
\end{tabular}

${ }^{1}$ This table only shows the values of the FIP components fully established in a regulatory manner, i.e., the premiums. Thus, the electricity market price and the reactive energy complement must be added to this economic parameter to obtain the total FIP of the power plant. 


\subsection{The 2004-2008 Subperiod: Ratifying the Unwavering and Forceful Commitment to Solar Power Projects in Spain}

The second regulatory period began with the approval of RD 436/2004 in March 2004 [73], which derogated both RD 2818/1998 and RD 841/2002. The 2004-2008 subperiod was characterized by an extremely favorable economic framework for RES facilities, and especially for solar power plants, first under RD 436/2004 [73] and later under RD 661/2007 [74], which repealed RD 436/2004. Thus, ratifying the Spanish government its strong commitment to the development and deployment of solar power plants.

Tables 3 and 4 provide a comprehensive overview of the main features of the different regulatory frameworks and economic regimes, respectively, in force for the Spanish solar power facilities in the period 2004-2008, namely RD 436/2004 and RD 661/2007.

Table 3. Major characteristics of the different regulatory frameworks in force for solar power systems in Spain in the period 2004-2008. Source: self-elaboration based on [73,74].

\begin{tabular}{ll}
\hline Legislation & Main Characteristics \\
\hline RD 436/2004 of March 2004 [73] & \\
\hline Subject & $\begin{array}{l}\text { Setting the methodology for systematizing and updating the legal-economic regime of the } \\
\text { power generation activity in the SR }\end{array}$ \\
\hline Previous regulations repealed or modified & Derogation of RD 2818/1998 and RD 841/2002 \\
\hline RES goals & $\begin{array}{l}\text { As for the whole RES sector, 29.4\% of electricity generation and } 12 \% \text { of total energy } \\
\text { consumption from RES by 2010, without increasing the cost of production of the }\end{array}$ \\
Spanish electricity system & $\begin{array}{l}\text { As for the solar power sector, } 150 \text { MW of solar PV and 200 MW of CSP eligible for the } \\
\text { initial remuneration }\end{array}$
\end{tabular}

b.1.1 for solar PV facilities and b.1.2 for CSP facilities (with an installed capacity not exceeding $50 \mathrm{MW}$ )

$>$ Two remuneration options for the electricity produced by the SR generation facilities:

(a) The sale of their electricity production to a distribution company receiving a fixed FIT for all periods

(b) The sale of its electricity production to the daily market receiving a premium plus an incentive on top of the electricity market price, i.e., a FIP

- Regardless the chosen electricity selling option, all solar power plants would also perceive a complement for reactive energy

$>\quad$ The chosen selling option should be kept for a minimum period of 1 year

$>\quad$ Both remuneration mechanisms were indexed to the yearly average electricity tariff (AET), which for 2004 had a value of $7.2072 \mathrm{cEUR} / \mathrm{kWh}$. The AET was established as a relationship between the expected costs necessary to remunerate the electricity supplying activities and the forecast, for the same period considered, of the final energy demand determined by the Spanish government [75]

$>$ After the first 25 years of receipt of any of the remuneration mechanisms, those public subsidies were reduced for the solar technology

> The first revision of FIT, premiums, incentives and complements was set for 2006 Thereafter, these economic parameters would be reviewed every 4 years, unless subgroup b.1.1 reached $150 \mathrm{MW}$ of installed capacity or subgroup b.1.2 reached $200 \mathrm{MW}$

$>$ The reviews would be made according to the evolution of the costs associated with the generation technologies, the participation degree of the SR in the energy production and its technical-economic management of the system. Moreover, the revisions would apply only to facilities coming into operation after the entry into force of the agreed revisions, thus eliminating their retroactive character

$>$ See Table 4 for a detailed summary of RD 436/2004 economic scheme for the solar power plants 
Table 3. Cont.

\begin{tabular}{ll}
\hline Legislation & Main Characteristics \\
\hline & $\begin{array}{l}\text { From the end of } 2005 \text { until the approval of RD } 661 / 2007 \text { it was required a guarantee of } 2 \% \text { of } \\
\text { the facility budget to request access to the transmission grid, but not for the distribution grid. } \\
\text { The guarantee would be canceled when the petitioner obtained the commissioning certificate } \\
\text { for the facility }\end{array}$ \\
\hline
\end{tabular}

> The CSP facilities in subgroup b.1.2 could use auxiliary equipment consuming fuels, i.e., propane or natural gas, only to maintain the heat storage system temperature. The annual fuel consumption, only during periods of interruption of electricity generation, for CSP facilities receiving a FIT should be less than $12 \%$ of their power generation. Otherwise, that percentage would raise to $15 \%$, without any time-limit of fuel use, for CSP plants selling electricity to the pool

Other issues

$>\quad$ At the end of 2004, RD 2351/2004 [76] modified the provisions on fuel usage for CSP plants belonging to the subgroup b.1.2 initially made by RD 436/2004. RD 2351/2004 enabled the use of any kind of fuel to maintain the heat transfer fluid temperature in the CSP facilities to compensate for the lack of solar irradiation that could compromise the expected supply of electricity. Thus, eliminating the requirement of fuel usage only during the periods of interruption of power production, while maintaining the percentages regarding the generation of electricity from fuel depending on the remuneration option chosen by the CSP facility

RD 661/2007 of May 2007 [74]

Subject

Regulation of some technical issues to contribute to the expansion of SR technologies, safeguarding the safety of the power system and guaranteeing its quality of supply, as well as to minimize restrictions on production

Previous regulations repealed or modified Suppression of RD 436/2004

RES goals

As for the whole RES sector, $29.4 \%$ of electricity generation and $12 \%$ of total energy consumption from RES by 2010

$>$ As for the solar power sector, $371 \mathrm{MW}$ of solar PV and $500 \mathrm{MW}$ of CSP

SR group for solar technology b.1.1 for solar PV plants and b.1.2 for CSP facilities (with an installed capacity not exceeding $50 \mathrm{MW}$ )

$>\quad$ The basic regulatory structure of the SR was maintained by RD 661/2007.

Nevertheless, based on Royal Decree Law (RDL) 7/2006 [77], which set that the AET future revisions would not apply to the remuneration of RES under the SR, it definitively decoupled the SR remuneration from the AET, ensuring a reasonable remuneration to the owners of the SR power plants for their investments

$>$ Two remuneration options for the electricity produced by the SR generation facilities:

(a) A fixed FIT for all periods

(b) A premium on top of the electricity market price, i.e., a FIP

$>$ RD 661/2007 bounded the FIP, i.e., the sum of the electricity pool price and the premium, between an upper boundary and a lower boundary. The new cap and floor system protected the promoter of the power plants under the FIP remuneration option when the income derived from the pool price was too low, and eliminated the premium when the pool price was high enough to ensure the coverage of its costs, thus removing irrationalities in the remuneration of technologies, whose costs were not directly linked to oil prices in international markets

Economic regime

> Regardless of the selected electricity selling option, all solar power plants would also receive a complement for reactive energy. This complement was set as a percentage, in accordance with the power factor with which the energy was delivered, of the value of $7.8441 \mathrm{cEUR} / \mathrm{kWh}$, which would be reviewed annually

> The chosen selling option should be kept for a minimum period of 1 year

$>$ After the first 25 years of receipt of any of the remuneration mechanisms, those public subsidies were reduced for the solar technology

$>\quad$ The FIT, premiums, complements and upper and lower bounds set by RD 661/2007 would be updated annually taking as a reference the rise in the consumer price index (CPI) minus 25 basis points (BP) until 31 December 2012, and 50 BP thereafter. However, in 2010, the year in which the REP 2005-2010 was expected to end, a review of these economic parameters was expected, which would be evaluated according to the variation in costs associated with each technology, the participation degree of the $\mathrm{SR}$ in the production of energy and its incidence in the technical-economic management of the system, ensuring a reasonable return. From then on, reviews would be carried out every 4 years 
Table 3. Cont.

\begin{tabular}{|c|c|c|}
\hline Legislation & $\mathbf{M}$ & Characteristics \\
\hline Economic regime & $\begin{array}{l}> \\
>\end{array}$ & $\begin{array}{l}\text { The revisions of the regulated tariff as well as the upper and lower bounds would not } \\
\text { affect the facilities whose commissioning certificate had been granted before } \\
\text { 1st January of the second year after that in which the revision was carried out } \\
\text { See Table } 4 \text { for a detailed summary of RD } 661 / 2007 \text { economic scheme for the solar } \\
\text { power plants } \\
\text { An additional mechanism to set the maintenance period of the regulated tariffs and } \\
\text { premiums was established by RD } 661 / 2007 \text {. Accordingly, once } 85 \% \text { of the power goal } \\
\text { of a technology was reached, a maximum period of not less than } 1 \text { year would be set. } \\
\text { During this period, those power plants properly enrolled in the administrative register } \\
\text { of generation plants under the SR would be entitled to the corresponding premiums or } \\
\text { regulated tariffs under RD } 661 / 2007\end{array}$ \\
\hline Administrative features & $>$ & $\begin{array}{l}\text { RD } 661 / 2007 \text { requested guarantees to process the access both to the distribution grid } \\
\text { as well as to the transmission grid. For the PV facilities these guarantees were of } \\
500 \text { EUR/kW, while for the CSP plants were of } 20 \mathrm{EUR} / \mathrm{kW} \text {. The guarantee would be } \\
\text { canceled when the petitioner obtained the commissioning certificate for the facility } \\
\text { It established priority of access and connection to the electricity network of RES } \\
\text { power plants }\end{array}$ \\
\hline Other issues & \multicolumn{2}{|r|}{$\begin{array}{l}\text { RD } 661 / 2007 \text { admitted the option of hybridization of different fuels and/or technologies. } \\
\text { Among the technologies that could participate in hybridizations was CSP (subgroup b.1.2), } \\
\text { but not solar PV (subgroup b.1.1) }\end{array}$} \\
\hline
\end{tabular}

\subsection{The 2008-2013 Subperiod: The Containment of the Spanish Solar Power Sector}

In August 2007, i.e., 3 months after entering into force RD 661/2007, 85\% of the installed PV power target for 2010 was exceeded. Specifically, 1000 MW of installed PV capacity had already been reached in May 2008.

In accordance with the remuneration maintenance mechanism set by RD 661/2007 [74], as of August 2007, once $85 \%$ of the installed PV power target had been reached, the maximum period of not less than 1 year began to count. Once this transition period was over, the remuneration model established by RD 661/2007 for solar PV technology plants in subgroup b.1.1 would be reviewed and updated. Accordingly, RD 1578/2008 was approved in September 2008 [78].

With RD 1578/2008 of September 2008 began the containment stage of the Spanish solar power sector, which would later be extended to the rest of the RES power sector.

Prior to the containment stage, the SR regulation did not establish sufficient mechanisms that allowed the planning of the power plants, nor the amount and the time limit of their remuneration premiums and therefore the effect on the costs attributed to the tariff scheme. Furthermore, the increasing impact of the SR remuneration on the tariff deficit, i.e., the lack of incomes of the electrical system to cover all its expenditures, could jeopardize the short-term sustainability of the electrical system, both from a technical perspective, also compromising the financial sustainability of the facilities already completed, and from an economic standpoint owing to its impact on the electricity tariff. Thus, unlike previous legislations aimed mainly at the development and promotion of RES, the new measures approved by the Spanish government as of 2009 would be mainly aimed at reducing the cost of the RES technologies to the electricity system.

Accordingly, in May 2009 RDL 6/2009 [79] came into effect. The measures envisaged in RDL 6/2009, through the creation of a register of pre-allocation of remuneration (RPAR), allowed knowing the facilities that were projected, as well as those that met the conditions to be executed and access the electrical system with all legal provisions, its capacity and the effect on the costs of the electricity tariff and its schedule. It established the principle of sufficiency of access tolls to cover all the costs of the regulated activities as of 2013, so that from then on, no tariff deficit could appear. As solar PV technology had its specific framework, namely RD 1578/2008, these power plants were not affected by RDL 6/2009. 
Table 4. Major characteristics of the different economic regimes in force for solar power systems in Spain in the period 2004-2008. Source: self-elaboration based on $[73,74]$.

\begin{tabular}{|c|c|c|c|c|c|c|c|c|}
\hline \multirow{3}{*}{ Legislation } & \multirow{3}{*}{ Technology } & \multirow{3}{*}{$\begin{array}{c}\text { SR } \\
\text { Group }\end{array}$} & \multirow{3}{*}{$\begin{array}{l}\text { Rated } \\
\text { Power }\end{array}$} & \multicolumn{3}{|c|}{ Remuneration Options } & \multirow{3}{*}{ Time Limit } & \multirow{3}{*}{ Review and Update } \\
\hline & & & & \multirow{2}{*}{$\begin{array}{c}\text { FIT } \\
\text { Regulated } \\
\text { Tariff [cEUR/kWh] }\end{array}$} & \multicolumn{2}{|c|}{ FIP $^{1}$} & & \\
\hline & & & & & $\begin{array}{c}\text { Premium } \\
\text { [cEUR/kWh] }\end{array}$ & $\begin{array}{c}\text { Incentive } \\
\text { [cEUR/kWh] }\end{array}$ & & \\
\hline \multirow{7}{*}{ RD 436/2004 } & \multirow{4}{*}{ Solar PV } & \multirow{4}{*}{ b.1.1 } & \multirow{2}{*}{$P \leq 100 \mathrm{~kW}$} & $575 \%$ of AET & - & - & First 25 years & \multirow{4}{*}{$\begin{array}{l}\text { For both FIT and FIP options: } \\
\text { - } \quad \text { Annual update according } \\
\text { to AET } \\
\text { - } \\
\text { Review in } 2006 \text { and thereafter } \\
\text { every } 4 \text { years or when } \\
\text { reaching } 150 \mathrm{MW}\end{array}$} \\
\hline & & & & $460 \%$ of AET & - & - & Thereafter & \\
\hline & & & \multirow{2}{*}{$P>100 \mathrm{~kW}$} & $300 \%$ of AET & $250 \%$ of AET & $10 \%$ of AET & First 25 years & \\
\hline & & & & $240 \%$ of AET & $200 \%$ of AET & $10 \%$ of $\mathrm{AET}$ & Thereafter & \\
\hline & \multirow{3}{*}{ Solar CSP } & \multirow{3}{*}{ b.1.2 } & \multirow{3}{*}{ Any } & & & & & \multirow{3}{*}{$\begin{array}{l}\text { For both FIT and FIP options: } \\
\text { - Annual update according } \\
\text { to AET } \\
\text { - } \quad \text { Review in } 2006 \text { and thereafter } \\
\text { every } 4 \text { years or when } \\
\text { reaching } 200 \mathrm{MW}\end{array}$} \\
\hline & & & & $300 \%$ of AET & $250 \%$ of AET & $10 \%$ of AET & First 25 years & \\
\hline & & & & $240 \%$ of AET & $200 \%$ of AET & $10 \%$ of $\mathrm{AET}$ & Thereafter & \\
\hline \multirow{8}{*}{ RD 661/2007 } & \multirow{5}{*}{ Solar PV } & \multirow{5}{*}{ b.1.1 } & $P \leq 100 \mathrm{~kW}$ & 44.0381 & - & - & First 25 years & \multirow{5}{*}{$\begin{array}{l}\text { For both FIT and FIP options: } \\
\text { - } \quad \text { Annual update according } \\
\text { to CPI } \\
\text { - } \quad \text { Review in } 2010 \text { and thereafter } \\
\text { every } 4 \text { years or not less than } \\
1 \text { year after reaching } 85 \% \text { of } \\
371 \mathrm{MW}\end{array}$} \\
\hline & & & \multirow{2}{*}{$100 \mathrm{~kW}<P \leq 10 \mathrm{MW}$} & 41.7500 & - & - & First 25 years & \\
\hline & & & & 33.4000 & - & - & Thereafter & \\
\hline & & & \multirow{2}{*}{$10 \mathrm{MW}<P \leq 50 \mathrm{MW}$} & 22.9764 & - & - & First 25 years & \\
\hline & & & & 18.3811 & - & - & Thereafter & \\
\hline & \multirow{3}{*}{ Solar CSP } & \multirow{3}{*}{ b.1.2 } & \multirow{3}{*}{ Any } & & & & & \multirow{3}{*}{$\begin{array}{l}\text { For both FIT and FIP options: } \\
\text { - } \quad \text { Annual update according } \\
\text { to CPI } \\
\text { - } \quad \text { Review in } 2010 \text { and thereafte } \\
\text { every } 4 \text { years or not less than } \\
1 \text { year after reaching } 85 \% \text { of } \\
500 \mathrm{MW}\end{array}$} \\
\hline & & & & 26.9375 & 25.4000 & - & First 25 years & \\
\hline & & & & 21.5498 & 20.3200 & - & Thereafter & \\
\hline
\end{tabular}

${ }^{1}$ This table only shows the values of the FIP components fully established in a regulatory manner, i.e., the premiums and the incentives. Thus, the electricity market price and the reactive energy complement must be added to these economic parameters to obtain the total FIP of the facility. 
The Resolution of 19 November 2009 of the State Secretariat for Energy [80] published the ordering of the projects presented to the RPAR for electrical energy production facilities provided for in RDL 6/2009. The electrical management system allowed the incorporation of $3100 \mathrm{MW}$ of capacity from new renewable facilities per year, until 2014, without compromising the technical-economic sustainability of the electrical system. Thus, it was necessary to defer the commissioning of the registered facilities.

The entry into operation of the registered CSP power plants was distributed in four successive steps until the end 2013 according to the following accumulated deployment rate: (a) step 1: $850 \mathrm{MW}$, (b) step 2: $1350 \mathrm{MW}$, (c) step 3: $1850 \mathrm{MW}$ and (d) step 4: rest of registered power under the provisions of RDL 6/2009 [80].

The growth in the number of generation facilities from RES, cogeneration and waste under the SR had been very important until 2010, becoming especially noteworthy for wind, solar PV and CSP technologies that reached and even exceeded the installed power targets set for that year. Thus, Spain became one of the leading countries in the expansion of these technologies. This growth occurred thanks to the existence of a predictable, stable and solid legal-economic support mechanism.

In this context, the management experience accumulated as a result of the application of the SR legal framework, advised the redefinition of certain concepts and the adaptation of procedures to the evolution of the sectors under the SR. Thus, the support regime should be adapted, preserving the legal certainty of investments and the principle of reasonable return to correct the imbalance revealed between production costs and the value of premiums.

Moreover, since the approval of RDL 6/2009, there had been a set of supervening circumstances such as the drop in the electricity demand because of the Spanish recession, the reduction of market prices due to the fragile international economic situation or the increase in the electricity production from RES due to favorable weather conditions, with a direct impact on the electricity system tariff deficit. That contextual situation did not have symmetrical effects in all the electricity sectors. Although the ordinary regime (conventional power plants) saw their operating hours and revenues reduced because of the fall in prices on the wholesale market, the SR generators were awarded under its specific regime that ensured selling the electricity produced through its preferential entry into the system.

Accordingly, five prominent regulations for the SR power plants and, specifically, for the solar power sector, were enacted by the Spanish government in 2010, i.e., RD 1003/2010 [81], RD 1565/2010 [82], RD 1614/2010 [83], RDL 14/2010 [84] and Law 2/2011 [85].

However, the measures adopted until then were not sufficient, putting at risk the final goal of suppressing the tariff deficit as of 2013 set by RDL 6/2009. The tariff deficit constituted a barrier for the adequate development of the electricity sector as a whole and in particular for the continuation of the policies to promote electricity production from RES. Thus, the complex economic and financial situation made it necessary to approve new containment measures in 2012, namely RDL 1/2012 [86], Law 15/2012 [87] and RDL 29/2012 [88].

Tables 5 and 6 provide a comprehensive summary of the main features of the different regulatory frameworks and economic regimes, respectively, in force for the Spanish solar power plants in the period 2008-2013. In turn, Table 7 shows the reference equivalent operating hours for CSP technology facilities established by RD 1614/2010, while Tables 8 and 9 display the reference equivalent operating hours for PV facilities established by RDL 14/2010 and the specific reference equivalent operating hours for PV plants under RD 661/2007 until 31 December 2013, respectively. The reference equivalent operating hours for the PV plants were classified according to the solar climatic zone where the PV facilities were located as well as by technology, whereas the equivalent operating hours for the facilities under RD 661/2007 until 31 December 2013 were classified only by technology. 
Table 5. Major characteristics of the different regulatory frameworks in force for solar power systems in Spain in the period 2008-2013. Source: self-elaboration based on [78,79,81-88].

Legislation

Main Characteristics

RD 1578/2008 of September 2008 [78]

Subject

RES goals

SR group for solar technology
Setting the new economic framework for PV plants which obtained their definitive registration in the administrative register of the SR production facilities after 29 September 2008

Amendment of RD 661/2007 for PV facilities in subgroup b.1.1 which obtained their definitive registration in the administrative register of the SR production facilities after 29 September 2008

Type I for roof-mounted or façade-mounted PV facilities, which in turn are subdivided into (a) subtype I.1 for those up to $20 \mathrm{~kW}$ of rated power and (b) subtype I.2 for those beyond $20 \mathrm{~kW}$ of rated power, and type II for ground-mounted PV plants and not included in type I
Economic regime
The new regulated tariff for the first call set by RD 1578/2008 for subtype I.1 PV plants under this remuneration option was set to $34.00 \mathrm{cEUR} / \mathrm{kWh}$, while for subtype I.2 and type II PV facilities it was set to $32.00 \mathrm{cEUR} / \mathrm{kWh}$. The regulated tariff for subtype I.1 facilities could never be less than that for subtype I.2 PV plants

$>\quad$ The values of the regulated tariff corresponding to the facilities enrolled in the RPAR associated with subsequent calls would be calculated based on the values of the previous call. If during two successive calls, $50 \%$ of the power quota for a type or subtype was not reached, the tariff for the next call could be increased by the same proportion that would be cut if the quota were covered

- For each call for registration in the RPAR, power quotas were established, consisting of base powers, and where appropriate, additional powers transferred, for each type of PV plant. For the first-year calls, the base powers were $66.75 \mathrm{MW}$ for type I PV facilities (10\% for subtype I.1 and $90 \%$ for subtype I.2) and 33.25 MW for type II PV plants

$>\quad$ The power quotas corresponding to the second and subsequent year calls would be calculated taking as a reference the base powers of the calls corresponding to the previous year, increasing or reducing them by the same cumulative percentage rate that reduced or increased, respectively, the remuneration corresponding to the calls held during the previous year. The mechanism for the transfer of additional power to the base power for the next call was established when some or all the power quotas of a call were not covered

$>\quad$ For type II facilities, extraordinary additional power quotas of $25 \mathrm{MW}$ for 2009 and 15 MW for 2010 were established per call

$>$ The rationalization of remuneration was considered necessary and, therefore, the new framework for PV plants modified the economic regime downwards, following the expected technology evolution, with a long-sighted prospect. Just as an insufficient remuneration would make investments unfeasible, a disproportionate remuneration could have a considerable impact on the costs of the electricity system

> The regulated tariff applicable to a PV facility would be kept for a maximum of 25 years from the commissioning date or the registration of the facility in the RPAR 
Table 5. Cont.

\begin{tabular}{ll}
\hline \multicolumn{1}{c}{ Legislation } & \multicolumn{1}{c}{ Main Characteristics } \\
\hline Economic regime & $\begin{array}{l}\text { The new FIT established by RD 1578/2008 would be updated annually } \\
\text { taking as a reference the rise in the CPI minus 25 BP until 31 December 2012, } \\
\text { and 50 BP thereafter, as of 1st January of the second year after the call in } \\
\text { which they were set. However, RD 1578/2008 contemplated the modification } \\
\text { of the remuneration of the activity of production of electrical energy through } \\
\text { solar PV technology in 2012, given the technological evolution of the sector } \\
\text { and the market as well as the performance of the remuneration regime } \\
\text { See Table } 6 \text { for a detailed summary of RD 1578/2008 economic scheme for } \\
\text { the solar PV facilities }\end{array}$ \\
\hline
\end{tabular}

$>$ To be entitled to the remuneration defined in RD 1578/2008, it was necessary to register, in advance, the facility projects in the RPAR. There were four annual calls to be able to register in this RPAR, while the maximum power of the PV facilities enrolled in the RPAR could not exceed $2 \mathrm{MW}$ for type I facilities and $10 \mathrm{MW}$ for type II plants

Administrative features

$>$ RD 1578/2008 also requested guarantees to process the access both to the distribution grid as well as to the transmission grid. These guarantees were of $50 \mathrm{EUR} / \mathrm{kW}$ for subtype I.1 PV plants and of $500 \mathrm{EUR} / \mathrm{kW}$ for subtype I.2 and type II PV facilities. The guarantee would be canceled when the petitioner obtained the corresponding commissioning certificate for the power plant

$>$ A new definition of power capacity was set to streamline the implementation of large plants on land belonging to a multiplicity of owners, in such a way as to avoid the division of a single facility into several smaller ones to obtain

Other issues a more favorable remuneration framework

$>$ It proposed a new mechanism for setting the annual power target that would evolve upwards in a coordinated manner with technological improvements, instead of using the total cumulative power

\begin{tabular}{|c|c|}
\hline RDL 6/2009 of May 2009 [79] & \\
\hline Subject & Control of the implementation of new power plants under the SR \\
\hline Previous regulations repealed or modified & - \\
\hline RES goals & - \\
\hline SR group for solar technology & b.1.2 for CSP facilities (PV plants in subgroup b.1.1 not affected) \\
\hline Economic regime & $\begin{array}{l}\text { In the case that the SR projects enrolled did not cover the power objective, } \\
\text { RD } 661 / 2007 \text { economic framework would be kept until the goal was reached. } \\
\text { However, if the power goal was exceeded, RD } 661 / 2007 \text { remuneration would } \\
\text { be applied to all the enrolled projects, but would not be extended beyond } \\
\text { A new regulatory and economic framework would be enacted for the power } \\
\text { plants enrolled in the administrative RPAR once RD } 661 / 2007 \text { remuneration } \\
\text { regime in force had been exhausted }\end{array}$ \\
\hline Administrative features & $\begin{array}{l}\text { Under RDL } 6 / 2009 \text {, the registration in the RPAR had to be a necessary } \\
\text { prerequisite for the granting of the right to the economic regime established } \\
\text { in RD 661/2007. The facilities would be registered chronologically in the } \\
\text { administrative RPAR until the power objective foreseen in each group and } \\
\text { subgroup was met } \\
\text { To get the enrolment in the RPAR a series of requirements should be fulfilled: } \\
\text { an access point to the electrical network for all the installed power, the } \\
\text { administrative authorization of the power plant, the construction permit, } \\
\text { sufficient financial resources to assume at least } 50 \% \text { of the project investment, } \\
\text { a purchase agreement for a minimum of } 50 \% \text { of the equipment value and a } \\
\text { new guarantee of } 100 \text { EUR } / \mathrm{kW} \text { for the CSP case }\end{array}$ \\
\hline
\end{tabular}


Table 5. Cont.

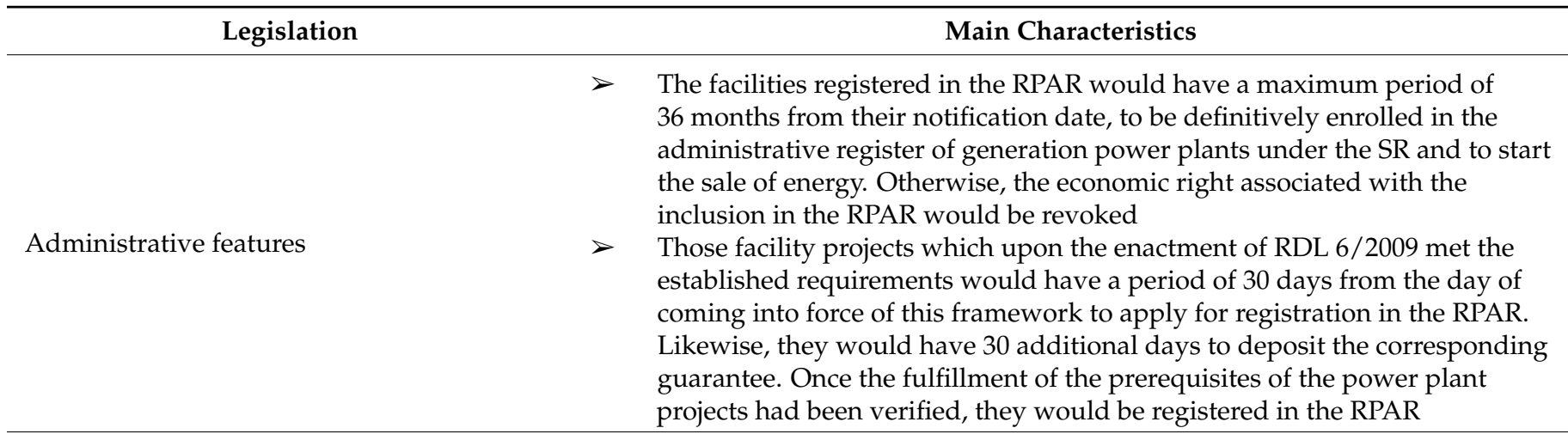

RD 1003/2010 of August 2010 [81]

Subject

Setting the procedure to improve the accreditation process of the different PV plants under RD 661/2007 and RD 1578/2008 remuneration frameworks, thus taking a further step in improving the efficiency of the remuneration framework corresponding to each PV facility based on its specific characteristics

\begin{tabular}{ll} 
Previous regulations repealed or modified & Amendment of RD 661/2007 and RD 1578/2008 \\
\hline RES goals & - \\
\hline SR group for solar technology & - \\
\hline Economic regime & - \\
\hline
\end{tabular}

All those PV plants under RD 661/2007 economic regime could make the request to renounce this remuneration scheme within a maximum period of 2 months from the enactment of RD 1003/2010. Thus, losing the right to perceive the regulated tariff or the premium set by RD 661/2007. However, it would entail the automatic inclusion of the PV facility in the conditions of

Administrative features the economic regime of the first call corresponding to the facilities registered in the RPAR regulated by RD 1578/2008

$>$ For the proper monitoring of the SR facilities without the right to a regulated tariff or premium, the registry of the SR without premium remuneration was established. The facilities registered in the register of SR without premium remuneration could participate in the administrative procedure for the pre-allocation of remuneration regulated in RD 1578/2008

RD 1565/2010 of November 2010 [82]

\begin{tabular}{ll}
\hline Subject & $\begin{array}{l}\text { Regulation and modification of certain issues related to the power generation } \\
\text { activity under the SR }\end{array}$ \\
\hline Previous regulations repealed or modified & Amendment of RD 661/2007 and RD 1578/2008 \\
\hline RES goals & -
\end{tabular}

It modified the classification set by RD 1578/2008 for solar PV facilities. It specified that there should be a contracted power supply point inside the PV

SR group for solar technology facility for at least $25 \%$ of its nominal power to be included in type I. Furthermore, PV plants located on greenhouse structures and on roofs of irrigation ponds were expressly excluded from this type I

$>$ It suppressed the values of the regulated tariffs set for SR facilities in subgroup b.1.1 under RD 661/2007 as of the twenty-sixth year

> It also carried out a remarkable shrinkage of the regulated PV tariff for the

Economic regime first call of the RPAR as of the entry into force of RD 1565/2010. Specifically, the regulated tariffs set by RD 1578/2008 for PV plants were reduced by $5 \%$ for subtype I.1, $25 \%$ for subtype I. 2 and $45 \%$ for subtype II. The percentage of reduction of the tariff values would not be considered for the computation of the power quotas for the following year 
Table 5. Cont.

\begin{tabular}{|c|c|}
\hline Legislation & Main Characteristics \\
\hline Economic regime & $\begin{array}{l}\text { It established the option of granting an additional specific remuneration to } \\
\text { innovative CSP projects for an aggregate total of } 80 \mathrm{MW} \text { by means of a } \\
\text { tender procedure } \\
\text { See Table } 6 \text { for a detailed summary of the changes introduced by RD } \\
1565 / 2010 \text { in both RD } 661 / 2007 \text { and RD } 1578 / 2008 \text { economic schemes for the } \\
\text { solar power facilities }\end{array}$ \\
\hline Administrative features & - \\
\hline Other issues & $\begin{array}{l}\text { A power plant should be made up of new and unused main equipment to be } \\
\text { included in the SR. Moreover, the SR facilities should have the necessary } \\
\text { electrical energy measurement equipment, before injecting electricity into } \\
\text { the grid } \\
\text { It redefined the concept of substantial modifications of power plants that } \\
\text { would imply losing the entitlement to the RD } 661 / 2007 \text { remuneration }\end{array}$ \\
\hline
\end{tabular}

\section{RD 1614/2010 of December 2010 [83]}

Subject

Regulation of certain economic aspects for power plants of wind and CSP technologies, as well as resolution of some inefficiencies in the application of the previous RDL 6/2009 for those technologies

\begin{tabular}{ll}
\hline Previous regulations repealed or modified & - \\
\hline RES goals & - \\
\hline SR group for solar technology & - \\
\hline
\end{tabular}

$>$ It limited the equivalent operating hours at rated power eligible for the RD $661 / 2007$ regulated tariff or premium for wind and CSP facilities (see Table 7). If the established equivalent operating hour limits were exceeded, in annual computation, the owners of the power plants should return the amounts received in excess, as a regulated tariff or premium, within a maximum period of 3 months

$>$ It set that the CSP technology facilities under RD 661/2007 could only opt for the regulated tariff as the remuneration option for selling their electricity in

Economic regime the first 12 full months after the date of commissioning. Accordingly, the CSP plants in operation would receive the regulated tariff from 1 January 2011 and those under construction since their date of commissioning. During the 12 -month period, the percentage of electricity production from fuel could rise to $15 \%$

$>$ For CSP plants under RD 661/2007, the revisions of the tariffs, premiums and lower and upper bounds would not affect either the power plants definitively enrolled in the administrative register of generation power plants under the SR, or those registered in the RPAR under RDL 6/2009

\begin{tabular}{|c|c|c|}
\hline Administrative features & \multicolumn{2}{|l|}{-} \\
\hline \multicolumn{3}{|l|}{ RDL 14/2010 of December 2010 [84] } \\
\hline Subject & \multicolumn{2}{|r|}{ Urgently undertake the correction of the power sector tariff deficit } \\
\hline Previous regulations repealed or modified & \multicolumn{2}{|c|}{ Amendment of RD 661/2007 } \\
\hline RES goals & \multicolumn{2}{|l|}{-} \\
\hline SR group for solar technology & \multicolumn{2}{|l|}{-} \\
\hline Economic regime & & $\begin{array}{l}\text { It limited the equivalent operating hours at rated power of PV plants. Thus, } \\
\text { those solar PV technology facilities would be entitled to receive each year its } \\
\text { recognized economic regime until reaching the reference number of } \\
\text { equivalent operating hours (see Tables } 8 \text { and } 9 \text { ) } \\
\text { It forced all power generators to pay a } 0.5 \text { EUR/MWh toll for the electricity } \\
\text { fed into the distribution and transmission grids, from } \\
1 \text { January } 2011 \text { onwards }\end{array}$ \\
\hline
\end{tabular}


Table 5. Cont.

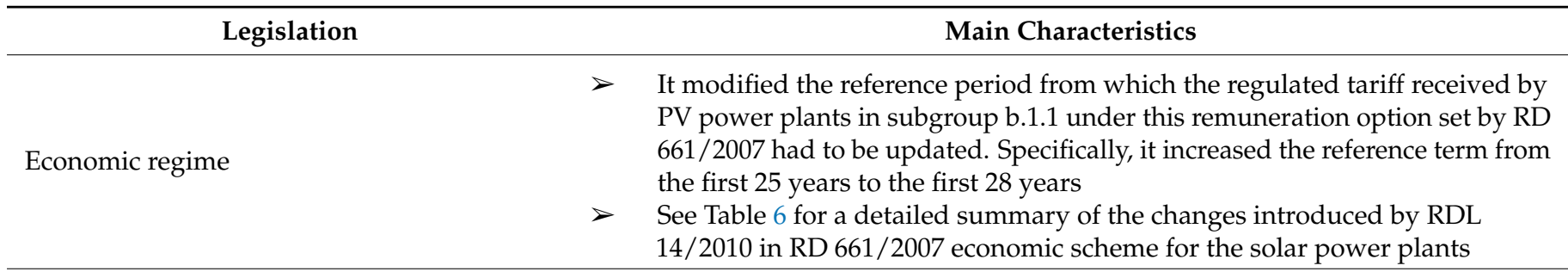

Administrative features
Law 2/2011 of March 2011 [85]

\begin{tabular}{|c|c|}
\hline Subject & $\begin{array}{l}\text { Promotion of a sustainable economic development by means of the transposition } \\
\text { into the Spanish legislation of the Directive } 2009 / 28 / \text { CE energy goals. } \\
\text { Furthermore, setting of the REP } 2011-2020 \text { elaboration }\end{array}$ \\
\hline Previous regulations repealed or modified & $\begin{array}{l}\text { Amendment of RD } 661 / 2007 \text { and RDL } 14 / 2010 \text { as for the solar PV } \\
\text { technology plants }\end{array}$ \\
\hline RES goals & Minimum 20\% share of RES in the final energy consumption by 2020 \\
\hline SR group for solar technology & - \\
\hline Economic regime & $\begin{array}{l}\text { The reference period for the application of the regulated tariff set for the } \\
\text { facilities in subgroup b.1.1 of RD } 661 / 2007 \text { under this remuneration scheme } \\
\text { was modified again, increasing from the first } 28 \text { years to the first } 30 \text { years } \\
\text { See Table } 6 \text { for a detailed summary of the changes introduced by Law } 2 / 2011 \\
\text { in RD } 661 / 2007 \text { economic scheme for the solar power plants }\end{array}$ \\
\hline
\end{tabular}

\begin{tabular}{ll}
\hline Administrative features & - \\
\hline & It specified that in the event of modifying the equivalent operating hours for the \\
PV plants by the Spanish government, those changes would only affect power & plants that were not in operation at the time of the entry into force of the \\
& corresponding new modification legislation
\end{tabular}

RDL 1/2012 of January 2012 [86]

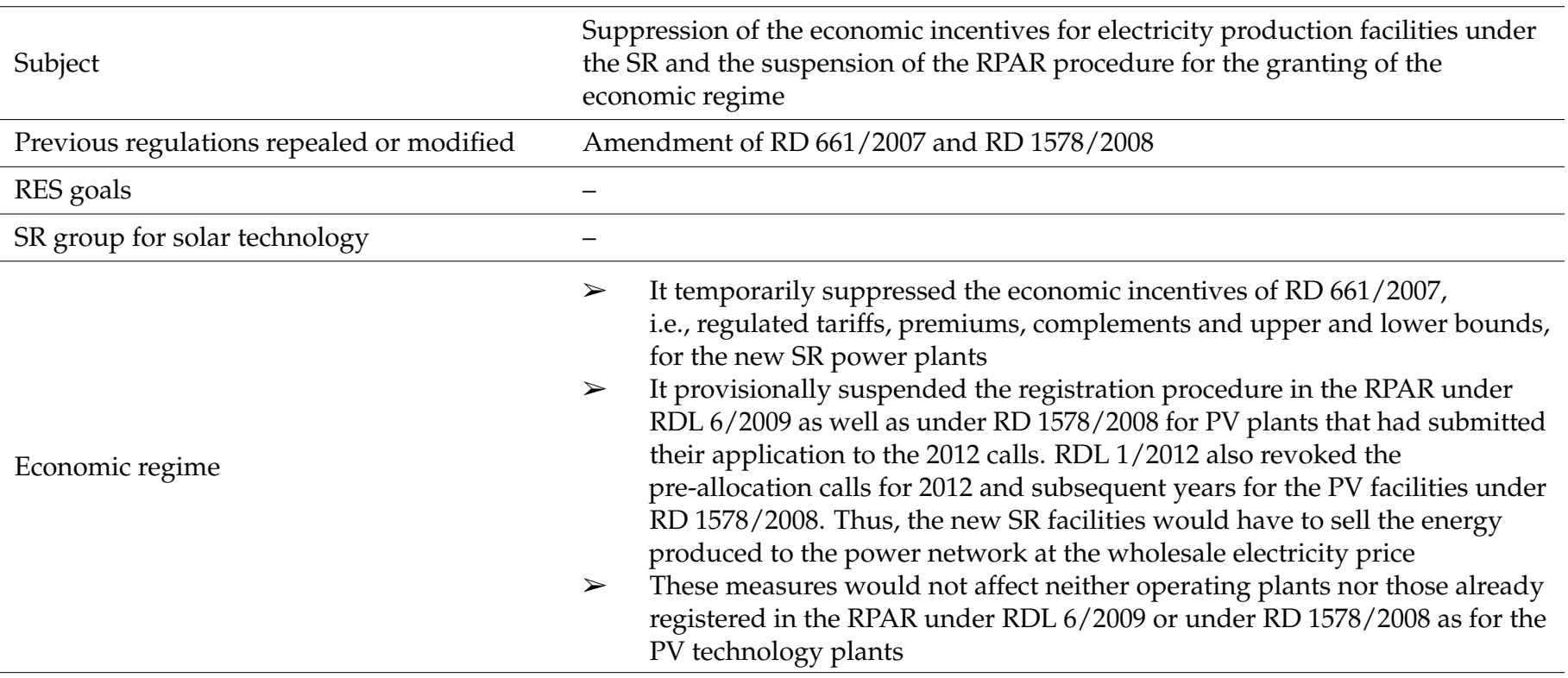

Administrative features

The SR facilities registered in the RPAR finally choosing not to carry out the power plant could renounce the registration in the RPAR without this implying the execution of the guarantees they had deposited, within a maximum period of 2 months from the enactment of RDL 1/2012, provided that the period for the final registration and sale of energy had not expired 
Table 5. Cont.

\begin{tabular}{|c|c|}
\hline Legislation & Main Characteristics \\
\hline \multicolumn{2}{|l|}{ Law 15/2012 of December 2012 [87] } \\
\hline Subject & $\begin{array}{l}\text { Harmonization of the Spanish tax system with a more efficient and respectful use } \\
\text { regarding the environment and sustainability }\end{array}$ \\
\hline Previous regulations repealed or modified & - \\
\hline RES goals & - \\
\hline SR group for solar technology & - \\
\hline Economic regime & $\begin{array}{l}\text { It added a new } 7 \% \text { tax on the gross revenues for the electricity generated, } \\
\text { measured in power plant busbars, by all electricity producers in the Spanish } \\
\text { electrical system to favor the budgetary balance of the system } \\
\text { It removed tax exemptions for the energy products used in the } \\
\text { power production } \\
\text { It eliminated the premium economic regime for electricity attributable to the } \\
\text { use of a fuel in a production power plant using any of the non-consumable } \\
\text { renewable energies as primary energy, except in the case of hybrid facilities } \\
\text { between RES non-consumables and consumables ones }\end{array}$ \\
\hline Administrative features & - \\
\hline \multicolumn{2}{|l|}{ RDL 29/2012 of December 2012 [88] } \\
\hline Subject & Implementation of some measures to reduce the electricity system tariff deficit \\
\hline Previous regulations repealed or modified & - \\
\hline RES goals & - \\
\hline SR group for solar technology & - \\
\hline Economic regime & - \\
\hline Administrative features & $\begin{array}{l}\text { It established that the premium economic regime for SR generation facilities } \\
\text { registered in the RPAR would become inapplicable if those facilities were not } \\
\text { fully completed by the expiration of the deadline set to be definitively } \\
\text { enrolled in the administrative register of generation power plants in SR } \\
\text { The power plant would be considered fully completed if it had all the } \\
\text { elements, equipment and infrastructure that were necessary to produce } \\
\text { energy and deliver it into the electrical system and whose characteristics } \\
\text { corresponded to the approved execution project }\end{array}$ \\
\hline
\end{tabular}


Table 6. Major characteristics of the different economic regimes in force for solar power systems in Spain in the period 2008-2013. Source: self-elaboration based on $[78,82,84,85]$.

\begin{tabular}{|c|c|c|c|c|c|c|c|c|}
\hline \multirow{3}{*}{ Legislation } & \multirow{3}{*}{ Technology } & \multirow{3}{*}{$\begin{array}{l}\text { SR } \\
\text { Group }\end{array}$} & \multirow{3}{*}{$\begin{array}{l}\text { Rated } \\
\text { Power and/or } \\
\text { Facility Type }\end{array}$} & \multicolumn{3}{|c|}{ Remuneration Options } & \multirow{3}{*}{ Time Limit } & \multirow{3}{*}{ Review and Update } \\
\hline & & & & FIT & & & & \\
\hline & & & & $\begin{array}{c}\text { Regulated } \\
\text { Tariff [cEUR/kWh] }\end{array}$ & $\begin{array}{c}\text { Premium } \\
\text { [cEUR/kWh] }\end{array}$ & $\begin{array}{c}\text { Incentive } \\
\text { [cEUR/kWh] }\end{array}$ & & \\
\hline \multirow{3}{*}{$\begin{array}{l}\text { RD 1578/2008 } \\
\text { modified by: } \\
\text {-RD 1565/2010 }\end{array}$} & \multirow{3}{*}{ Solar PV } & \multirow{3}{*}{ b.1.1 } & $\begin{array}{l}\text { Subtype I.1 } \\
P<2 \text { MW }\end{array}$ & $\begin{array}{c}34.0000 \\
\text { (first call under RD } \\
1578 / 2008) / 0.95^{*} \mathrm{FIT} \text { first } \\
\text { call (RD } 1565 / 2010) \\
\end{array}$ & - & - & 25 years maximum & \multirow{3}{*}{$\begin{array}{ll}\text { - } & \text { Annual update according } \\
& \text { to CPI } \\
\text { - } & \text { FIT of subsequent calls } \\
& \text { calculated by means of RD } \\
& 1578 / 2008 \text { equations } \\
\text { - } & \text { Review in } 2012\end{array}$} \\
\hline & & & $\begin{array}{l}\text { Subtype I.2 } \\
P<2 \text { MW }\end{array}$ & $\begin{array}{c}32.0000 \\
\text { (first call under RD } \\
1578 / 2008) / 0.75^{*} \mathrm{FIT} \text { first } \\
\text { call (RD 1565/2010) }\end{array}$ & - & - & 25 years maximum & \\
\hline & & & $\begin{array}{c}\text { Type II } \\
P<10 \text { MW }\end{array}$ & $\begin{array}{c}32.0000 \\
\text { (first call under RD } \\
1578 / 2008) / 0.55^{*} \mathrm{FIT} \text { first } \\
\text { call (RD } 1565 / 2010)\end{array}$ & - & - & 25 years maximum & \\
\hline \multirow{8}{*}{$\begin{array}{l}\text { RD 661/2007 } \\
\text { modified by: } \\
\text {-RD 1565/2010 } \\
\text {-RDL 14/2010 } \\
\text {-Law 2/2011 }\end{array}$} & \multirow{6}{*}{ Solar PV } & \multirow{6}{*}{ b.1.1 } & $P \leq 100 \mathrm{~kW}$ & 44.0381 & - & - & $\begin{array}{c}\text { First } 28 \text { years (RDL } \\
\text { 14/2010)/First } 30 \text { years } \\
\text { (Law } 2 / 2011 \text { ) }\end{array}$ & \multirow{6}{*}{$\begin{array}{l}\text { For both FIT and FIP options: } \\
\text { - } \\
\text { Annual update according } \\
\text { - } \quad \text { to CPI } \\
\text { Review in } 2010 \text { and } \\
\text { thereafter every } 4 \text { years or } \\
\text { not less than } 1 \text { year after } \\
\text { reaching } 85 \% \text { of } 371 \mathrm{MW}\end{array}$} \\
\hline & & & & $\begin{array}{c}0 \\
\text { (RD 1565/2010) }\end{array}$ & - & - & Thereafter & \\
\hline & & & $100 \mathrm{~kW}<P \leq 10 \mathrm{MW}$ & 41.7500 & - & - & $\begin{array}{c}\text { First } 28 \text { years (RDL } \\
\text { 14/2010)/First } 30 \text { years } \\
\text { (Law } 2 / 2011)\end{array}$ & \\
\hline & & & & $\begin{array}{c}0 \\
\text { (RD 1565/2010) } \\
\end{array}$ & - & - & Thereafter & \\
\hline & & & \multirow[t]{2}{*}{$10 \mathrm{MW}<P \leq 50 \mathrm{MW}$} & 22.9764 & - & - & $\begin{array}{l}\text { First } 28 \text { years (RDL } \\
\text { 14/2010)/First } 30 \text { years } \\
\text { (Law } 2 / 2011 \text { ) }\end{array}$ & \\
\hline & & & & $\begin{array}{c}0 \\
\text { (RD 1565/2010) }\end{array}$ & - & - & Thereafter & \\
\hline & \multirow[t]{2}{*}{ Solar CSP } & \multirow[t]{2}{*}{ b.1.2 } & \multirow[t]{2}{*}{ Any } & 26.9375 & 25.4000 & - & First 25 years & \multirow[t]{2}{*}{$\begin{array}{l}\text { For both FIT and FIP options: } \\
\text { - } \quad \text { Annual update according } \\
\text { to CPI } \\
\text { - Review in } 2010 \text { and } \\
\text { thereafter every } 4 \text { years or } \\
\text { not less than } 1 \text { year after } \\
\text { reaching } 85 \% \text { of } 500 \mathrm{MW}\end{array}$} \\
\hline & & & & 21.5498 & 20.3200 & - & Thereafter & \\
\hline
\end{tabular}

${ }^{1}$ This table only shows the values of the FIP components fully established in a regulatory manner, i.e., the premiums and the incentives. Thus, the electricity market price and the reactive energy complement must be added to these economic parameters to obtain the total FIP of the facility. 
Table 7. Reference equivalent operating hours for CSP power plants set by RD 1614/2010. Source: self-elaboration based on [83].

\begin{tabular}{cc}
\hline CSP Technology & Reference Equivalent Operating Hours per Year \\
\hline Stirling & 2350 \\
Fresnel & 2450 \\
Saturated steam tower & 2750 \\
Parabolic trough without storage & 2855 \\
Parabolic trough with 4 h storage & 3450 \\
Parabolic trough with 7 h storage & 3950 \\
Parabolic trough with 9 h storage & 4000 \\
Salt tower with 15 h storage & 6450 \\
\hline
\end{tabular}

Table 8. Reference equivalent operating hours for PV power plants set by RDL 14/2010. Source: self-elaboration based on [84].

\begin{tabular}{cccccc}
\hline \multirow{2}{*}{ Solar PV Technology } & \multicolumn{5}{c}{ Reference Equivalent Operating Hours per Year } \\
\cline { 2 - 6 } & Zone I & Zone II & Zone III & Zone IV & Zone V \\
\hline $\begin{array}{c}\text { One-axis solar } \\
\text { tracking facility }\end{array}$ & 1602 & 1770 & 1940 & 2122 & 2279 \\
Two-axis solar & 1664 & 1838 & 2015 & 2204 & 2367 \\
tracking facility & 1232 & 1362 & 1492 & 1632 & 1753 \\
Fixed facility & & &
\end{tabular}

Table 9. Reference equivalent operating hours for PV power plants under RD 661/2007 until 31 December 2013 set by RDL 14/2010. Source: self-elaboration based on [84].

\begin{tabular}{cc}
\hline Solar PV Technology & Reference Equivalent Operating Hours per Year \\
\hline One-axis solar tracking facility & 1644 \\
Two-axis solar tracking facility & 1707 \\
Fixed facility & 1250 \\
\hline
\end{tabular}

\subsection{The 2013-2020 Subperiod: A New Paradigm for the Spanish Solar Power Sector}

From 1998 to 2013, economic incentives for power generation power plants using RES, cogeneration and waste had amounted to more than 50,000 M EUR, increasing by more than $800 \%$ from 2005 to 2013 , when premiums for these facilities reached approximately 9000 M EUR.

Premiums for renewable, cogeneration and waste technologies had been mainly financed by electricity consumers through their bills. In addition, and as of 1 January 2013, part of those RES public support costs was financed by the Spanish General State Budgets, with the income derived from the levies included in Law 15/2012.

Following with the cost-containment measures approved until 2012, RDL 2/2013 [89] was enacted in February 2013 to continue mitigating the electricity system deficit. Subsequently, it was approved RDL 9/2013 [90] in July 2013, which introduced the specific principles on which a new regulatory and economic regime for the SR power plants would be based. Thus, laying the foundations of the new paradigm for the Spanish RES power sector, and specifically for the solar power sector, which unlike the cost-containment measures approved until then, dismantled the previous regulatory and economic framework.

As a result of the failure of the numerous legal measures enacted in recent years to remove the tariff deficit, The new SES Law 24/2013 of December 2013 [56] established as two of its major objectives the recovery of the long-lost economic and financial stability of the power sector and the suppression of the undesirable regulatory dispersion existing in such a relevant economic sector. Then, the new legislation for the generation power plants from RES was governed by RD 413/2014 of June 2014 [57], which implemented the fundamentals already included in RDL 9/2013 and incorporated in Law 24/2013. 
During the 2015-2017 period, given the need to comply with the binding objectives established in the Directive 2009/28/CE on the promotion of the use of energy from RES by 2020, it was necessary to boost the penetration of new renewable capacity in the Spanish electrical system. Thus, three RES auctions under RD 413/2014 framework were called in Spain.

The assignment of the specific remuneration regime and the standard value of the initial investment would be determined through a competitive tendering to introduce the most cost-efficient RES projects into the Spanish electricity system. It was a mechanism providing an incentive to the investment on the capital expenditures of the project (EUR/MW) so that it always achieved the reasonable profitability (Russia was the unique country to provide investment-based support as in Spain [32]). Thus, the products to be auctioned would be the installed power with the right to receive the specific remuneration regime, obtaining as a result of the auction a percentage of reduction of the standard value of the initial investment of the standard facility that they were willing to waive for installing the power plant. The projects offering higher discounts with respect to the standard values of the facilities, and therefore causing a lower cost overrun in the system, were awarded until the maximum established power quota was reached.

The first RES auction was held on 14 January 2016 and according to RD 947/2015 [91] and the Order IET/2212/2015 [92] of October 2015, the call was only set for the allocation of the specific remuneration regime under RD 413/2014 to new facilities for the electricity generation from biomass in the peninsular power system (200 MW awarded) and from wind technology (500 MW awarded). The allocation of the specific remuneration regime was carried out through a technology-specific auction procedure geographically neutral.

In April 2017, RD 359/2017 [93] and the Order ETU/315/2017 [94] approved a second technology-neutral call for the concession of the specific remuneration regime under RD 413/2014 up to a maximum of $3000 \mathrm{MW}$ of installed power for new electricity production facilities from wind, PV and non-PV and wind technologies of group $\mathrm{b}$ located in the peninsular electricity system (geographically neutral). The allocation of the specific remuneration regime was determined by a static auction method with a uniform pricing rule. The Resolutions of 10 April 2017 of the State Secretariat for Energy $[95,96]$ established the procedure and rules of the auction according to RD 359/2017 and Order ETU/315/2017, and called the auction for 17 May 2017.

That second RES auction established the following minimum and maximum values of the offered percentage of reduction of the standard value of the initial investment of the reference type facility, respectively: $0 \%$ and $63.43 \%$ for wind, $0 \%$ and $51.22 \%$ for solar PV, and $0 \%$ and $99.99 \%$ for the rest of technologies of group b [95]. Meanwhile, the amount of the economic guarantee requested as a prerequisite for participation in the auction would be of $60 \mathrm{EUR} / \mathrm{kW}$ (gradually recovered) [93,94].

The second auction carried out on 17 May 2017 resulted in the allocation of $3000 \mathrm{MW}$ of renewable power plants at no cost to the consumers at least during the first regulatory period, as the successful bidders offered the maximum possible discount for the standard value of the initial investment. Specifically, 2979.664 MW were awarded to wind plants, only 1.037 MW for solar PV technology and 19.299 MW for the rest of group b technologies, mainly biomass [97]. Only $16 \mathrm{~kW}$ of wind technology and $21 \mathrm{~kW}$ of solar PV of the total of $3000 \mathrm{MW}$ awarded were not finally enrolled in the registry of the specific remuneration regime in a pre-allocation state [98]. The cost attributable to the organization of the auction would be borne by those participants who were awarded in the auction through a rate of $0.08 \mathrm{EUR} / \mathrm{kW}$ [95].

In June 2017, RD 650/2017 [99] and the Order ETU/615/2017 [100] approved a new technology-neutral call for the concession of the specific remuneration regime under RD $413 / 2014$ up to a maximum of $3000 \mathrm{MW}$ of installed power for new electricity production facilities from wind and solar PV technologies located in the peninsular electricity system (geographically neutral). The granting of the specific remuneration regime was determined by a static auction method with a uniform pricing rule. 
That third RES auction established the following minimum and maximum values of the offered percentage of reduction of the standard value of the initial investment of the reference type facility, respectively: $0 \%$ and $87.08 \%$ for wind, and $0 \%$ and $69.88 \%$ for solar PV [101]. Furthermore, that call included the possibility of increasing the power quota with the power of all those bids with the same extra cost as the last bid awarded, provided that the extra cost for the system was null and less than the value set in the confidential clause of the resolution calling for the auction [99].

The remuneration parameters of the standard facilities applicable to this new call, the mechanisms for assigning the specific remuneration regime, as well as the other aspects established for the proper holding of the auction would be those set in the previous Order ETU/315/2017. Likewise, the procedure and rules of the auction would be those established in the previous Resolution of the State Secretariat for Energy of 10 April 2017 [100]. In turn, the Resolution of 30 June 2017 of the State Secretariat for Energy [101] called the auction for 26 July 2017 under the provisions of RD 650/2017.

The third auction carried out on 26 July 2017 resulted in the allocation of $5036.921 \mathrm{MW}$ of renewable power plants at no cost to the consumers at least during the first regulatory period, as the successful bidders offered the maximum possible discount for the standard value of the initial investment. Specifically, 1127.818 MW were awarded to wind technology and 3909.103 MW for solar PV technology [102]. All the awarded power was finally enrolled in the registry of the specific remuneration regime in a pre-allocation state [103]. The cost attributable to the organization of the auction would be borne by those participants who were awarded in the auction through a rate of $0.08 \mathrm{EUR} / \mathrm{kW}$ [101].

Already in November 2019, RDL 17/2019 [104] adopted urgent measures for the necessary adjustment of the remuneration parameters affecting the electricity system. As regards production facilities from RES, cogeneration and waste that were entitled for a premium remuneration upon the enactment of RDL 9/2013, various arbitration procedures were pending resolution accumulating large claims for the damages allegedly caused by the retroactively cuts in RES subsidies based on an alleged breach of the Energy Charter Treaty.

Tables 10 and 11 provide a comprehensive summary of the main features of the different regulatory frameworks and economic regimes, respectively, in force for the Spanish solar power plants in the period 2013-2020.

Table 10. Major characteristics of the different regulatory frameworks in force for solar power systems in Spain in the period 2013-2020. Source: self-elaboration based on $[56,57,89,90,104]$.

\begin{tabular}{|c|c|}
\hline Legislation & Main Characteristics \\
\hline \multicolumn{2}{|l|}{ RDL 2/2013 of February 2013 [89] } \\
\hline Subject & $\begin{array}{l}\text { Adoption of urgent cost reduction measures to continue mitigating the electricity } \\
\text { system deficit }\end{array}$ \\
\hline Previous regulations repealed or modified & Amendment of RD 661/2007 \\
\hline RES goals & - \\
\hline SR group for solar technology & - \\
\hline Economic regime & $\begin{array}{l}\text { It established that all those methodologies for updating remuneration linked } \\
\text { to the CPI should replace it with the CPI at constant taxes without } \\
\text { unprocessed food and energy products since } 1 \text { January } 2013 \text {, to use a more } \\
\text { stable index not affected by the volatility of the prices of unprocessed foods } \\
\text { or fuels for domestic use } \\
\text { Bearing in mind the volatility of the electricity pool price, the premium on } \\
\text { top of the electricity market price was set to } 0 \text { cEUR/kWh and its upper and } \\
\text { lower bounds were removed for all the SR facilities under RD } 661 / 2007 \text {. } \\
\text { Thus, guaranteeing a reasonable profitability for these facilities and avoiding } \\
\text { an over-remuneration at the same time }\end{array}$ \\
\hline
\end{tabular}


Table 10. Cont.

\begin{tabular}{|c|c|c|}
\hline Legislation & & Main Characteristics \\
\hline Economic regime & $>$ & $\begin{array}{l}\text { It set that the premium economic regime should be based solely on the } \\
\text { regulated tariff option, without prejudice to the fact that the SR facilities } \\
\text { could freely sell their energy in the pool without perceiving a premium }\end{array}$ \\
\hline Administrative features & - & \\
\hline \multicolumn{3}{|l|}{ RDL 9/2013 of July 2013 [90] } \\
\hline Subject & \multicolumn{2}{|r|}{ To ensure the financial stability of the power sector in Spain } \\
\hline Previous regulations repealed or modified & $>$ & $\begin{array}{l}\text { Derogation of RD 661/2007, RD 1578/2008 and the RPAR mechanism for SR } \\
\text { facilities of RDL 6/2009 } \\
\text { Amendment of the SES Law 54/1997 to introduce the standards on which a } \\
\text { new regulatory and economic regime for the SR power plants would } \\
\text { be based }\end{array}$ \\
\hline RES goals & - & \\
\hline SR group for solar technology & - & \\
\hline Economic regime & $\begin{array}{l}> \\
> \\
>\end{array}$ & $\begin{array}{l}\text { The previous remuneration options, namely the regulated tariff and the } \\
\text { premium on top of the electricity market price, were superseded by the } \\
\text { electricity market price plus an additional specific remuneration for } \\
\text { offsetting the investment and operating costs that could not be regained with } \\
\text { the revenues from the sale of energy in the market } \\
\text { The specific remuneration would change in accordance with the typology of } \\
\text { the SR power plants and would be such that an "efficient and well-managed" } \\
\text { plant could acquire a reasonable return of investment along its regulatory } \\
\text { useful life allowing it to cover costs and compete on an equal basis with all } \\
\text { other technologies on the electricity pool } \\
\text { For the specific remuneration computation, the standard income from the } \\
\text { sale of electricity in the pool, the standard operating costs and the standard } \\
\text { value of the initial investment for an "efficient and well-managed" facility } \\
\text { would be considered throughout its useful life } \\
\text { Only the costs and investments established by provisions enforceable to the } \\
\text { entire Spanish territory and those responding solely to the electricity } \\
\text { generation activity would be considered for the computation of the } \\
\text { specific remuneration } \\
\text { The reasonable return was defined, before taxes, at the average yield during } \\
\text { determined period of the } 10 \text {-year Spanish bonds in the secondary market } \\
\text { plus an appropriate differential } \\
\text { The specific remuneration parameters could be reviewed every } 6 \text { years } \\
\text { For the particular issue of those SR power plants eligible for a premium } \\
\text { economic regime before RDL } 9 / 2013 \text { effective date, the average yield of the } \\
10 \text {-year Spanish bonds would be computed over the last } 10 \text { years and a } \\
\text { differential of } 300 \text { BP would be added (amounting to } 7.398 \% \text { ) } \\
\text { Although the future regulatory and economic framework was deployed, the } \\
\text { remuneration of these SR power plants would be temporarily paid as } \\
\text { defined in RD } 661 / 2007 \text { and RD } 1578 / 2008 \text {, but it would be recalculated } \\
\text { afterwards in accordance with the new legislation. As an exception, the } \\
\text { innovative CSP projects awarded under RD } 1565 / 2010 \text { maintained its } \\
\text { specific remuneration regime }\end{array}$ \\
\hline
\end{tabular}


Table 10. Cont.

Legislation

Administrative features
Law 24/2013 of December 2013 [56]

Subject

Previous regulations repealed or modified

RES goals -

SR group for solar technology

Economic regime

$-$

\section{Main Characteristics}

To qualify for the new economic regime for the SR facilities, the enrolment in the specific remuneration regime register managed by the Spanish government became mandatory. Those SR facilities not enrolled in that registry would receive, exclusively, the market price

An "efficient and well-managed" facility was understood as a plant with the necessary resources to conduct its activity, with the same costs as for an efficient facility in the same activity and considering the corresponding income and a reasonable benefit for the performance of its functions

Setting of the power sector regulation so as to ensure the supply of electricity and to adjust it to the consumers' needs in terms of efficiency, security, transparency, objectivity and at the lowest cost

$>$ Repeal almost entirely the SES Law 54/1997, while partially repealed RDL $14 / 2010$ and RDL 2/2013

Amendment of Law 15/2012

The standards of RDL 9/2013 for the remuneration of the generation power plants from RES were integrated, even though new items to adjusting the remuneration to the cyclic situation of the economy and to the power sector needs were added

- The new RES generation power plants would qualify for a specific remuneration only on certain exceptional basis set by the Spanish government, namely when there was an obligation to comply with energy objectives derived from EU rules or when their introduction implied a decrease in energy costs and external energy dependency

$>$ The specific remuneration would be granted by a competitive procedure

$>$ The conditions, technologies or group of specific facilities that could participate in the competitive competition mechanism would be established by RD

$>\quad$ The average yield of the 10-year Spanish bonds for the first regulatory period of the new power plants would be computed over the three months prior to the enactment of RDL 9/2013 and a differential of 300 BP would be added

$>\quad$ The remuneration parameters would be reviewed at the beginning of the 6-year regulatory periods, except the regulatory useful life and the standard value of the initial investment. In turn, some of these regulatory parameters could also be adjusted at the 3-year half-periods

$>$ For the production activities from RES, cogeneration and waste in the specific remuneration regime, the first regulatory period began on RDL 9/2013 effective date and ended on 31 December 2019, while the first regulatory half-period began on RDL 9/2013 enactment date and ended on 31 December 2016

$>$ The remunerations received by the existing SR power plants before the enactment of RDL 9/2013 would not prompt any complaint even if the reasonable return set in the new economic legislation for their regulatory useful life was overstepped 
Table 10. Cont.

\begin{tabular}{|c|c|}
\hline Legislation & Main Characteristics \\
\hline Administrative features & - \\
\hline Other issues & $\begin{array}{l}\text { It removed the SR concept and referred instead to generation power plants } \\
\text { with specific remuneration } \\
\text { It regulated the provisional closure of generation power plants } \\
\text { It set regulatory periods of } 6 \text { years and regulatory half-periods of } 3 \text { years } \\
\text { It established the priority criteria for access and dispatch of electricity from } \\
\text { RES facilities, while the share of electricity produced from fuels would not } \\
\text { receive the specific remuneration, but only the market price }\end{array}$ \\
\hline
\end{tabular}

RD 413/2014 of June 2014 [57]

Subject

Development of the fundamentals already included in RDL 9/2013 and incorporated in Law 24/2013

Previous regulations repealed or modified

SR group for solar technology
It suppressed the RPAR under RD 1578/2008 and under RDL 6/2009, the RPAR for SR experimental facilities under RD 1565/2010, as well as the registry of the SR without premium remuneration under RD 1003/2010 $>\quad$ It repealed RD 1565/2010 and RD 1614/2010

$-$

The generation power plants using solar energy as primary energy continued to belong to group b.1 (PV plants in subgroup b.1.1 and CSP facilities in subgroup b.1.2)

$>$ Generation facilities would be obliged to make financial offers to the electricity market operator for each programming period either directly or through an agent

$>\quad$ Once the RES facilities exceeded its regulatory useful life under RD 413/2014 economic regime, they would no longer receive the specific remuneration, i.e., the remuneration for the investment and the remuneration for the operation. However, these facilities could remain in operation, perceiving exclusively the remuneration obtained from the sale of electricity in the pool. In turn, RES facilities that, even within their regulatory useful life, would have reached a reasonable profitability level, would have a return on investment equal to zero and would keep the return on operation during their regulatory lifetime

$>$ The annual income perceived from the specific remuneration regime under RD 413/2014 by a facility whose number of equivalent operating hours in a given year did not exceed the minimum number of equivalent operating hours of the corresponding standard facility, would be reduced and would be null if it did not exceed the operating threshold defined for that facility type

Economic regime

$>$ A classification of standard facilities would be established based on technology, installed power, year of commissioning, electrical system, as well as any other segmentation deemed necessary for the application of the remuneration regime. Each standard power plant defined was identified by a different code. In turn, the remuneration parameters for each standard facility under RD 413/2014 economic regime were set by the Spanish government through Ministerial Orders. The Order IET/1045/2014 of June 2014 [105], the Order ETU/130/2017 of February 2017 [106] and the Order TED/171/2020 of February 2020 [107], defined these remuneration parameters for the first, second and third half-periods, respectively

$>\quad$ For the PV power plants (subgroup b.1.1) under RD 413/2014, a total of 91 standard facilities ranging from IT-00001 to IT-00091 were defined. Regarding CSP technology (subgroup b.1.2), a total of 20 standard facilities ranging from IT-00601 to IT-00620 were set

> See Table 11 for a detailed summary of RD 413/2014 economic scheme for the solar facilities

$>$ For a comprehensive overview of the economic model related to the solar facilities under RD 413/2014 regulatory framework the interested reader is addressed to [46] for the solar PV technology and to [30] for the CSP technology 
Table 10. Cont.

Legislation

Administrative features

Main Characteristics

> Generation facilities under RD 413/2014 should be compulsorily registered in definitive state in the administrative register of electricity generation power plants (first section for facilities whose installed power is greater than $50 \mathrm{MW}$ and second section for facilities whose installed power is equal to or less than $50 \mathrm{MW}$ )

$>$ For the perception of the specific remuneration regime under RD 413/2014, it should be a necessary condition that the facilities were enrolled in operation state in the registry of the specific remuneration regime. For registration in the specific remuneration regime registry in a pre-allocation state, namely prior to the operation state, the facilities should deposit an economic guarantee

$>$ The installed power would correspond to the maximum active power that a production unit could reach. As for the PV plants, the installed power would be the sum of the maximum unit powers of the solar PV modules of the power plant

Other issues

$>\quad$ It would be a necessary condition for obtaining the specific remuneration regime that the facility was made up of new and unused main equipment

RDL 17/2019 of November 2019 [104]

Subject

Adoption of immediate measures for the necessary adjustment of the remuneration parameters affecting the power system

\begin{tabular}{lc}
\hline Previous regulations repealed or modified & - \\
\hline RES goals & - \\
\hline SR group for solar technology & - \\
\hline
\end{tabular}

$>$ It established at $7.09 \%$ the value of the reasonable profitability applicable from the second regulatory period onwards for the standard facilities under RD 413/2014 legal-economic framework

$>$ Exceptionally, for those generation facilities that were entitled for a premium remuneration upon the entry into force of RDL 9/2013, the value of the reasonable profitability set for the first regulatory period, i.e., $7.398 \%$, could not be reviewed during the next two consecutive regulatory periods as of 1 January 2020. Thus, guaranteeing economic certainty to these facilities with a reasonable profitability of $7.398 \%$ during the $2020-2031$ period, higher than the $7.09 \%$ established during the $2020-2025$ period, and avoiding the uncertainty of the 2026-2031 period. However, these facilities could renounce this exception before 1 April 2020, thus a reasonable profitability of $7.09 \%$ for them being applicable

$>$ The measure would not be applicable when an arbitration procedure based on the modification of the special remuneration regime operated after RD $661 / 2007$ had previously been initiated on the profitability of these facilities, including those derived from the entry into force of RDL 9/2013, and its implementing regulations. Conversely, the aforementioned facilities could benefit from the exceptional regime when it was accredited before 30 September 2020, the early termination of the arbitration procedure and the waiver of its restart or its continuation, or the waiver of the receipt of compensation that had been recognized as a consequence of such procedures

Administrative features

Other issues
New standard facilities were created for those power plants under the new reasonable profitability of $7.09 \%$, with identical technical and economic characteristics as those under the $7.398 \%$ profitability, except for the reasonable return applicable to them. The new standard facility codes to which a profitability of 7.09\% was applied for solar PV technology were comprised between IT-20001 and IT-20091, while for CSP technology they were comprised between IT-20601 and IT-20620 [107] 
Table 11. Major characteristics of the different economic regimes in force for solar power systems in Spain in the period 2013-2020. Source: self-elaboration based on [56,57,90].

\begin{tabular}{|c|c|c|c|c|c|c|}
\hline \multirow{2}{*}{ Legislation } & \multirow{2}{*}{ Technology } & \multirow{2}{*}{$\begin{array}{c}\text { SR } \\
\text { Group }\end{array}$} & \multirow{2}{*}{ Facility Type } & Remuneration Option & \multirow{2}{*}{ Time Limit } & \multirow{2}{*}{ Review and Update } \\
\hline & & & & Specific Remuneration ${ }^{1}$ & & \\
\hline \multirow{4}{*}{$\begin{array}{l}\text { RD } 413 / 2014 \\
\text { (in accordance } \\
\text { with RDL } \\
9 / 2013 \text { and } \\
\text { Law 24/2013) }\end{array}$} & & & & For the first regulatory period: & & \\
\hline & Solar PV & b.1.1 & $\begin{array}{l}91 \text { standard facilities } \\
\text { ranging from } \\
\text { IT-00001 to IT-00091 } \\
\text { based on technology, } \\
\text { installed power, year } \\
\text { of commissioning and } \\
\text { electrical system }\end{array}$ & $\begin{array}{l}\text { Reasonable return for } \\
\text { existing facilities } \\
\text { of } 7.398 \% \\
\text { Reasonable return for } \\
\text { new facilities: average } \\
\text { yield during the last } \\
3 \text { months plus a } \\
\text { differential of } 300 \mathrm{BP} \\
\end{array}$ & $\begin{array}{l}\text { Regulatory } \\
\text { lifetime } \\
\text { (30 years) }\end{array}$ & $\begin{array}{l}\text { Review every 6-year } \\
\text { regulatory period } \\
\text { and/or each 3-year } \\
\text { regulatory half-period }\end{array}$ \\
\hline & & & & For the first regulatory period: & & \\
\hline & Solar CSP & b.1.2 & $\begin{array}{l}20 \text { standard facilities } \\
\text { ranging from } \\
\text { IT-00601 to IT-00620 } \\
\text { based on technology, } \\
\text { installed power, year } \\
\text { of commissioning and } \\
\text { electrical system }\end{array}$ & $\begin{array}{l}\text { Reasonable return for } \\
\text { existing facilities } \\
\text { of } 7.398 \% \\
\text { Reasonable return for } \\
\text { new facilities: average } \\
\text { yield during the last } \\
3 \text { months plus a } \\
\text { differential of } 300 \mathrm{BP} \\
\end{array}$ & $\begin{array}{l}\text { Regulatory } \\
\text { lifetime } \\
\text { (25 years) }\end{array}$ & $\begin{array}{l}\text { Review every 6-year } \\
\text { regulatory period } \\
\text { and/or each 3-year } \\
\text { regulatory half-period }\end{array}$ \\
\hline & & $\begin{array}{l}1 \text { The } \\
24 / 20 \\
\text { ulato } \\
\text { from }\end{array}$ & $\begin{array}{l}\text { muneration option es } \\
\text { consisted of the electri } \\
\text { manner, compensating } \\
\text { e sale of electricity in th }\end{array}$ & $\begin{array}{l}\text { lished by RD } 413 / 2014 \text { frame } \\
\text { market price plus an additiona } \\
\text { the investment and operating } \\
\text { market. The specific remunerat }\end{array}$ & $\begin{array}{l}\text { in accordar } \\
\text { cific remune } \\
\text { that could no } \\
\text { was awarded }\end{array}$ & $\begin{array}{l}\text { vith RDL } 9 / 2013 \text { and } \\
\text { n, fully established in a } \\
\text { regained with the reve } \\
\text { competitive procedure }\end{array}$ \\
\hline
\end{tabular}

\section{Assessment of the 1998-2020 Energy Policy for the Solar Power Plants in Spain}

\subsection{Analysis of the 1998-2008 Promotion Stage}

\subsubsection{Concerning the Solar PV Technology Sector}

First, the 1998-2004 subperiod was characterized by a stable remuneration system for PV facilities in group b.1 under RD 2818/1998 legal-economic framework. However, the solar PV generation technology did not develop as expected in the REP 2000-2010 with a 135 MW PV capacity target to be added for 2010, owing to the relatively low support levels and the uncertainty for investors related to the support annual updating [26]. Specifically, only 22.8 MW of PV capacity was put into operation at the end of 2004.

Subsequently, the 2004-2008 subperiod was marked by a much more favorable economic framework under RD 436/2004 and RD 661/2007 for PV facilities.

RD 436/2004 increased the regulated tariff, with respect to RD $2818 / 1998$, by $4.5 \%$ for facilities up to $5 \mathrm{~kW}$ of installed power and by $91.5 \%$ for plants beyond $5 \mathrm{~kW}$ and up to $100 \mathrm{~kW}$, while eliminating the possibility of FIP for these PV assets. Although PV plants above $100 \mathrm{~kW}$ almost kept the same value for both the FIT and the premium on top of the electricity pool price, incorporating an extra incentive to the FIP remuneration option. In all cases taking into account a time limit of 25 years from which the incentives and premiums would be reduced.

In this regard, the cumulative PV capacity installed in Spain at the end of 2006 was 145.6 MW, i.e., in just 2 years under RD 436/2004 the cumulative PV capacity was multiplied by 6.4, ensuring RD 436/2004 150 MW PV capacity target.

Although the evolution of the cumulative PV capacity installed under RD 436/2004 was quite positive, it was decided to modify the economic scheme again through RD 661/2007. This new economic framework eliminated the FIP option for all PV facilities (and it consequently lowered the risk related to the PV remuneration scheme, since the PV support levels were not linked to the electricity prices [26]), and, in turn, increased the FIT by $6.3 \%$ for plants up to $100 \mathrm{~kW}$, by $93 \%$ for facilities above $100 \mathrm{~kW}$ and up to $10 \mathrm{MW}$, and by $6.3 \%$ for plants beyond $10 \mathrm{MW}$ and up to $50 \mathrm{MW}$. Thus, over-incentivizing the PV plants unnecessarily led to a higher financial burden for the final consumers. In terms of the promotion of increasingly competitive solar PV energy, inflated rewards were considered 
potentially detrimental to competition and cost reduction, thus discouraging technological research into this type of technology [12].

Even though periodic adjustments and revisions of the economic scheme were established by the different frameworks, the PV system behaved similar to an open-loop system during the whole period 1998-2008, in which the incentives were decoupled from the compliance level of the PV capacity goals set [9].

In 2007-2008, with the first symptoms of the economic crisis, the solar PV sector was seen as a safe and economically profitable business for investors due to its attractive RD $661 / 2007$ economic framework with high internal rates of return (actual internal rates of return for projects were estimated to have been between $10 \%$ to $15 \%$, as opposed to the targeted rate of 5\% to 9\% [23]) and very small risks [9]. The end of the Spanish housing market boom led professional as well as non-professional investors to shifted capital from the real estate sector to the power sector in the pursuit of cost-effective investment opportunities in a business legally implemented by the public administration and with high premiums $[11,41]$.

Furthermore, other factors contributed to the great expansion of the solar PV sector in Spain in the 2007-2008 period, such as the ease of accessing low-interest loans to finance projects ( $75 \%$ of the $20,000 \mathrm{M}$ EUR invested in this business came from national or foreign banks), the non-implementation of subsidy degression measures in order to lessen support in line with the evolving costs of solar PV projects, the modular and easy-to-install features of solar PV (particularly regarding the smaller facilities), the repowering of PV facilities with more efficient equipment while maintaining their nominal capacity, quick permit provisions, poor coordination between regional and national authorities and the favorable EUR/USD exchange rate since 2006 until 2008, fostering imports of solar PV cells and modules due to the stronger euro $[23,26,41,47]$. These extraordinary conditions attracted an enormous amount of capital, including investments from many small investors who, relying on government guarantees, did not doubt to use their family savings or become indebted by mortgaging their family assets. Financial expenses in this period raised as the number and amount of bank loans awarded to the sector increased considerably [12,41].

In addition, RD 661/2007 announced a transition mechanism that would be applied once it reached $85 \%$ of the PV capacity target (371 MW). This mechanism generated high uncertainty in the solar PV sector about its entering into force and duration. As a result, it acted as a "call for investment" before the highly favorable remuneration scheme finished. For example, to maintain the same IRR as before the approval of the new economic framework, it would have been necessary to reduce the solar PV production cost from 6.3 EUR/Wp to 0.5 EUR/Wp [9].

Consequently, the cumulative PV capacity installed in Spain at the end of 2008 was 3397.8 MW (545 MW and 2707 MW of new PV power were installed in 2007 and 2008, respectively), far above the 400 MW PV capacity goal set by REP 2005-2010 for 2010 . Turning Spain into the second country in Europe with the largest cumulative installed PV capacity, with investments in the Spanish solar PV market accounting for more than $40 \%$ of the world's total solar power plants in 2008 [9,11]. A total of $80 \%$ of that increase was due to the rise in capacity deployed by facilities with capacity lower than $100 \mathrm{~kW}$ (most of these plants being solar parks), and the remaining $20 \%$ took place in the segment from $100 \mathrm{~kW}$ to $10 \mathrm{MW}$, which was the one which experienced the greatest rise in remuneration [26].

Although the 1998-2008 promotion policies did not reduce the LCOE of PV systems installed during that period, they had an enormous impact on the maturity of solar PV technology making the country a leader within the PV market. This fact was reflected afterwards with a strong reduction in its unitary prices [35,36].

In this vein, Spain suffered a diffusion solar PV bubble between June 2007 and September 2008, in which the PV power plants were conceived more as investment products rather than environmental awareness-raising and commitment issues. Even banks included such systems in their product portfolios offered to their clients [36]. In addition, later, a profitability bubble between 2009 and 2011. Paradoxically, when PV incentives decreased between 
2009 and 2012, cost effectiveness rocketed owing to the even stronger reduction of PV system prices. The spike in profitability was not accompanied, however, by a consequent expansion because of the cost-containment measures enacted in that period in Spain [47].

It is also important to stress that the on-roof PV systems promotion mechanism initially established by RD 2818/1998 was one of the greatest obstacles to its development. In this regard, the economic framework set by RD 2818/1998 guaranteed a more beneficial remuneration for small plants with a rated power up to $5 \mathrm{~kW}$ (subsequently, RD 436/2004 updated this rated power limit to $100 \mathrm{~kW}$ ), with the incorrect assumption that roof-mounted PV systems would be those with the smallest installed powers. This ill-defined control scheme, relating the incentives to the rated power rather than to the PV facility type, was not corrected until the approval of RD 661/2007 [9].

This loophole allowed the segmentation of the ground-based PV facilities into modules of $5 \mathrm{~kW}$ under RD 2818/1998 or $100 \mathrm{~kW}$ under RD 436/2004 eligible for the highest premiums while benefiting of the lower costs of large facilities, giving rise to the so-called solar parks. Thus, boosting cost effectiveness above the levels intended by the regulation. More than $90 \%$ of the total PV capacity installed in the 2007-2008 period was some type of solar park, while $65 \%$ of the installed PV capacity in that period belonged to solar parks of more than $10 \mathrm{MW}$ of total size divided into units of up to $100 \mathrm{~kW}[9,27,47]$.

This fact generated a high uncertainty and contributed to the failure of on-roof PV systems development, as less than $10 \%$ of the PV plants in Spain were located on a roof, as well as to the unbalanced development of the whole solar PV sector. Thereupon, although around $80-90 \%$ of the Spanish PV plants were located on ground, virtually $100 \%$ of them benefited from the incentives originally thought for on-roof PV systems [9,27,47].

The Spanish administrative process related to the commissioning of a solar PV power plant was lengthy because of the requirement to acquire different licenses, the processing of which involved the contact of up to three administrative layers at a local, provincial and autonomous level, in addition to a degree of unwillingness and even philistinism and lack of coordination between competent authorities. In this respect, the same procedure could have different results within the same autonomous community, owing to the specific understanding of the regulation of each administrative body. Specifically, it could take several years from the moment that a stakeholder decided to enter the PV electricity generation business until the facility network connection and the activity final commissioning $[19,108]$.

Lastly, the costs of the power system associated with the remuneration of the solar PV sector raised significantly over the latter part of the 1998-2008 promotion stage. The solar PV sector represented a small share of RES in Spain and, simultaneously, an important portion of the total cost of RES promotion [26]. Figure 4 shows the evolution of the annual costs resulting from the public support devoted to the solar PV sector development in Spain during the period 1998-2020 using a red solid line. In addition, the amount of the specific remuneration costs related to the investment remuneration (see the purple-colored vertical bars in Figure 4) and the operation remuneration (see the yellow-colored vertical bars in Figure 4) are also plotted from 2014 when the new RD 413/2014 legal-economic framework came into force.

As can be seen in Figure 4, during the 1998-2004 subperiod, the solar PV development costs followed a fairly smooth growth, increasing from $0.08 \mathrm{M}$ EUR in 1998 to $2.53 \mathrm{M}$ EUR in 2003. Otherwise, as of the approval of RD 436/2004 and RD 661/2007, these public support costs of the solar PV sector began to take an increasing spiral. Thus, in 2004, the solar PV sector costs increased by $143 \%$ compared to the previous year reaching $6.15 \mathrm{M}$ EUR. 


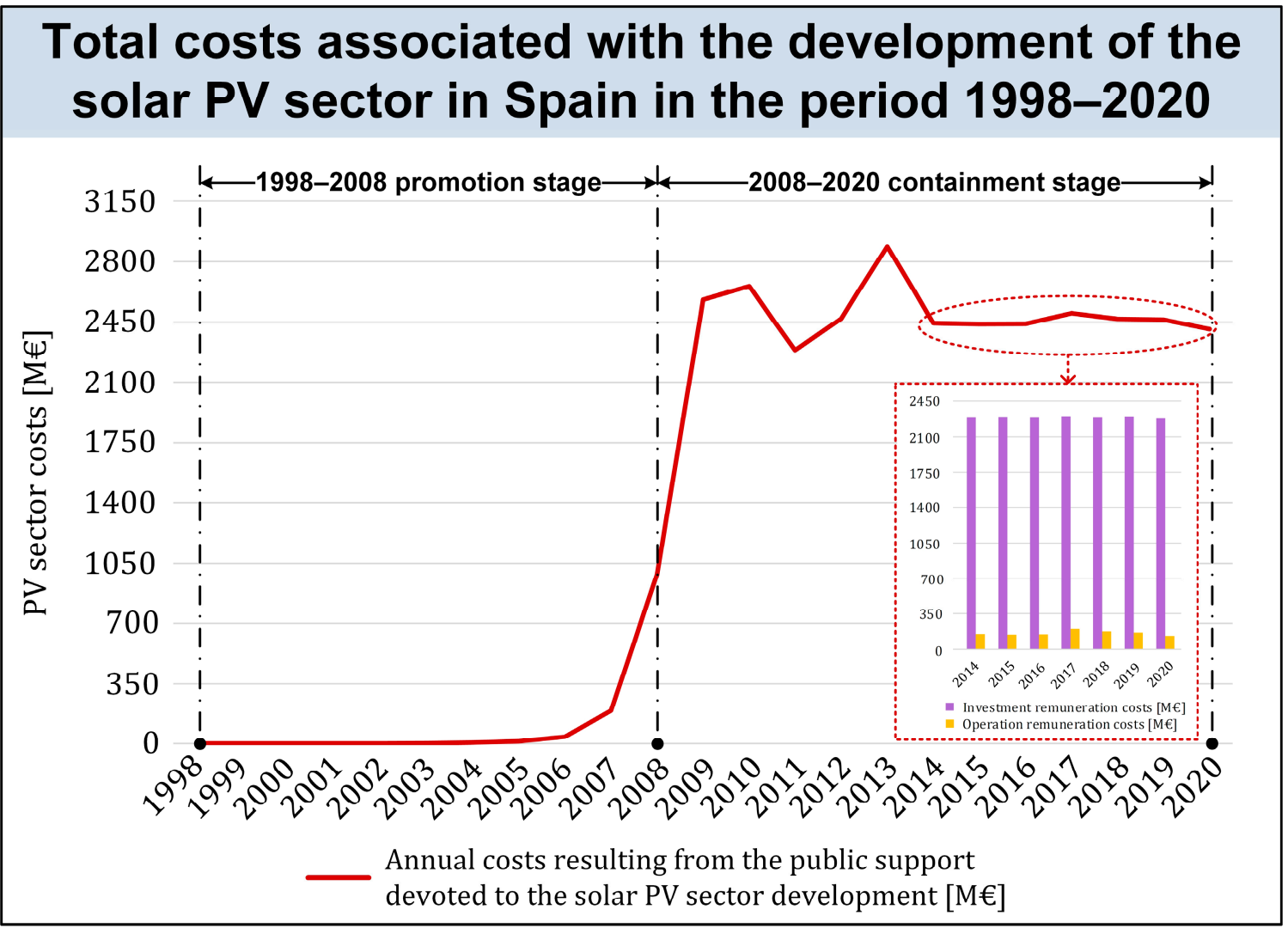

Figure 4. Evolution of the annual costs associated with the Spanish solar PV sector development in the period 1998-2020. Source: self-elaboration based on [69].

Table 12 presents a comparison between the real annual development costs of the Spanish solar PV sector and those expected by the REP 2005-2010 during the period 2005-2010. During the validity period of RD 436/2004, the public support costs of the solar PV sector increased at an annual rate of $130-185 \%$, almost doubling the costs expected by REP 2005-2010. However, during the period 2007-2008, with the enactment of RD $661 / 2007$, the solar PV development costs grew by around $400 \%$ annually, quadrupling in 2007 and multiplying by almost 12 in 2008 the costs anticipated by the REP 2005-2010. In this respect, around $80 \%$ of the total cost of all the solar PV systems under RD 661/2007 corresponded to the PV facilities installed in 2008 [28].

Furthermore, the 600 M EUR increase in the solar PV sector public support costs for 2008 over the previous year foreseen by the Spanish government was widely exceeded. Specifically, as denoted in Table 12, an increase of almost 800 M EUR was obtained, which in turn represented an increase around $4.9 \%$ on the consumers electricity tariff [27].

Table 12. Comparison between the real annual development costs of the Spanish solar PV sector and those expected by the REP 2005-2010 during the period 2005-2010. Source: self-elaboration based on $[66,69]$.

\begin{tabular}{ccc}
\hline Year & $\begin{array}{c}\text { Real PV Costs } \\
\text { [M EUR] }\end{array}$ & PV Costs Expected by the REP 2005-2010 [M EUR] \\
\hline 2005 & 14.00 & 9.42 \\
2006 & 39.89 & 22.67 \\
2007 & 191.75 & 46.56 \\
2008 & 984.80 & 85.01 \\
2009 & 2579.14 & 134.92 \\
2010 & 2656.29 & 200.84 \\
\hline
\end{tabular}




\subsubsection{Concerning the CSP Technology Sector}

First, the 1998-2004 subperiod was characterized by continuous changes in the economic framework of CSP technology facilities. Initially they were in the same remuneration group as the solar PV plants, namely group b.1, under RD 2818/1998. Later they became part of group b.3 under RD 1955/2000 with reductions in its incentives of 70-80\% under the FIT option and $80-90 \%$ under the FIP option. In addition, finally, RD 841/2002 defined its own remuneration subgroup within the b.1 solar technology group, i.e., the subgroup b.1.2, which only allowed them to access the FIP remuneration scheme.

In this regard, in addition to the high uncertainty introduced by the continuous changes in the remuneration scheme, hindering the decision-making in the mid and the long term, the low level of remuneration caused that no CSP plant was put into operation in this subperiod. However, the REP 2000-2010 set a CSP capacity target of 200 MW for 2010.

Thereupon, the 2004-2008 subperiod was characterized by a much more favorable economic framework for CSP facilities. RD 436/2004 once again allowed CSP facilities to access the FIT remuneration option, in addition to incorporating an extra incentive to the premium on top of the electricity pool price option. In this sense, at the end of 2004 there were already three CSP projects in progress totaling $110 \mathrm{MW}$, as well as other initiatives in the development stage totaling $325 \mathrm{MW}$ [10]. In short, with the remuneration system defined in RD 436/2004, RD 436/2004 200 MW capacity target and the 500 MW capacity goal set by REP 2005-2010 for 2010 were insured.

Even though only one CSP plant of 11.02 MW had just been put into operation, the economic framework was once again modified through RD 661/2007. This new economic scheme increased the incentives for CSP facilities by around 20\% under the FIT option and around $30 \%$ under the FIP option, though the established capacity targets were virtually assured. Thus, over-incentivizing the CSP plants unnecessarily led to a higher financial burden for the final consumers.

Although periodic adjustments and revisions of the economic scheme were established, as in the solar PV sector, the CSP system also behaved similar to an open-loop system during the whole period 1998-2008, in which the incentives were decoupled from the compliance level of the CSP capacity goals set [10].

In addition, as for the PV plants, RD 661/2007 announced a transition mechanism to be applied once $85 \%$ of the 500 MW CSP capacity target had been reached, generating high uncertainty in the CSP sector about its date of entering into force and its duration, as well as a call for investment before the highly favorable remuneration scheme finished. Consequently, $4100 \mathrm{MW}$ of CSP capacity had requested access to the grid by 2007 and 15,563 MW by 2009 [10]. Furthermore, a second CSP plant of 49.90 MW entered in operation at the end of 2008 totaling $60.92 \mathrm{MW}$ of installed CSP capacity in Spain, which represented an increase in the cumulative installed CSP capacity of $453 \%$ with respect to the previous year. A CSP bubble was taking shape.

In Spain, the absence of a social backlash against the technology seemed to be related to CSP deployment being a win-win for most local actors due to its environmental and socioeconomic benefits [38].

In conclusion, the costs of the power system associated with the remuneration of the CSP sector started to increase at the end of the 1998-2008 promotion stage. Figure 5 depicts the evolution of the annual costs resulting from the public support devoted to the CSP sector development in Spain during the period 1998-2020 using a blue solid line. In addition, the amount of the specific remuneration costs related to the investment remuneration (see the purple-colored vertical bars in Figure 5) and the operation remuneration (see the yellow-colored vertical bars in Figure 5) are also plotted from 2014 when the new RD 413/2014 legal-economic framework came into force. 


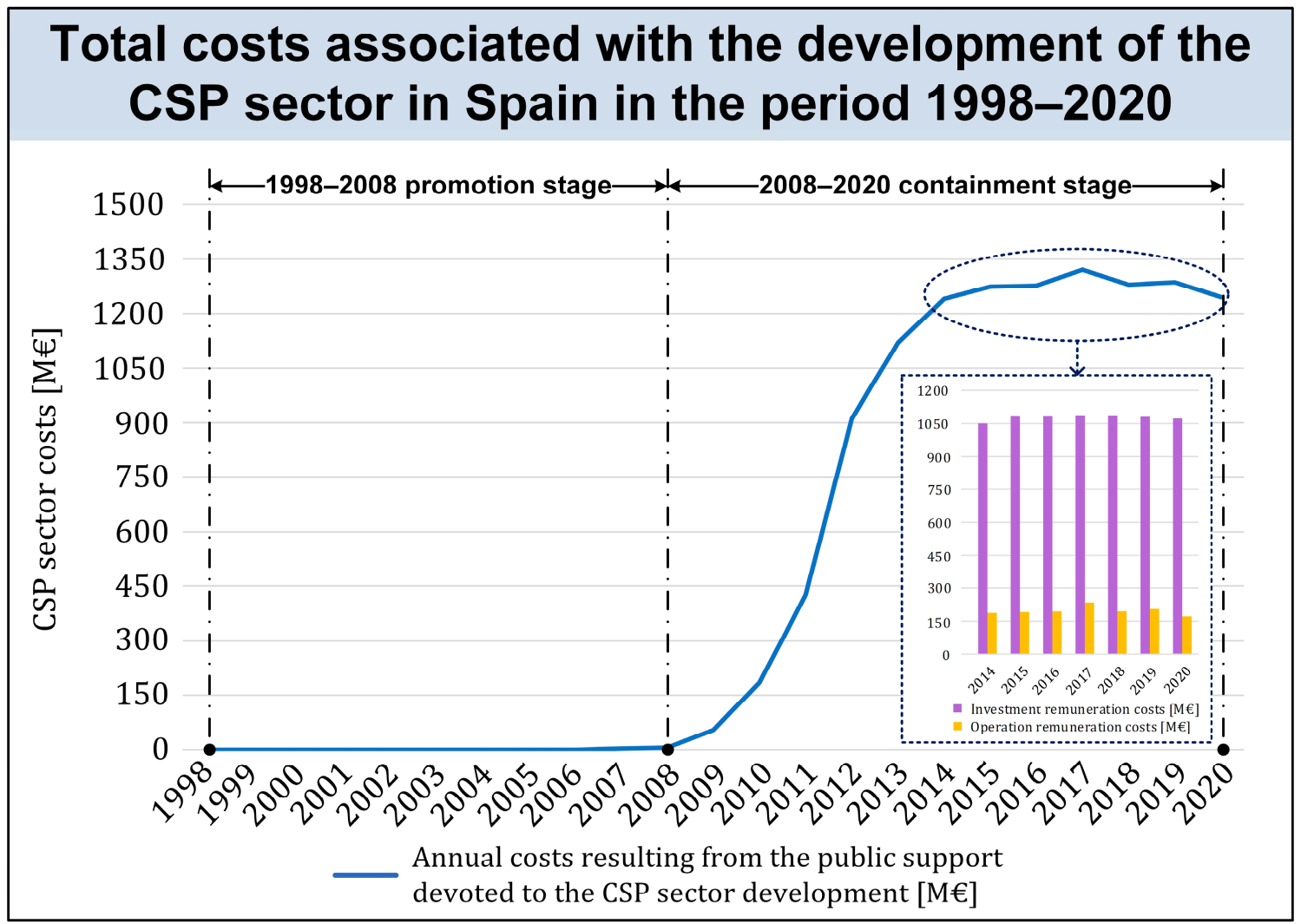

Figure 5. Evolution of the annual costs associated with the Spanish CSP sector development in the period 1998-2020. Source: self-elaboration based on [69].

As can be observed in Figure 5, during the 1998-2006 period no CSP plant was put into operation in Spain, thus the development costs of the CSP sector were zero. In 2007, the first 11.02 MW CSP plant was put into operation with public support costs for the CSP sector of 3.07 M EUR. In turn, with the commissioning of a second 49.90 MW CSP plant in 2008 , those costs increased by $96 \%$ to 6.02 M EUR.

\subsection{Analysis of the 2008-2020 Containment Stage}

4.2.1. Concerning the Solar PV Technology Sector

Containment Stage and RD 1578/2008

The 2008-2013 subperiod was characterized by the implementation of different measures to first control the Spanish PV boom that took place in 2007-2008 and then, to reduce the economic impact on the power sector of existing and future PV plants, ensuring its economic sustainability.

First, RD 1578/2008 was approved as a control structure aimed at adapting the remuneration scheme for new PV facilities once RD 661/2007 PV power targets had been largely exceeded due to the solar PV boom. It established a saturation mechanism through the creation of the RPAR that limited the total new PV power installed in the electricity system, as shown in Figure 6. Thus, the PV power finally awarded for registration in the RPAR was not allowed to exceed the quarterly power calls, which varied according to the system evolution. Given the small quotas legislated and the delay in their allocation, many awarded PV projects were delayed in their implementation as installed capacity $[27,41]$. However, the saturation mechanism could create an overheating of the market and boomand-bust cycles if the capacity was provided on a first-come-first-served basis as in the Spanish case [44]. 
Figure 6 depicts the evolution of the solar PV technology under RD 1578/2008 control structure during the 3-year 2009-2011 period, in which a total of 12 power calls were carried out for each type of PV plant, i.e., 4 calls per year.

On the one hand, the first column of graphs shows the PV power awarded per call (see the green-colored vertical bars in Figure 6), as well as the PV power admitted but not awarded due to the full coverage of the quotas established (see the orange-colored vertical bars in Figure 6), the PV power not admitted due to the existence of formal defects (see the red-colored vertical bars in Figure 6) and the maximum PV quota established (see the black dashed line in Figure 6) for each PV plant typology, i.e., subtype I.1, subtype I.2 and type II.

On the other hand, the second column of graphs depicts the cumulative PV power awarded as the calls progressed (see the green solid line in Figure 6), as well as the maximum cumulative PV quota established (see the blue-colored vertical bars in Figure 6) for each type of PV facility, namely subtype I.1, subtype I.2 and type II.

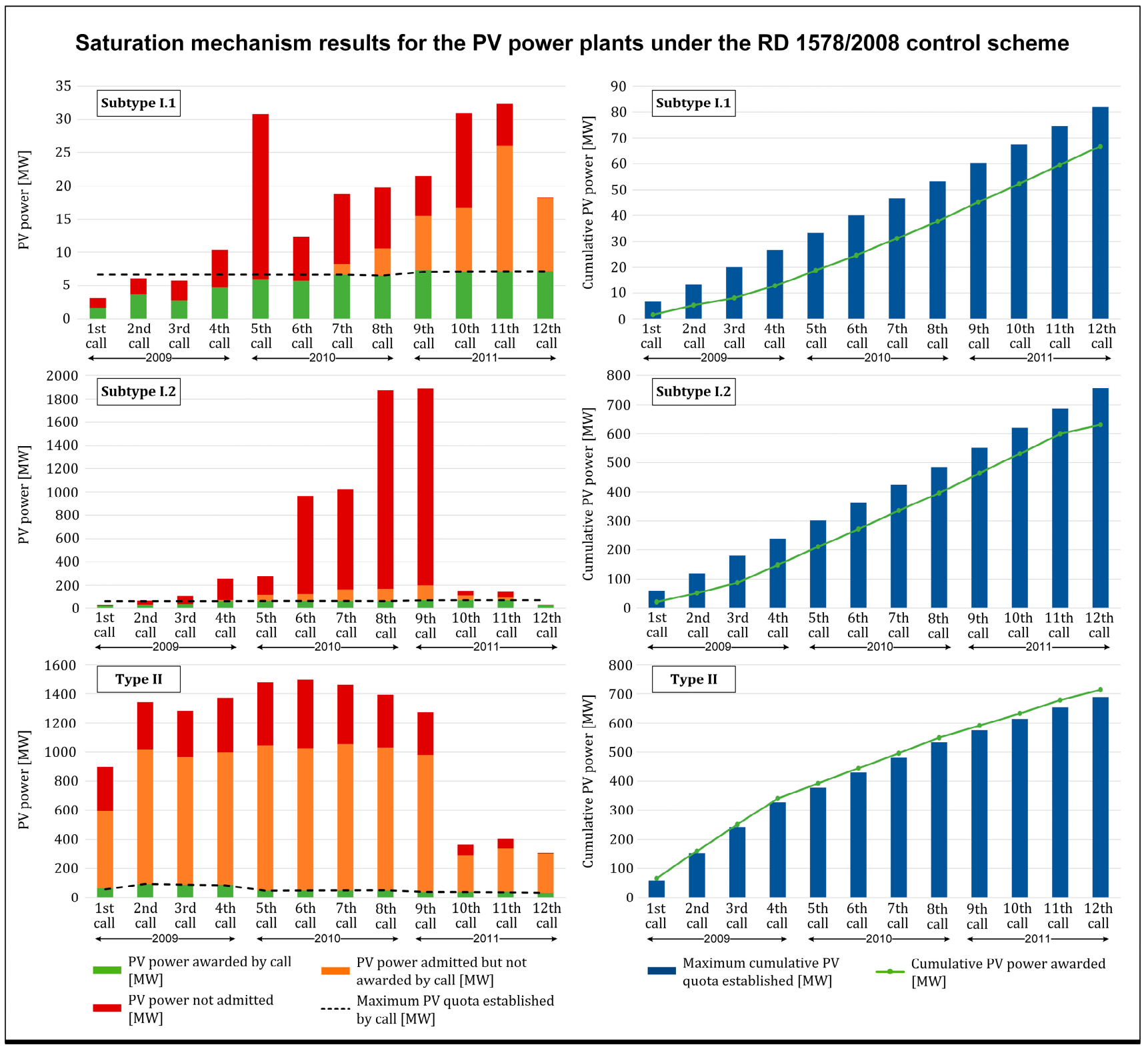

Figure 6. Evolution of the solar PV technology under RD 1578/2008 control structure during the period 2009-2011. Source: self-elaboration based on [69]. 
During the 3-year 2009-2011 period under RD 1578/2008 saturation mechanism, 66.7 MW of cumulative PV power for subtype I.1 (4.73\% of the total awarded PV power), 630.9 MW for subtype I.2 (44.70\% of the total awarded PV power) and 713.65 MW for type II (50.57\% of the total awarded PV power) were awarded in the different power calls, as shown in Figure 6.

By contrast, without the control mechanism established by RD 1578/2008, the cumulative PV power awarded during the same period would have been 119.8 MW for subtype I.1, 1169.57 MW for subtype I.2 and 9655.18 MW for type II (see Figure 6). Obtaining, in this case, an excess in the cumulative PV power awarded with respect to the maximum cumulative PV quota established of $46.38 \%$ for subtype I.1, 54.63\% for subtype I.2 and $1301.17 \%$ for type II.

Hence, the saturating effect of RD 1578/2008 RPAR was an effective mechanism to guarantee the stability and predictability of the PV system. It could be estimated that 125-171 M EUR for subtype I.2 and 615-842 M EUR for type II was saved for the Spanish electricity sector at the end of 2010 [27].

Furthermore, RD 1578/2008 corrected the previous decoupling of the regulated tariff and the compliance degree of the power goals, putting an end to the former open-loop control for new PV plants. Accordingly, it adjusted the annual power goals of each PV system type as a function of the regulated tariff, offsetting the rise in power targets with the decrease of its remuneration, as seen in Figure 7. Thus, limiting the economic impact on the power system of the new PV power plants, but without waiving the PV investment. Specifically, in the most likely scenario of full coverage of all the power calls, a FIT annual reduction of approximately $10 \%$ was obtained [27].

As the support levels evolution depended on the market reaction, it mitigated the asymmetric information problem related to technology costs common in the past (the Spanish government failed to estimate the costs of solar PV as well as their evolution and, thus, higher support levels than necessary were provided [44]). Thus, allowing the market to reveal the true costs of the technology [26]. However, the flexible degression tariff mechanism under RD 1578/2008 introduced uncertainty to investors, since they did not know exactly the level of support a period before they invested [26,44].

Figure 7 plots the evolution of the solar PV technology under RD 1578/2008 control structure during the 3-year 2009-2011 period in terms of the cumulative PV power awarded (see Figure 7a) and the eligible FIT for the PV power awarded (see Figure 7b), for each type of PV plant, i.e., subtype I.1 (see the dark-blue solid lines in Figure 7), subtype I.2 (see the light-blue solid lines in Figure 7) and type II (see the green solid lines in Figure 7).

As observed in Figure 7, during the 2009-2011 period, as the cumulative PV power awarded increased in a certain type of PV plant, the FIT decreased for that type of facility. Specifically, the cumulative PV power awarded during the 2009-2011 period increased from 1.67 MW to 66.70 MW for subtype I.1, from 20.92 MW to 630.90 MW for subtype I.2 and from 66.11 MW to 713.65 MW for type II. However, the FIT was reduced from $34 \mathrm{cEUR} / \mathrm{kWh}$ to $27.38 \mathrm{cEUR} / \mathrm{kWh}$ for subtype I.1 (19.47\% of reduction), from $32 \mathrm{cEUR} / \mathrm{kWh}$ to $19.32 \mathrm{cEUR} / \mathrm{kWh}$ for the subtype I.2 (39.63\% of reduction) and from $32 \mathrm{cEUR} / \mathrm{kWh}$ to $12.5 \mathrm{cEUR} / \mathrm{kWh}$ for type II (60.94\% of reduction).

In addition, RD 1578/2008 control structure could have also contributed to the growth of rooftop PV plants, representing $49.43 \%$ of the new PV facilities with a total of $697.6 \mathrm{MW}$ awarded during the 2009-2011 period.

Therefore, after a total of 2707.34 MW of PV power had been put into operation in 2008, there was a slowdown in installed PV capacity of almost one year, from October 2008 until practically November 2009, due to the increase in the administrative complexity and cueing procedures resulting from the enactment of RD 1578/2008 RPAR. Since then, the different calls under RD 1578/2008 control mechanism caused the commissioning of $1248.36 \mathrm{MW}$ of new PV power in the 2009-2013 period. Thus, at the end of 2013, the cumulative PV power in Spain was $4646.15 \mathrm{MW}$, representing an increase of $36.74 \%$ compared to the cumulative PV power in 2008. 


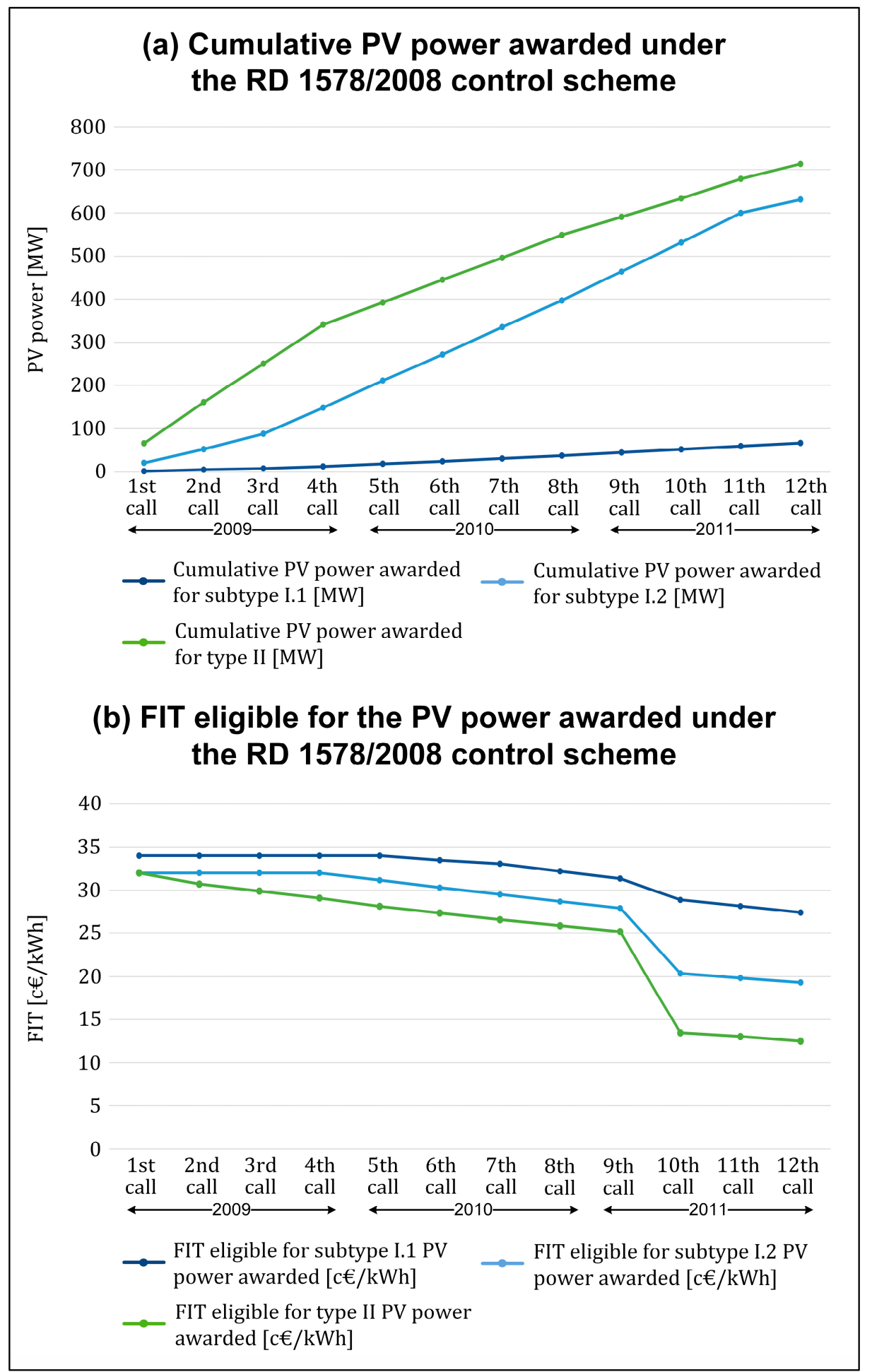

Figure 7. Evolution of the solar PV technology under RD 1578/2008 control structure during the period 2009-2011 in terms of: (a) the cumulative PV power awarded; (b) the FIT eligible for the PV power awarded. Source: self-elaboration based on [69].

Containment Stage and Retroactive Energy Policy from 2010 to 2012

Subsequently, the Spanish government enacted a retroactive energy policy in the period 2010-2012 to lessen the financial burden to the electricity system. The promotion cumulative cost of PV systems was expected to be less than 499.4 M EUR at the end of the period 2005-2010. However, at the end of 2010, this cost was, at least, 6802.8 M EUR, which 
raised the Spanish power tariff deficit and, consequently, the electricity tariff charged to consumers [27].

The 2010-2012 energy policy changed the cost effectiveness of the PV power plants by impacting on their income and on their operating cost. The new energy measures representing savings to the electricity sector resulted in minor revenue for the power plants. However, the measures introducing new incomes for the electricity system were directly translated into an increment of their operating cost [28].

RD 1578/2008 did not regulate the PV cost-containment expressly. Thus, in 2010, 3 new rules entered into force to amend the inefficient cost control scheme, namely RD 1003/2010, RD 1565/2010 and RDL 14/2010.

The first saving action, introduced by RD 1003/2010, was the possible shrinkage of the PV power under RD 661/2007 depending on the existing fraud detection, which would imply the exclusion of the PV facilities involved from the remuneration framework of RD $661 / 2007$. Thus, entailing a decrease on the final cumulative cost overrun [28].

RD 1565/2010 imposed a drastic decrease of the regulated tariffs applied to PV systems under RD 1578/2008 (note that about 80\% of all PV facilities installed at that moment in Spain fell under RD 661/2007 [26]). The accumulated FIT reductions reached 32.3\% for subtype I.1 PV systems, 52.5\% for subtype I.2 and 68.8\% for type II, respectively, regarding the conditions established by RD 661/2007. Thus, this control measure represented an annual saving of around $140 \mathrm{M}$ EUR and countered the cost increment of approximately 138 M EUR per year provoked by the experienced growth in generation capacity [27].

RDL 14/2010 limited the operating time eligible for premium of PV facilities under both RD 661/2007 and RD 1578/2008. Then, the electricity generated exceeding that threshold should be sold at the wholesale market, thus reducing its revenues. This control measure prevented the consolidation of the experimented increase in generation capacity and therefore, future cost deviations. However, it could limit the efficient functioning of existing plants as well as the development of more efficient solar PV technologies, because it discouraged improvements in efficiency as a path to increase income [26,27]. With the enactment of RDL 14/2010, the government planned to decrease the expenditures of the power sector by 4600 M EUR in 3 years, namely from 2011 to 2013 . Half of this amount was expected to come from the reduction of the PV plants revenues, representing an annual saving of $740 \mathrm{M}$ EUR for consumers [11,26].

Moreover, measures were also implemented to increase the income of the electricity system under the 2010-2012 energy policy. Specifically, RDL 14/2010 obligated all power generators to pay a $0.5 \mathrm{EUR} / \mathrm{MWh}$ toll for the electricity fed into the distribution and transmission grids [84], and Law 15/2012 added a 7\% tax on the gross revenues for the electricity generated by all electricity producers in the Spanish electrical system [87]. The solar PV sector claimed that the 0.5 EUR/MWh grid access charge reduced the revenues of ground-mounted PV facilities by $0.2 \%$ and those of roof facilities by $0.3 \%$, while the RES generators receiving support through FIT could not pass the amount of this $7 \%$ fee to customers and, therefore, should assume the additional costs fully [11].

According to [11], the $7 \%$ generation charge had the greatest impact among the 2010-2012 containment measures, followed by RDL 2/2013 change in the tariff-updating mechanism, RDL 14/2010 generation cap, RD 1565/2010 shortening of the support period and the $0.5 \mathrm{EUR} / \mathrm{MWh}$ grid access charge. However, the rise of the support period length under RDL 14/2010, first, and under Law 2/2011, later, improved the profitability of the PV plants.

The urgent need to decrease the skyrocketing Spanish power tariff deficit forced the government to approve RDL 1/2012 in 2012, which cancelled economic incentives for all new RES power plants. Still, the main problem of regulating the Spanish solar PV industry by that moment was how to deal with the overflowed cost caused by the control deficiencies of the previous legislations [27]. Numerous solar PV manufacture companies either had to close or merge because neither minimum returns nor capital amortization were guaranteed, and employment in the sector fell from a high of 41,700 reported jobs to fewer than 10,000 
in 2012 [23,41]. Even though a public credit line was launched by the Spanish government in July 2011, with a variable interest rate and a repayment term of 7 years maximum, that initiative was not enough to replace the private financing [41].

As shown in Figure 4, during the 2008-2013 subperiod, the solar PV sector development costs followed a significant and sustained growth, increasing from 984.80 M EUR in 2008 to 2889.11 M EUR in 2013. In 2009, the solar PV costs increased by $162 \%$ compared to the previous year reaching 2579.14 M EUR (in that year solar PV received almost $60 \%$ of all support for renewable electricity in Spain, despite providing only $12 \%$ of its renewable electricity and almost 3\% of the total electricity generation $[11,23])$. However, thereafter, due to the cost-containment retroactive energy policy measures, the evolution in costs stabilized with a downward trend. Thus, solar PV costs grew 3\% in 2010, decreased $14 \%$ in 2011, and again grew 8\% in 2012 and 17\% in 2013.

\section{Containment Stage and Retroactive Energy Policy from 2013 to 2020}

The cost reduction capability of the 2010-2012 energy policy had not been enough. Thus, in 2013, RDL 9/2013 broke with the legal philosophy applied so far, which had introduced cost reducing measures without dismantling the established economic framework [28].

Therefore, the 2013-2020 subperiod, unlike the 2008-2013 subperiod, was characterized by the dismantling of the previous open-loop control structure for the whole solar PV sector. Thus, RDL 9/2013 laid the foundations for a new closed-loop control scheme, the financial sustainability of the electricity system being a declared objective. Subsequently, the SES Law 24/2013 and RD 413/2014 developed this new control mechanism for both new PV plants under RD 1578/2008 and existing ones under RD 661/2007. The new remuneration scheme set by RD 413/2014 reasonable profitability cost-containment mechanism caused a considerable profitability reduction in the PV plants with respect to the former frameworks.

Moreover, the intrinsic complexity of RD 413/2014 framework, with a great number of regulatory parameters and a high uncertainty associated with their future evolution, severely hampered understanding its effects on the economic performance of the PV systems in the mid and the long term [46].

It is also important to stress that even though the minimum threshold of operating hours imposed by RD 413/2014 to PV plants could have represented an opportunity to force the owner to keep their facilities at their optimum status and, therefore, generating as much energy as possible, RD 413/2014 established that minimum threshold below 50\% of the average operating hours of a standard PV power plant in Spain. Consequently, some investors wondered if it was worth keeping the annual investment in operating and management protocols to acquire high energy yields provided that the minimum threshold was achieved, as the economic effort to optimally maintain the PV facility did not exceed the maximum threshold of operating hours and its corresponding revenues [36].

After implementing the containment measures in the Spanish solar PV sector through the different regulatory frameworks enacted, the PV economic investments changed from an attractive initial cost-effective scenario to a limited situation in terms of the original business plans [36]. In this regard, more than one third of the existing PV plants in that moment were bearing negative returns and liquidity problems (additionally damaged by the slow pace of the government's subsidy payments [36]), leading to many appeals and legal claims in the court against the Spanish State. Most of the producers were pushed to refinance their bank debt under more burdensome terms or to sale the PV plants to foreign investment groups. In turn, many small investors were indirectly forced to abandon their plans, i.e., canceling the annual expenditures on operating and management tasks, so they could divert those operational expenditures to their loan duties and overcome possible bankruptcy scenarios. In those bankruptcy scenarios, private equity or vulture funds ([36] stated that there could be a certain degree of government complicity with some powerful equity funds or energy companies) were discovering market opportunities, either by acquiring PV-related enterprises or buying large PV plants [12,18,35,36,46,53]. 
Spain dropped from second position among the EU countries in 2008, with $32.5 \%$ of generation, to fifth in 2015, with $5.1 \%$ of production. Similarly, there were 1942 companies in operation in the solar PV sector in 2008, while 848 companies had disappeared in 2014 over a 6-month period, constituting 44\% of companies active in 2008 [12].

During the 2014-2018 period there was a significant stoppage in the commissioning of new PV power. Specifically, only 53 MW of PV capacity were installed in Spain. This trend changed in the 2019-2020 period with the installation of 3311.71 MW in 2019 and 2243.95 MW in 2020 of new PV capacity as a result of RD 413/2014 auctions carried out in 2017. Thus, at the end of 2020 the cumulative PV power installed in Spain was $10,254.78 \mathrm{MW}$, representing an increase of $118 \%$ compared to the cumulative PV power in 2018. Although the first 2007-2008 PV boom was led by small companies, this second boom is linked to larger companies [37].

As shown in Figure 4, during the 2013-2020 subperiod the development costs of the solar PV sector remained practically constant with annual variations between $-15 \%$ and +2.5\%. The solar PV costs evolved from 2889.11 M EUR in 2013 to 2409.77 M EUR in 2020.

During the 2013-2020 subperiod, the investment remuneration represented 92-94\% of the specific remuneration costs, while the operation remuneration only represented the remaining $6-8 \%$, as shown in Figure 4.

\subsubsection{Concerning the CSP Technology Sector}

Containment Stage and Retroactive Energy Policy from 2010 to 2013

The 2008-2013 subperiod was characterized by the implementation of a set of concurrent saving measures to the existing control system to limit the CSP bubble that was taking shape and the associated overrun cost to the power sector. To that effect, first, RDL 6/2009 replicated the control structure defined by RD 1578/2008 for PV plants, to avoid that the solar PV boom and its economic impact on the electricity system could occur in other renewable sectors such as CSP or wind.

RDL 6/2009 established a saturation mechanism through the creation of the RPAR that limited the total CSP power installed in the system. In this way, it was possible to limit the CSP bubble generated under RD 661/2007. Accordingly, only 29\% of the 15,563 MW of CSP capacity, which had requested access to the electricity network and had deposited the corresponding economic guarantees, finally applied for the RPAR (4499 MW). Furthermore, only half of the CSP power that applied to the RPAR was definitely awarded [10].

However, the almost $2440 \mathrm{MW}$ of CSP capacity awarded and registered in the RPAR five-fold increased the 500 MW CSP capacity goal set by REP 2005-2010 for 2010. Thus, the entry into operation of the enrolled CSP power plants was distributed in four stages until the end 2013 to defer the overrun costs to the electricity system.

Thereupon, $471 \mathrm{MW}$ were put into operation in the first phase (years 2009-2010), $467 \mathrm{MW}$ in the second phase (year 2011), $951 \mathrm{MW}$ in the third phase (year 2012) and the last $350 \mathrm{MW}$ in the fourth phase (year 2013). This new yearly installed capacity represented an increase in the cumulative CSP capacity compared to the previous year of $281 \%$ reaching $232 \mathrm{MW}$ in 2009, 129\% reaching $532 \mathrm{MW}$ in 2010, 88\% reaching almost $1000 \mathrm{MW}$ in 2011, 95\% reaching $1950 \mathrm{MW}$ in 2012 and 18\% reaching almost $2300 \mathrm{MW}$ in 2013.

In addition, other regulatory measures were implemented to decrease the soaring costs of the electrical system, such as RD 1614/2010, which limited the equivalent operating hours at rated power eligible for the regulated tariff or premium of RD 661/2007 for CSP facilities [83], or RDL 1/2012, which temporarily suppressed the economic incentives of RD 661/2007 as well as the registration procedure in the RPAR under RDL 6/2009 for new SR power plants [86].

Moreover, measures were also implemented to increase the income of the electricity system such as RDL 14/2010, which obligated all power generators to pay a $0.5 \mathrm{EUR} / \mathrm{MWh}$ toll for the electricity fed into the distribution and transmission grids [84], or Law 15/2012, which added a $7 \%$ tax on the gross revenues for the electricity generated by all electricity producers in the Spanish electrical system [87]. 
As shown in Figure 5, during the 2008-2013 subperiod, the development costs of the CSP sector followed a significant and sustained growth, increasing from 6.02 M EUR in 2008 to 1120.75 M EUR in 2013. In 2009, the CSP public support costs increased by $815 \%$ compared to the previous year reaching 55.13 M EUR. However, thereafter, due to the cost deferral mechanism incorporated by RDL 6/2009, the increase in development costs stabilized with a downward trend. Thus, CSP costs grew 234\% in 2010, 132\% in 2011, 113\% in 2012 and $23 \%$ in 2013.

Containment Stage and Retroactive Energy Policy from 2013 to 2020

Then, the 2013-2020 subperiod, unlike the 2008-2013 subperiod, was characterized by the dismantling of the previous open-loop control structure. Thus, RDL 9/2013 laid the foundations for a new closed-loop control scheme where the cost to the electrical system was the controlled variable. Subsequently, the SES Law 24/2013 and RD 413/2014 developed this new control mechanism, adjusting the remuneration of the RES facilities to the needs of the Spanish power system. The remuneration parameters were periodically reviewed and updated, seeking a reasonable profitability for the RES facilities, in which were included the CSP plants, while maintaining the economic sustainability of the electrical system [10].

By the end 2013, 50 CSP facilities with 2299.5 MW of cumulative capacity were commercially operating in Spain, turning it into the world leader in terms of installed CSP capacity, followed by the United States. A total of ten out of the 60 initially envisaged facilities, as well as the innovative CSP project, were finally withdrawn due to the cuts in the CSP remuneration introduced by the latest regulatory changes. Specifically, the new legislation implied a 15\% mean cut in the CSP remuneration, which added to the retroactive measures adopted in the previous years increased the cumulative cut to $50 \%[10,30]$.

Accordingly, one of the most significant problems for the CSP sector was the liquidity shortage and the decrease of their legitimate expectations in the income statement. Furthermore, RD 413/2014 legal-economic framework introduced an enormous complexity and uncertainty in the Spanish CSP sector remuneration mechanism. Thus, significantly hampering their economic assessment and decision-making in the mid and the long term, and reducing the Spanish project developers, with only engineering, procurement and construction firms remaining in the sector $[10,30,38,54]$.

CSP is still considered an immature non-competitive technology with the absence of public support. The principal reason for the sluggish growth of CSP is notably related to its huge generation costs (the most relevant barrier of the CSP technology compared to conventional power plants and other RES technologies according to [38]). This situation is strongly illustrated in Spain, where the solar power sector came to complete stagnation when the recession forced the national government to shorten the subsidies that had prompted its rapid development several years earlier. The feasibility of this type of CSP facilities essentially depend on a sharp decrease in operating costs and a rise in income from electricity sales [39].

The size limit of $50 \mathrm{MW}$ to be eligible for support in Spain was regarded as a limit to further innovation and cost reductions, since CSP projects needed to be relatively large to function properly while upsizing is a relevant source of cost reductions $[38,40]$.

No new CSP plant was installed in Spain as of 2013. Thus, as shown in Figure 5, during the 2013-2020 subperiod the development costs of the CSP sector remained practically constant with annual variations between $-3 \%$ and $+10 \%$. The CSP public support costs evolved from 1120.75 M EUR in 2013 to 1244.46 M EUR in 2020, going through a peak of 1320.76 M EUR in 2017.

During the 2013-2020 subperiod, the investment remuneration represented 82-86\% of the specific remuneration costs, while the operation remuneration only represented the remaining $14-18 \%$, as shown in Figure 5. 


\section{Conclusions}

This work provides a comprehensive review of the energy policy evolution for the whole solar power sector in Spain, namely both solar PV and CSP technologies, from 1998 to 2020. Thus, this review deals with the complete boom-and-bust cycle experienced by the Spanish solar power sector in the last 23 years.

Spain has become one of the most successful countries in the world in promoting electricity generation from RES, and specifically from the solar resource due to the great country-specific solar potential, through a highly favorable energy policy combined with strong public incentives set by Spanish governments mainly during the first decade of the 2000s. Nevertheless, the initial highly favorable regime applicable to solar power plants turned into an extremely unfavorable scenario during the second decade of the 2000s.

The Spanish solar power sector has suffered continuous and significant changes in its regulation, denoting a great dynamism in recent years. In this vein, a survey of the different legislation in force during the 1998-2020 period was first conducted to contextualize and describe the last 23 years of solar energy policy in Spain. Two major stages have been identified, namely the 1998-2008 promotion stage, which began with the enactment of the first SES Law 54/1997, and the 2008-2020 cost-containment stage, which ended with the approval of the new RD 960/2020 economic regime for RES. During the 1998-2008 promotion stage, a total of two REPs, two European directives and seven meaningful national regulations were implemented for the solar power sector. In turn, during the 2008-2020 cost-containment period, a total of one REP, one European Directive and up to 22 relevant national regulations were implemented for that renewable electricity production sector. As regards the promotion stage, the first part began by laying the foundations of the Spanish electricity production sector from RES, and more specifically from solar technologies, through RD 2818/1998 framework and its revisions, i.e., RD 1955/2000 and RD 841/2002. However, during the second half of that period the Spanish government ratified its unwavering and forceful commitment to the development of solar power plants by an extremely favorable economic framework for those facilities, first under RD 436/2004 and later under RD 661/2007.

As for the cost-containment stage, the first part was characterized by the enactment of a set of measures aimed at controlling the excessive growth of solar capacity, derived from the Spanish solar boom that was taking shape during the period 2007-2008, and its huge impact on the electricity system costs, namely RD 1578/2008, RDL 6/2009, RD 1003/2010, RD 1565/2010, RD 1614/2010, RDL 14/2010 and Law 2/2011. However, the measures adopted until 2011 were not sufficient, putting at risk the final goal of suppressing the tariff deficit, which emerged because of the mismatch between the income and the costs of the Spanish power system, as of 2013. Thus, new containment measures were approved in 2012, namely RDL 1/2012, Law 15/2012 and RDL 29/2012. However, during the second half of that period, and after the approval of RDL 2/2013 which continued to seek the electricity system tariff deficit mitigation in line with the previous measures, the Spanish government retroactively dismantled the previous promotion frameworks breaking with the cost-containment philosophy applied so far, to reduce the high economic burden to the Spanish power system ultimately paid by the end consumers. Thus, laying the foundations of a new paradigm for the entire Spanish renewable power sector, in which were included the solar power plants, by means of RD 413/2014 regulation, which built the fundamentals already included in RDL 9/2013 and integrated in Law 24/2013. During the second half of the cost-containment stage, three RES auctions under RD 413/2014 framework were called in Spain to comply with the RES binding European targets by 2020.

Subsequently, a survey of the most relevant existing academic literature dealing with this issue was conducted to carefully assess the last 23 years of solar energy policy in Spain based on their results and conclusions. In short, it is important to stress the decisive role of Spanish governments in promoting the solar power sector during the 1998-2008 period by providing a stable, quite favorable and easily predictable RES regulatory support mechanism quite attractive for investors. However, during the 1998-2008 promotion stage, 
the Spanish solar system behaved as an open-loop system without any control structure adjusting public support levels to the RES generation costs and / or to the compliance degree of the targets set by the Spanish solar energy policy, leading to uncontrolled growth in RES capacity and, therefore, to large system cost increases ultimately affecting end consumers. One of the biggest lessons extracted from the Spanish solar experience is that the specific design elements of RES support schemes and not so much the instrument chosen were a major factor for their efficiency and well-functioning.

In Spain, cost-containment measures were applied from 2008 onwards after the renewable energy policy had been implemented and investments had been made. Therefore, the RES stakeholders that invested ex-ante in the RES electricity production sector under the favorable conditions set by the Spanish government saw ex-post how it retroactively changed the legislation and substantially reduced or even eliminated the profitability of such investments. The fact that the Spanish governments were forced to implement retroactive measures during the period 2008-2020, dismantling the previous legal-economic framework for RES, clearly indicated a malfunctioning of the energy policy control mechanism. The new retroactive closed-loop control mechanism developed by the SES Law 24/2013 and RD 413/2014 had a critical impact on the profitability of the existing solar facilities, and could even lead to the bankruptcy of these RES facilities. Furthermore, the high complexity and uncertainty of the new retroactive investment-based remuneration scheme awarded by competitive tenders, significantly hindered the economic assessment and decision-making of both new and existing solar power plants in the mid and the long term. Conversely, the new RD 413/2014 legal-economic scheme has not been subjected to substantial modifications after coming into effect in 2014, therefore introducing a period of considerable regulatory stability.

On balance, it is expected that the lessons extracted from this 23-year comprehensive review of the Spanish solar power sector pathway could be quite useful for other countries either in the initial development stage or fully immersed in the promotion of solar power sector or any other renewable technology. First, a simple but robust, stable and predictable development model in the mid and long term, combined with an administrative process as simple and agile as possible to prevent it from acting as a barrier for renewable energy stakeholders, is extremely important. Thus, providing investors with maximum legaleconomic security and reliability. Furthermore, a good planning of the energy development model is fundamental, establishing how much energy can be assumed at the national level and at what price. Therefore, limiting the implementation of retroactive measures, as happened in the Spanish cost-containment stage, which can seriously jeopardize the viability of the power plants in operation, as well as compromising the legal-economic stability of the renewable energy sector, thus, generating distrust and uncertainty among investors. In this respect, it is important to highlight the great importance of designing robust and adequate renewable technology support schemes, as well as of its updating mechanisms, to provide investors with certainty and good predictability of the income statement of their renewable assets in the mid and long term. In such a way that open-loop models without any control structure detecting and reacting to problematic situations, as occurred during the Spanish promotion stage, should be avoided. In recent years, the price setting system of auction mechanisms has shown a high effectiveness when setting electricity prices by limiting the costs for the power system, greater than that established through legislation by country-specific governments.

Future works will cover a detailed comparison between the Spanish case and the pathways experienced in the development of the renewable power sector in other countries of the world, as well as an extensive criticism of the solar energy policies implemented in Spain over the last 23 years by describing and assessing in detail the political and management implications. In addition, the authors are considering undertaking a comprehensive review of the self-consumption solar photovoltaic sector. 
Author Contributions: Conceptualization, S.C. and J.d.1.H.; methodology, S.C., J.d.1.H. and À.A.; validation, S.C., J.d.1.H., À.A. and H.M.; formal analysis, S.C. and J.d.1.H.; investigation, S.C.; data curation, S.C., À.A.; writing-original draft preparation, S.C.; writing-review and editing, S.C., J.d.1.H., À.A. and H.M.; visualization, S.C.; supervision, J.d.1.H. and H.M.; project administration, J.d.l.H. and H.M.; funding acquisition, S.C. All authors have read and agreed to the published version of the manuscript.

Funding: This research was funded by Agència de Gestió d'Ajuts Universitaris i de Recerca (AGAUR) and European Social Fund, grant number 2020FI_B2_00055.

Institutional Review Board Statement: Not applicable.

Informed Consent Statement: Not applicable.

Conflicts of Interest: The authors declare no conflict of interest. The funders had no role in the design of the study; in the collection, analyses, or interpretation of data; in the writing of the manuscript, or in the decision to publish the results.

\section{Nomenclature}

$\begin{array}{ll}\text { AET } & \text { Average electricity tariff } \\ \text { BP } & \text { Basis points } \\ \mathrm{CO}_{2} & \text { Carbon dioxide } \\ \mathrm{CPI} & \text { Consumer price index } \\ \mathrm{CSP} & \text { Concentrating solar power } \\ \mathrm{EU} & \text { European Union } \\ \text { FIP } & \text { Feed-in premium } \\ \text { FIT } & \text { Feed-in tariff } \\ \text { GHG } & \text { Greenhouse gas } \\ \text { IEA } & \text { International Energy Agency } \\ \text { IRR } & \text { Internal rate of return } \\ \text { LCOE } & \text { Levelized cost of electricity } \\ \text { NPV } & \text { Net present value } \\ \text { PV } & \text { Photovoltaic } \\ \text { RD } & \text { Royal Decree } \\ \text { RDL } & \text { Royal Decree Law } \\ \text { REP } & \text { Renewable energy plan } \\ \text { RES } & \text { Renewable energy sources } \\ \text { RPAR } & \text { Register of pre-allocation of remuneration } \\ \text { SES } & \text { Spanish electricity sector } \\ \text { SR } & \text { Special regime }\end{array}$

\section{References}

1. Del Río, P. Analysing future trends of renewable electricity in the EU in a low-carbon context. Renew. Sustain. Energy Rev. 2011, 15, 2520-2533. [CrossRef]

2. Dinçer, F. The analysis on photovoltaic electricity generation status, potential and policies of the leading countries in solar energy. Renew. Sustain. Energy Rev. 2011, 15, 713-720. [CrossRef]

3. Espinosa, M.P.; Pizarro-Irizar, C. Is renewable energy a cost-effective mitigation resource? An application to the Spanish electricity market. Renew. Sustain. Energy Rev. 2018, 94, 902-914. [CrossRef]

4. REN21. Renewables 2021 Global Status Report. Paris. 2021. Available online: https://www.ren21.net/wp-content/uploads/20 19/05/GSR2021_Full_Report.pdf (accessed on 10 November 2021).

5. IEA. World Energy Outlook 2021. Paris. 2021. Available online: https://iea.blob.core.windows.net/assets/888004cf-1a38-4716-9 e0c-3b0e3fdbf609/WorldEnergyOutlook2021.pdf (accessed on 10 November 2021).

6. Ciarreta, A.; Gutiérrez-Hita, C.; Nasirov, S. Renewable energy sources in the Spanish electricity market: Instruments and effects. Renew. Sustain. Energy Rev. 2011, 15, 2510-2519. [CrossRef]

7. Abdmouleh, Z.; Alammari, R.A.M.; Gastli, A. Review of policies encouraging renewable energy integration \& best practices. Renew. Sustain. Energy Rev. 2015, 45, 249-262. [CrossRef]

8. Bianco, V.; Driha, O.M.; Sevilla-Jiménez, M. Effects of renewables deployment in the Spanish electricity generation sector. Util. Policy 2019, 56, 72-81. [CrossRef] 
9. De la Hoz, J.; Boix, O.; Martín, H.; Martins, B.; Graells, M. Promotion of grid-connected photovoltaic systems in Spain: Performance analysis of the period 1998-2008. Renew. Sustain. Energy Rev. 2010, 14, 2547-2563. [CrossRef]

10. Martín, H.; de la Hoz, J.; Velasco, G.; Castilla, M.; García de Vicuña, J.L. Promotion of concentrating solar thermal power (CSP) in Spain: Performance analysis of the period 1998-2013. Renew. Sustain. Energy Rev. 2015, 50, 1052-1068. [CrossRef]

11. Mir-Artigues, P.; Cerdá, E.; del Río, P. Analyzing the impact of cost-containment mechanisms on the profitability of solar PV plants in Spain. Renew. Sustain. Energy Rev. 2015, 46, 166-177. [CrossRef]

12. Ibarloza, A.; Heras-Saizarbitoria, I.; Allur, E.; Larrea, A. Regulatory cuts and economic and financial performance of Spanish solar power companies: An empirical review. Renew. Sustain. Energy Rev. 2018, 92, 784-793. [CrossRef]

13. Liu, W.; Zhang, X.; Feng, S. Does renewable energy policy work? Evidence from a panel data analysis. Renew. Energy 2019, 135, 635-642. [CrossRef]

14. Marques, A.C.; Fuinhas, J.A.; Macedo, D.P. The impact of feed-in and capacity policies on electricity generation from renewable energy sources in Spain. Util. Policy 2019, 56, 159-168. [CrossRef]

15. Zafrilla, J.-E.; Arce, G.; Cadarso, M.-Á.; Córcoles, C.; Gómez, N.; López, L.-A.; Monsalve, F.; Tobarra, M.-Á. Triple bottom line analysis of the Spanish solar photovoltaic sector: A footprint assessment. Renew. Sustain. Energy Rev. 2019, 114, 109311. [CrossRef]

16. Gürtler, K.; Postpischil, R.; Quitzow, R. The dismantling of renewable energy policies: The cases of Spain and the Czech Republic. Energy Policy 2019, 133, 110881. [CrossRef]

17. Trujillo-Baute, E.; del Río, P.; Mir-Artigues, P. Analysing the impact of renewable energy regulation on retail electricity prices. Energy Policy 2018, 114, 153-164. [CrossRef]

18. Mir-Artigues, P.; Cerdá, E.; del Río, P. Analysing the economic impact of the new renewable electricity support scheme on solar PV plants in Spain. Energy Policy 2018, 114, 323-331. [CrossRef]

19. Díez-Mediavilla, M.; Alonso-Tristán, C.; Rodríguez-Amigo, M.C.; García-Calderón, T. Implementation of PV plants in Spain: A case study. Renew. Sustain. Energy Rev. 2010, 14, 1342-1346. [CrossRef]

20. Girard, A.; Gago, E.J.; Ordoñez, J.; Muneer, T. Spain's energy outlook: A review of PV potential and energy export. Renew. Energy 2016, 86, 703-715. [CrossRef]

21. IEA. Spain 2021 Energy Policy Review. Paris. 2021. Available online: https://iea.blob.core.windows.net/assets/2f405ae0-46174e16-884c-7956d1945f64/Spain2021.pdf (accessed on 10 November 2021).

22. Del Río, P.; Gual, M.A. An integrated assessment of the feed-in tariff system in Spain. Energy Policy 2007, 35, 994-1012. [CrossRef]

23. Del Río, P.; Mir-Artigues, P. A Cautionary Tale: Spain's Solar PV Investment Bubble. International Institute for Sustainable Development, 2014. Available online: https://www.iisd.org/gsi/sites/default/files/rens_ct_spain.pdf (accessed on 3 September 2021).

24. Blanco-Díez, P.; Díez-Mediavilla, M.; Alonso-Tristán, C. Review of the Legislative Framework for the Remuneration of Photovoltaic Production in Spain: A Case Study. Sustainability 2020, 12, 1214. [CrossRef]

25. Salas, V.; Olias, E. Overview of the photovoltaic technology status and perspective in Spain. Renew. Sustain. Energy Rev. 2009, 13, 1049-1057. [CrossRef]

26. Del Río, P.; Mir-Artigues, P. Support for solar PV deployment in Spain: Some policy lessons. Renew. Sustain. Energy Rev. 2012, 16, 5557-5566. [CrossRef]

27. De la Hoz, J.; Martín, H.; Ballart, J.; Córcoles, F.; Graells, M. Evaluating the new control structure for the promotion of grid connected photovoltaic systems in Spain: Performance analysis of the period 2008-2010. Renew. Sustain. Energy Rev. 2013, 19, 541-554. [CrossRef]

28. De la Hoz, J.; Martín, H.; Ballart, J.; Monjo, L. Evaluating the approach to reduce the overrun cost of grid connected PV systems for the Spanish electricity sector: Performance analysis of the period 2010-2012. Appl. Energy 2014, 121, 159-173. [CrossRef]

29. Del Río, P.; Calvo-Silvosa, A.; Iglesias, G. The New Renewable Electricity Support Scheme in Spain: A Comment. Renew. Energy Law Policy Rev. 2015, 6, 17-24.

30. De la Hoz, J.; Martín, H.; Montalà, M.; Matas, J.; Guzman, R. Assessing the 2014 retroactive regulatory framework applied to the concentrating solar power systems in Spain. Appl. Energy 2018, 212, 1377-1399. [CrossRef]

31. Schallenberg-Rodriguez, J.; Haas, R. Fixed feed-in tariff versus premium: A review of the current Spanish system. Renew. Sustain. Energy Rev. 2012, 16, 293-305. [CrossRef]

32. Del Río, P. Designing auctions for renewable electricity support: The case of Spain. Renew. Energy Law Policy Rev. 2017, 8, 23-37.

33. Del Río, P.; Bleda, M. Comparing the innovation effects of support schemes for renewable electricity technologies: A function of innovation approach. Energy Policy 2012, 50, 272-282. [CrossRef]

34. Avril, S.; Mansilla, C.; Busson, M.; Lemaire, T. Photovoltaic energy policy: Financial estimation and performance comparison of the public support in five representative countries. Energy Policy 2012, 51, 244-258. [CrossRef]

35. Talavera, D.L.; Muñoz-Cerón, E.; Ferrer-Rodríguez, J.P.; Nofuentes, G. Evolution of the cost and economic profitability of grid-connected PV investments in Spain: Long-term review according to the different regulatory frameworks approved. Renew. Sustain. Energy Rev. 2016, 66, 233-247. [CrossRef]

36. Lomas, J.C.; Muñoz-Cerón, E.; Nofuentes, G.; de la Casa, J. Sale of profitable but unaffordable PV plants in Spain: Analysis of a real case. Energy Policy 2018, 117, 279-294. [CrossRef]

37. Fernández-González, R.; Arce, E.; Garza-Gil, D. How political decisions affect the economy of a sector: The example of photovoltaic energy in Spain. Energy Rep. 2021, 7, 2940-2949. [CrossRef] 
38. Del Río, P.; Peñasco, C.; Mir-Artigues, P. An overview of drivers and barriers to concentrated solar power in the European Union. Renew. Sustain. Energy Rev. 2018, 81, 1019-1029. [CrossRef]

39. San Miguel, G.; Corona, B. Economic viability of concentrated solar power under different regulatory frameworks in Spain. Renew. Sustain. Energy Rev. 2018, 91, 205-218. [CrossRef]

40. Kiefer, C.P.; del Río, P. Analysing the barriers and drivers to concentrating solar power in the European Union. Policy implications. J. Clean. Prod. 2020, 251, 119400. [CrossRef]

41. Fernández-González, R.; Suárez-García, A.; Álvarez Feijoo, M.Á.; Arce, E.; Díez-Mediavilla, M. Spanish Photovoltaic Solar Energy: Institutional Change, Financial Effects, and the Business Sector. Sustainability 2020, 12, 1892. [CrossRef]

42. Ortega, M.; del Río, P.; Montero, E.A. Assessing the benefits and costs of renewable electricity. The Spanish case. Renew. Sustain. Energy Rev. 2013, 27, 294-304. [CrossRef]

43. Sarasa-Maestro, C.J.; Dufo-López, R.; Bernal-Agustín, J.L. Photovoltaic remuneration policies in the European Union. Energy Policy 2013, 55, 317-328. [CrossRef]

44. Del Río, P.; Cerdá, E. The policy implications of the different interpretations of the cost-effectiveness of renewable electricity support. Energy Policy 2014, 64, 364-372. [CrossRef]

45. Ciarreta, A.; Pizarro-Irizar, C.; Zarraga, A. Renewable energy regulation and structural breaks: An empirical analysis of Spanish electricity price volatility. Energy Econ. 2020, 88, 104749. [CrossRef]

46. De la Hoz, J.; Martín, H.; Miret, J.; Castilla, M.; Guzman, R. Evaluating the 2014 retroactive regulatory framework applied to the grid connected PV systems in Spain. Appl. Energy 2016, 170, 329-344. [CrossRef]

47. López Prol, J. Regulation, profitability and diffusion of photovoltaic grid-connected systems: A comparative analysis of Germany and Spain. Renew. Sustain. Energy Rev. 2018, 91, 1170-1181. [CrossRef]

48. Del Río, P. Ten years of renewable electricity policies in Spain: An analysis of successive feed-in tariff reforms. Energy Policy 2008, 36, 2917-2929. [CrossRef]

49. Arocena, P.; Kühn, K.-U.; Regibeau, P. Regulatory reform in the Spanish electricity industry: A missed opportunity for competition. Energy Policy 1999, 27, 387-399. [CrossRef]

50. Del Río, P.; Unruh, G. Overcoming the lock-out of renewable energy technologies in Spain: The cases of wind and solar electricity. Renew. Sustain. Energy Rev. 2007, 11, 1498-1513. [CrossRef]

51. Caldés, N.; Varela, M.; Santamaría, M.; Sáez, R. Economic impact of solar thermal electricity deployment in Spain. Energy Policy 2009, 37, 1628-1636. [CrossRef]

52. Heras-Saizarbitoria, I.; Cilleruelo, E.; Zamanillo, I. Public acceptance of renewables and the media: An analysis of the Spanish PV solar experience. Renew. Sustain. Energy Rev. 2011, 15, 4685-4696. [CrossRef]

53. Azofra, D.; Saenz-Díez, J.C.; Martínez, E.; Jiménez, E.; Blanco, J. Ex-post economic analysis of photovoltaic power in the Spanish grid: Alternative scenarios. Renew. Energy 2016, 95, 98-108. [CrossRef]

54. Coronas, S.; Martín, H.; de la Hoz, J.; García de Vicuña, L.; Castilla, M. MONTE-CARLO probabilistic valuation of concentrated solar power systems in Spain under the 2014 retroactive regulatory framework. Renew. Sustain. Energy Rev. 2021, 138, 110670. [CrossRef]

55. Law 54/1997, of 27 November. BOE no. 285, 28 November 1997. Available online: https://www.boe.es/eli/es/1/1997/11/27/54 (accessed on 7 September 2021).

56. Law 24/2013, of 26 December. BOE no. 310, 27 December 2013. Available online: https://www.boe.es/eli/es/1/2013/12/26/24 (accessed on 15 September 2021).

57. RD 413/2014, of 6 June. BOE no. 140, 10 June 2014. Available online: https:/ /www.boe.es/eli/es/rd/2014/06/06/413 (accessed on 15 September 2021).

58. RD 960/2020, of 3 November. BOE no. 291, 4 November 2020. Available online: https://www.boe.es/eli/es/rd/2020/11/03/960 (accessed on 15 September 2021).

59. Law 82/1980, of 30 December. BOE no. 23, 27 January 1981. Available online: https://www.boe.es/eli/es/1/1980/12/30/82 (accessed on 7 September 2021).

60. RD 2366/1994, of 9 December. BOE no. 313, 31 December 1994. Available online: https://www.boe.es/eli/es/rd/1994/12/09/2 366 (accessed on 15 September 2021).

61. Law 40/1994, of 30 December. BOE no. 313, 31 December 1994. Available online: https://www.boe.es/eli/es/1/1994/12/30/40 (accessed on 15 September 2021).

62. Ministerio de Ciencia y Tecnología. Instituto para la Diversificación y Ahorro de la Energía, IDEA. Plan de Fomento de las Energías Renovables en España 2000-2010. 1999. Available online: https://www.idae.es/uploads/documentos/documentos_40 44_PFER2000-10_1999_1cd4b316.pdf (accessed on 7 September 2021).

63. Energy for the Future: Renewable Sources of Energy. White Paper for a Community Strategy and Action Plan. European Commission. Communication from the Commission. COM(97)599 Final (26/11/1997). 1997. Available online: https:/ / europa. eu/documents/comm/white_papers/pdf/com97_599_en.pdf (accessed on 7 September 2021).

64. Directive 2001/77/CE, of 27 September, 2001. Official Journal of the European Union, L 283. 27 October 2001. Available online: https:/ / www.boe.es/doue/2001/283/L00033-00040.pdf (accessed on 7 September 2021).

65. Directive 2003/30/CE, of 8 May, 2003. Official Journal of the European Union, L 123. 17 May 2003. Available online: https: //www.boe.es/doue/2003/123/L00042-00046.pdf (accessed on 7 September 2021). 
66. Ministerio de Industria, Turismo y Comercio; Instituto para la Diversificación y Ahorro de la Energía, IDAE. Plan de Energías Renovables en España 2005-2010. 2005. Available online: https://www.idae.es/sites/default/files/documentos/publicaciones_ idae/documentos_10359_plan_de_energias_renovables_2005_2010_9da32b5e.pdf (accessed on 7 September 2021).

67. Directive 2009/28/CE, of 23 April, 2009. Official Journal of the European Union, L 140. 5 June 2009. Available online: https: / www.boe.es/doue/2009/140/L00016-00062.pdf (accessed on 7 September 2021).

68. Instituto para la Diversificación y Ahorro de la Energía, IDAE. Plan de Energías Renovables 2011-2020. Ministerio de Industria, Turismo y Comercio. November 2011. Available online: https://www.idae.es/sites/default/files/documentos/publicaciones_ idae/documentos_11227_per_2011-2020_def_93c624ab.pdf (accessed on 7 September 2021).

69. CNMC. Energía. Estadísticas. Available online: https://www.cnmc.es/estadisticas (accessed on 7 September 2021).

70. RD 2818/1998, of 23 December. BOE no. 312, 30 December 1998. Available online: https://www.boe.es/eli/es/rd/1998/12/23 /2818 (accessed on 15 September 2021).

71. RD 1955/2000, of 1 December. BOE no. 310, 27 December 2000. Available online: https://www.boe.es/eli/es/rd/2000/12/01/1 955 (accessed on 15 September 2021).

72. RD 841/2002, of 2 August. BOE no. 210, 2 September 2002. Available online: https://www.boe.es/eli/es/rd/2002/08/02/841 (accessed on 15 September 2021).

73. RD 436/2004, of 12 March. BOE no. 75, 27 March 2004. Available online: https://www.boe.es/eli/es/rd/2004/03/12/436 (accessed on 15 September 2021).

74. RD 661/2007, of 25 May. BOE no. 126, 26 May 2007. Available online: https://www.boe.es/eli/es/rd/2007/05/25/661 (accessed on 15 September 2021).

75. RD 1432/2002, of 27 December. BOE no. 313, 31 December 2002. Available online: https://www.boe.es/eli/es/rd/2002/12/27/1 432 (accessed on 15 September 2021).

76. RD 2351/2004, of 23 December. BOE no. 309, 24 December 2004. Available online: https://www.boe.es/eli/es/rd/2004/12/23 /2351 (accessed on 15 September 2021).

77. RDL 7/2006, of 23 June. BOE no. 150, 24 June 2006. Available online: https://www.boe.es/eli/es/rdl/2006/06/23/7 (accessed on 15 September 2021).

78. RD 1578/2008, of 26 September. BOE no. 234, 27 September 2008. Available online: https://www.boe.es/eli/es/rd/2008/09/26 /1578 (accessed on 15 September 2021).

79. RDL 6/2009, of 30 April. BOE no. 111, 7 May 2009. Available online: https://www.boe.es/eli/es/rdl/2009/04/30/6 (accessed on 15 September 2021).

80. Resolution of the State Secretariat for Energy of 19 November 2009. BOE no. 283, 24 November 2009. Available online: https: / / www.boe.es / diario_boe/txt.php?id=BOE-A-2009-18772 (accessed on 15 September 2021).

81. RD 1003/2010, of 5 August. BOE no. 190, 6 August 2010. Available online: https://www.boe.es/eli/es/rd/2010/08/05/1003 (accessed on 15 September 2021).

82. RD 1565/2010, of 19 November. BOE no. 283, 23 November 2010. Available online: https://www.boe.es/eli/es/rd/2010/11/19 /1565 (accessed on 15 September 2021).

83. RD 1614/2010, of 7 December. BOE no. 298, 8 December 2010. Available online: https://www.boe.es/eli/es/rd/2010/12/07/1614 (accessed on 15 September 2021).

84. RDL 14/2010, of 23 December. BOE no. 312, 24 December 2010. Available online: https://www.boe.es/eli/es/rdl/2010/12/23/14 (accessed on 15 September 2021).

85. Law 2/2011, of 4 March. BOE no. 55, 5 March 2011. Available online: https://www.boe.es/eli/es/1/2011/03/04/2 (accessed on 15 September 2021).

86. RDL 1/2012, of 27 January. BOE no. 24, 28 January 2012. Available online: https://www.boe.es/eli/es/rdl/2012/01/27/1 (accessed on 15 September 2021).

87. Law 15/2012, of 27 December. BOE no. 312, 28 December 2012. Available online: https://www.boe.es/eli/es/1/2012/12/27/15 (accessed on 15 September 2021).

88. RDL 29/2012, of 28 December. BOE no. 314, 31 December 2012. Available online: https://www.boe.es/eli/es/rdl/2012/12/28/29 (accessed on 15 September 2021).

89. RDL 2/2013, of 1 February. BOE no. 29, 2 February 2013. Available online: https://www.boe.es/eli/es/rdl/2013/02/01/2 (accessed on 15 September 2021).

90. RDL 9/2013, of 12 July. BOE no. 167, 13 July 2013. Available online: https:/ /www.boe.es/eli/es/rdl/2013/07/12/9 (accessed on 15 September 2021).

91. RD 947/2015, of 16 October. BOE no. 249, 17 October 2015. Available online: https://www.boe.es/eli/es/rd/2015/10/16/947 (accessed on 15 September 2021).

92. Order IET/2212/2015, of 23 October. BOE no. 255, 24 October 2015. Available online: https://www.boe.es/eli/es/o/2015/10/23 / iet2212 (accessed on 15 September 2021).

93. RD 359/2017, of 31 March. BOE no. 78, 1 April 2017. Available online: https://www.boe.es/buscar/doc.php?id=BOE-A-2017-3 639 (accessed on 15 September 2021).

94. Order ETU/315/2017, of 6 April. BOE no. 84, 8 April 2017. Available online: https://www.boe.es/eli/es/o/2017/04/06/etu315 (accessed on 15 September 2021). 
95. Resolution of the State Secretariat for Energy of 10 April 2017. BOE no. 87, 29592-29595, 12 April 2017. Available online: https:/ / www.boe.es/buscar/doc.php?id=BOE-A-2017-4094 (accessed on 15 September 2021).

96. Resolution of the State Secretariat for Energy of 10 April 2017. BOE no. 87, 29596-29622, 12 April 2017. Available online: https:/ / www.boe.es/buscar/doc.php?id=BOE-A-2017-4095 (accessed on 15 September 2021).

97. Resolution of the Directorate General for Energy Policy and Mines of 19 May 2017. BOE no. 125, 26 May 2017. Available online: https:/ / www.boe.es/diario_boe/txt.php?id=BOE-A-2017-5848 (accessed on 15 September 2021).

98. Resolution of the Directorate General for Energy Policy and Mines of August 1, 2017. BOE no. 185, 4 August 2017. Available online: https:/ / www.boe.es/diario_boe/txt.php?id=BOE-A-2017-9317 (accessed on 15 September 2021).

99. RD 650/2017, of 16 June. BOE no. 144, 17 June 2017. Available online: https:/ / www.boe.es/diario_boe/txt.php?id=BOE-A-2017 -6940 (accessed on 15 September 2021).

100. Order ETU/615/2017, of 27 June. BOE no. 153, 28 June 2017. Available online: https:/ /www.boe.es/eli/es/o/2017/06/27/etu615 (accessed on 15 September 2021).

101. Resolution of the State Secretariat for Energy of 30 June 2017. BOE no. 156, 1 July 2017. Available online: https:/ / www.boe.es / diario_boe/txt.php?id=BOE-A-2017-7632 (accessed on 15 September 2021).

102. Resolution of the Directorate General for Energy Policy and Mines of 27 July 2017. BOE no. 179, 28 July 2017. Available online: https:/ / www.boe.es/diario_boe/txt.php?id=BOE-A-2017-8997 (accessed on 15 September 2021).

103. Resolution of the Directorate General for Energy Policy and Mines of 10 October 2017. BOE no. 247, 13 October 2017. Available online: https:/ / www.boe.es/diario_boe/txt.php?id=BOE-A-2017-11737 (accessed on 15 September 2021).

104. RDL 17/2019, of 22 November. BOE no. 282, 23 November 2019. Available online: https://www.boe.es/eli/es/rdl/2019/11/22 /17 (accessed on 15 September 2021).

105. Order IET/1045/2014, of 16 June. BOE no. 150, 20 June 2014. Available online: https://www.boe.es/eli/es/o/2014/06/16/iet1 045 (accessed on 15 September 2021).

106. Order ETU/130/2017, of 17 February. BOE no. 45, 22 February 2017. Available online: https://www.boe.es/eli/es/o/2017/02/ $17 /$ etu130 (accessed on 15 September 2021).

107. Order TED/171/2020, of 24 February. BOE no. 51, 28 February 2020. Available online: https://www.boe.es/eli/es/o/2020/02/ 24/ted171 (accessed on 15 September 2021).

108. De la Hoz, J.; Martín, H.; Martins, B.; Matas, J.; Miret, J. Evaluating the impact of the administrative procedure and the landscape policy on grid connected PV systems (GCPVS) on-floor in Spain in the period 2004-2008: To which extent a limiting factor? Energy Policy 2013, 63, 147-167. [CrossRef] 